\author{
Universidade de São Paulo \\ Instituto de Física
}

\title{
Análise quantitativa das propriedades ópticas de aerossol urbano e de queimadas na Amazônia
}

\author{
Clarice Miranda Fiorese Furtado
}

Orientador: Prof. Dr. Paulo Eduardo Artaxo Netto

Dissertação de mestrado apresentada ao Instituto de Física para a obtenção do título de Mestre em Ciências

Banca Examinadora:

Prof. Dr. Paulo Eduardo Artaxo Netto (IF/USP)

Prof. Dr. Eduardo Landulfo (IPEN)

Prof. Dr. Marcelo de Paula Corrêa (IRN/UNIFEI) 


\section{FICHA CATALOGRÁFICA \\ Preparada pelo Serviço de Biblioteca e Informação do Instituto de Física da Universidade de São Paulo}

Furtado, Clarice Miranda Fiorese

Análise quantitativa das propriedades ópticas de aerossol urbano e de queimadas na Amazônia. São Paulo, 2016.

Dissertação (Mestrado) - Universidade de São Paulo. Instituto de Física. Depto. de Física Aplicada.

Orientador: Prof. Dr. Paulo Eduardo Artaxo Netto

Área de Concentração: Física

Unitermos: 1. Poluição atmosférica; 2 Queimadas - Amazônia;

3. Aerosol; 4. Sensoriamento remoto; 5. Radiação atmosférica . 
Ao meu avô Antônio Carlos (in memoriam). 



\section{AGRADECIMENTOS}

Ao meu pai, Fernando, por ter sempre confiado em meu potencial, pelo incentivo e apoio incondicionais.

À minha mãe, Graça, pelo cuidado, pelo amor imensurável e, sobretudo, pela compreensão. Aos meus irmãos, Nando e Pedro, por terem sido companhia mesmo de longe, por sempre me ouvirem e ajudarem com paciência e carinho.

À minha avó, dona Ruth, por toda a preocupação e pelas valiosas demonstrações de amor.

Ao Professor Paulo Artaxo, pela orientação, pela oportunidade e pela confiança depositada em mim.

Ao Joel Brito, por toda a atenção, pela incrível dedicação, paciência e disponibilidade.

À Bruna Holanda, por ter me ajudado a recomeçar sem medir esforços, por ter sido sempre tão atenciosa e um exemplo de dedicação e compromisso.

À Marina Mendonça, por todo o cuidado, pela companhia e apoio, por ter divido comigo os momentos de angústia e cansaço.

À Luciana Rizzo e Samara Carbone, pela ajuda na obtenção e processamento dos dados.

Aos técnicos Alcides, Ana, Fabinho e Fernando, por todo o esforço para garantir que o trabalho fosse feito com qualidade.

Aos colegas da sala 102 (Alex, André, Elisa, Natália, Patrícia, Rafael e Wilmer), pela convivência, pelas conversas e por terem tornado os dias mais leves e divertidos.

A todos os amigos, do Pé Descalço, da música, do apartamento 21A, do francês, por terem sido abraços, companhia e risadas durante todos estes anos. 



\section{RESUMO}

Este trabalho tem como foco o entendimento das propriedades ópticas do aerossol na Amazônia utilizando várias técnicas: sensoriamento remoto em solo, sensoriamento remoto por satélites e medidas in situ. Propriedades ópticas medidas continuamente ao longo de mais de 15 anos pela rede AERONET na Amazônia foram analisadas buscando compreender como os eventos anuais de queima de biomassa e as emissões urbanas de Manaus afetam as propriedades das partículas. Medidas de longo prazo do sensor MODIS utilizando o sistema Giovanni da NASA foram úteis para caracterizar o impacto da pluma urbana de Manaus nas propriedades de aerossol e nuvens na Amazônia Central. A partir de medições in situ realizadas nas várias estações amostradoras do experimento GoAmazon2014/5, analisou-se em detalhes propriedades de absorção e espalhamento de aerossol antes e depois do impacto da pluma urbana de Manaus.

Foi observada uma alta variabilidade na profundidade óptica do aerossol (AOD) bem como em outras propriedades, tais como absorção, espalhamento e distribuição de tamanho. Valores muito elevados de AOD foram observados em todos os sítios durante a estação seca, em particular na região do arco do desflorestamento. Análises dos expoentes Ångström de espalhamento e absorção separam as diferentes componentes absorvedoras do aerossol, entre eles o carbono elementar (EC), carbono orgânico (OC), poeira mineral e partículas biogênicas. Uma análise da forçante radiativa no topo da atmosfera em conjunto com a Matriz Ångström auxiliou no entendimento do papel da componente orgânica de espalhamento (OC) e da componente de absorção (BC) no aerossol de queimadas e urbano na forçante radiativa.

A região menos afetada por queimadas na Amazônia foi caracterizada pela presença de um aerossol altamente espalhador durante a estação seca, com valores de albedo de espalhamento simples (SSA) na faixa de 0,91-0,94. Por outro lado, constatou-se valores médios de 0,85 a 0,89 em regiões fortemente impactadas por queimadas. Através de medidas in situ e medidas obtidas a partir da rede AERONET, foi possível observar significativo impacto da pluma de Manaus vento abaixo da cidade, especialmente na componente de absorção. $\mathrm{O}$ efeito da absorção do aerossol urbano na forçante radiativa é significativo, indo de uma forçante no sítio da EMBRAPA, antes da pluma, de $-24 \mathrm{~W} / \mathrm{m}^{2}$ para cerca de $-18 \mathrm{~W} / \mathrm{m}^{2}$ em Manacapuru, com o efeito da pluma de Manaus. A partir da análise de 12 anos de medidas dos sensores MODIS e MISR, observou-se alterações nas propriedades de nuvens e na carga atmosférica de aerossol. Foram analisadas a AOD, a temperatura do topo da nuvem e o raio efeito de gotículas de nuvens. Ficou clara a presença de nuvens mais altas e com raio efetivo menor em regiões com maior carga de aerossol, vento abaixo de Manaus. 



\begin{abstract}
This work focuses on understanding the optical properties of aerosol in the Amazon, using various techniques: remote sensing from the ground, remote sensing from satellites and in situ measurements. Aerosol optical properties continuously measured over more than 15 years carried out by the AERONET network in the Amazon were analyzed seeking to understand how the annual biomass burning emissions and urban emissions of Manaus affect particle properties. Long-term measurements of MODIS using the Giovanni NASA system were useful to characterize the impact of the urban plume of Manaus in the properties of aerosol and clouds in the central Amazon. Based on in situ measurements in the various sampling sites of the GoAmazon2014/5 experiment, the absorption and scattering properties of aerosol before and after the impact of Manaus urban plume were analyzed in detail.

It was observed a large spatial and temporal variability in the aerosol optical depth (AOD) as well as in various properties such as absorption and scattering coefficients and size distribution. Very high levels of AOD were observed at all sites during the dry season, particularly in the deforestation arc region. Analysis of scattering and absorption Ångström exponents helps to identify different absorber components of the aerosol, including elemental carbon (EC), organic carbon (OC), mineral dust and biogenic particles. An analysis of the radiative forcing at the top of the atmosphere together with the Angström Matrix helps in understanding the role of the scattering organic component (OC) versus the absorption component (BC) in biomass burning and urban aerosol particles in the radiative forcing.

The region least affected by fires in the Amazon was characterized by a highly scattering aerosol during the dry season with Single Scattering Albedo (SSA) values in the range of 0.910.94 , while we found mean values of 0.85 to 0.89 in heavily affected biomass burning regions. Through in situ measurements and AERONET observations it was possible to measure the significant impact of Manaus plume downwind of the urban area, especially in the absorption component. The effect of absorption of urban aerosol in the radiative forcing is significant, with measurements at the EMBRAPA site, before the impact of the plume, at $-24 \mathrm{~W} / \mathrm{m}^{2}$ going to $-18 \mathrm{~W} / \mathrm{m}^{2}$ in Manacapuru that is effect of the Manaus plume. It was also analyzed the changes in the properties of clouds and atmospheric aerosol loading over the last 12 years of MODIS and MISR measurements. The analysis of AOD, cloud top temperature and the radius of cloud droplets show a clear signal of Manaus plume. It was observed clouds with smaller effective radius in regions with higher aerosol load, downwind of Manaus.
\end{abstract}





\section{LISTA DE ILUSTRAÇÕES}

Figura 1 - Mapa da Amazônia brasileira. Cerca de $80 \%$ da floresta corresponde à floresta tropical primária.

Figura 2 - Série temporal das taxas anuais de desmatamento na Amazônia Legal no período de 1988 a 2015 22

Figura 3 - Número de focos de incêndios ativos no Brasil entre os anos de 1998 e 2015.......22

Figura 4 - Diagrama esquemático do balanço de energia terrestre médio global. .23

Figura 5 - Estimativa da média global da forçante radiativa para o ano 2011 em relação a 1750 para os principais fatores que alteram o balanço radiativo terrestre

Figura 6 - Distribuição de tamanho das partículas de aerossol. Principais modas, fontes e mecanismos de formação e remoção.

Figura 7 - Estimativa da média global da forçante radiativa do black carbon entre 1750 e 2005 . 30

Figura 8 - Sítios de amostragem em operação durante o experimento GoAmazon2014/5 .... 32 Figura 9 - Rosa dos ventos para estação seca e estação chuvosa com base em médias de meia hora da velocidade e da direção do vento medidas a $81 \mathrm{~m}$ AGL no período de 18 de outubro de 2012 e 23 de julho de 2014 no ATTO (T0a).

Figura 10 - Representação do espectro eletromagnético em seus vários comprimentos de onda.

Figura 11 - Espectro normalizado de emissão de um corpo negro a $5.780 \mathrm{~K}$ (Sol) e a $255 \mathrm{~K}$ (Terra) em escala logarítmica.

Figura 12 - Irradiância solar espectral no topo da atmosfera e ao nível do mar.

Figura 13 - Parâmetro de tamanho $x$ como função do comprimento de onda da radiação incidente $\lambda$ e do raio da partícula $r$.

Figura 14 - Representação da atenuação da radiação eletromagnética ao atravessar um meio homogêneo.

Figura 15 - Sistema de coordenadas para uma atmosfera plano-paralela. 46

Figura 16 - Esquema do posicionamento do fotômetro solar para a realização de medições no plano principal e no almucântara

Figura 17 - Mapa com a localização dos fotômetros da rede AERONET. 52

Figura 18 - Área selecionada no sistema NASA-Giovanni vento acima e vento abaixo de Manaus. 
Figura 19 - Representação dos 9 ângulos de visada e das 4 bandas espectrais nos quais o sensor MISR realiza medições de propriedades de aerossol e de superfície.

Figura 20 - Desenho esquemático do Aetalômetro.....................................................................58

Figura 21 - Diagrama esquemático do MAAP.

Figura 22 - Esquema interno do Nefelômetro de três comprimentos de onda, modelo TSI3563.

Figura 23 - Série temporal de todos os valores da profundidade óptica do aerossol (AOD) em 500 nm disponíveis entre os anos de 1999 e 2014.

Figura 24 - Médias da distribuição volumétrica de tamanho do aerossol na estação chuvosa e na estação seca entre os anos de 1999 e 2014.

Figura 25 - Dependência espectral do albedo de espalhamento simples (SSA) na estação chuvosa e na estação seca entre os anos de 1999 e 2014.

Figura 26 - Histograma normalizado das medidas de albedo de espalhamento simples (SSA) em $675 \mathrm{~nm}$ para AOD entre 0,4 e 0,7 e para AOD maior que 1,0 em Cuiabá Miranda. 68

Figura 27 - Matriz Ångström de absorção e espalhamento para os sítios de Alta Floresta, Cuiabá Miranda, Rio Branco e Ji Paraná-Rondônia

Figura 28 - Matriz Ångström de absorção e espalhamento para os sítios de Balbina e Belterra.

Figura 29 - Médias mensais da profundidade óptica do aerossol (AOD) em $637 \mathrm{~nm}$ medida na EMBRAPA, vento acima da pluma de Manaus, e em Manacapuru, vento abaixo da pluma, nos anos de 2014 e 2015. 73

Figura 30 - Médias da distribuição volumétrica de tamanho do aerossol para EMBRAPA e Manacapuru nas estações chuvosa e seca, nos anos de 2014 e 2015.

Figura 31 - Dependência espectral do albedo de espalhamento simples (SSA) na estação chuvosa e na estação seca nos anos de 2014 e 2015. 75

Figura 32 - Médias mensais da profundidade óptica de absorção (AAOD) em 637 nm medida na EMBRAPA, vento acima da pluma de Manaus, e em Manacapuru, vento abaixo da pluma, nos anos de 2014 e 2015. 75

Figura 33 - Média da forçante radiativa no topo da atmosfera na estação chuvosa e na estação seca, para a EMBRAPA e para Manacapuru, nos anos de 2014 e 2015.

Figura 34 - Comparação entre os coeficientes de absorção medidos pelo MAAP e pelo Aetalômetro modelo AE30 no ATTO para o corte de tamanho $\mathrm{PM}_{10}$. 
Figura 35 - Comparação entre os coeficientes de absorção medidos pelo Aetalômetro modelo AE33 e pelo MAAP no sítio experimental da ZF2 para os cortes de tamanho $\mathrm{PM}_{10}$ e $\mathrm{PM}_{2.5}$ feita por HOLANDA (2015).

Figura 36 - Histograma normalizado dos valores de albedo de espalhamento simples (SSA) em 637 nm medidos in situ no ATTO (T0a) e em Manacapuru (T3) durante a estação seca em todos os anos de análise. 78

Figura 37 - Série temporal para o albedo de espalhamento simples (SSA) em $637 \mathrm{~nm}$ obtido a partir da rede AERONET e a partir de medidas in situ entre os anos de 2012 e 2015 vento acima de Manaus.

Figura 38 - Série temporal para o albedo de espalhamento simples (SSA) em $637 \mathrm{~nm}$ obtido a partir da rede AERONET e a partir de medidas in situ entre os anos de 2014 e 2015 vento abaixo de Manaus 80

Figura 39 - Médias anuais da profundidade óptica do aerossol em $550 \mathrm{~nm}$ medida pelo MODIS-Terra na estação chuvosa e na estação seca entre os anos de 2003 e 2015. 82 Figura 40 - Médias anuais da profundidade óptica do aerossol (AOD) em $550 \mathrm{~nm}$ medida pelo MODIS-Aqua na estação chuvosa e na estação seca entre os anos de 2003 e 2015. Figura 41 - Médias anuais da temperatura do topo da nuvem medida pelo MODIS-Terra na estação chuvosa e na estação seca.

Figura 42 - Médias anuais do raio efetivo de gotículas de nuvem medido pelo MODIS-Aqua na estação chuvosa e na estação seca. .85 Figura 43 - Comparação entre as medidas da profundidade óptica do aerossol (AOD) em 550 nm obtidas a partir do sensor MODIS e a partir de interpolação dos valores obtidos pela rede AERONET vento acima e vento abaixo de Manaus. 



\section{LISTA DE TABELAS}

Tabela 1 - Coordenadas geográficas dos sítios de amostragem em operação durante o experimento GoAmazon2014/5

Tabela 2 - Instrumentos utilizados neste trabalho e o período de análise no ATTO (T0a), na EMBRAPA (T0e) e em Manacapuru (T3).

Tabela 3 - Coordenadas geográficas das estações da rede AERONET. 53

Tabela 4 - Coordenadas geográficas das áreas selecionadas no Giovanni vento acima e vento abaixo de Manaus.

Tabela 5 - Valores médios do raio volumétrico médio $(\mu \mathrm{m})$ da moda fina e da moda grossa medidos na estação chuvosa e na estação seca entre os anos de 1999 e 2014. 66 Tabela 6 - Valores médios do albedo de espalhamento simples em $675 \mathrm{~nm}$ medidos na estação chuvosa e na estação seca.

Tabela 7 - Valores médios do albedo de espalhamento simples obtidos a partir da AERONET encontrados na literatura. 



\section{LISTA DE ABREVIATURAS E SIGLAS}

$\begin{array}{ll}\text { AAE } & \text { Absorption Angström Exponent } \\ \text { AAOD } & \text { Absorption Aerosol Optical Depth } \\ \text { AERONET } & \text { Aerosol Robotic Network } \\ \text { AGL } & \text { Above Ground Level } \\ \text { AOD } & \text { Aerosol Optical Depth } \\ \text { ATTO } & \text { Amazonian Tall Tower Observatory } \\ \text { BC } & \text { Black Carbon } \\ \text { BOA } & \text { Bottom of Atmosphere } \\ \text { BrC } & \text { Brown Carbon } \\ \text { COVs } & \text { Compostos Orgânicos Voláteis } \\ \text { CTT } & \text { Cloud Top Temperature } \\ \text { EBC } & \text { Equivalent Black Carbon } \\ \text { EC } & \text { Elemental Carbon }\end{array}$

EMBRAPA Empresa Brasileira de Pesquisas Agropecuárias

EOS Earth Observing System

GAME Global Atmospheric Model

GES DISC Goddard Earth Sciences Data and Information Services Center

Giovanni Goddard Interactive Online Visualization and Analysis Infrastructure

GoAmazon Green Ocean Amazon

INPA Instituto Nacional de Pesquisas da Amazônia

INPE Instituto Nacional de Pesquisas Espaciais

IPCC Intergovernmental Panel on Climate Chance

MAAP Multi Angle Absorption Photometer

MISR Multi-angle Imaging SpectroRadiometer

MODIS Moderate Resolution Imaging Spectroradiometer

NCN Núcleo de Condensação de Nuvem

OC Organic Carbon

PRODES Programa de Monitoramento da Floresta Amazônica Brasileira por Satélite

rBC Refractory Black Carbon

RDS Reserva de Desenvolvimento Sustentável

RF Radiative Forcing 
SAE Scattering Ångström Exponent

SAOD $\quad$ Scattering Aerosol Optical Depth

SSA Single Scattering Albedo

TOA Top of Atmosphere

UTC Coordinated Universal Time

ZCIT Zona de Convergência Intertropical 


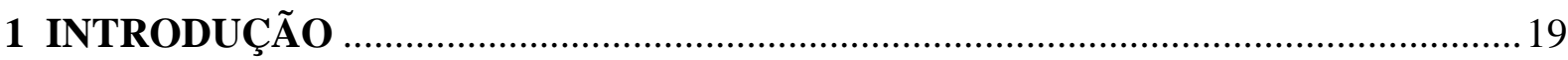

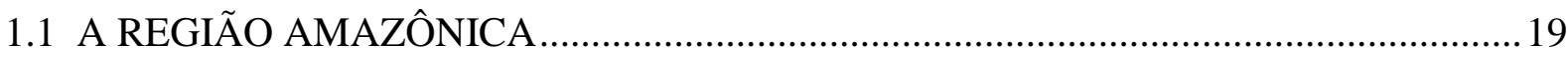

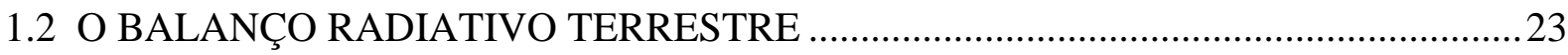

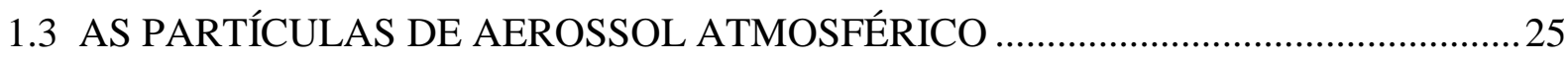

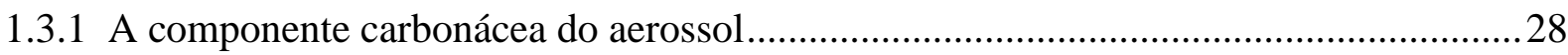

1.3.2 Os efeitos das partículas aerossol no clima .................................................................. 30

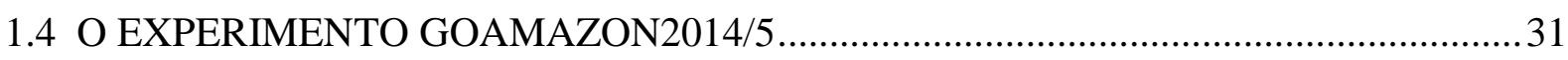

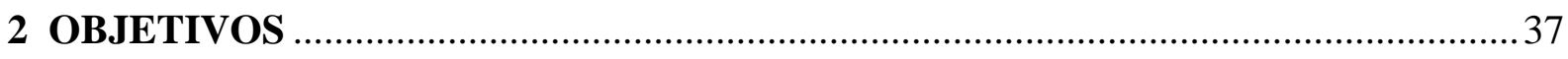

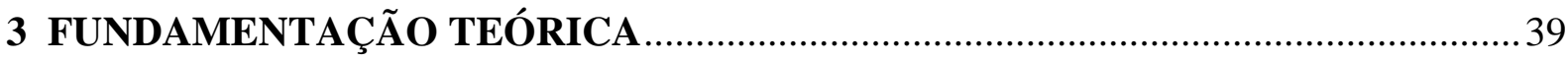

3.1 TRANSFERÊNCIA RADIATIVA NA ATMOSFERA …………………………............

3.1.1 Absorção e espalhamento da radiação por partículas e gases ...........................................41

3.1.2 A Lei de Beer-Lambert-Bouguer.................................................................................4

3.2 PROPRIEDADES INTENSIVAS DAS PARTÍCULAS DE AEROSSOL …………….....46

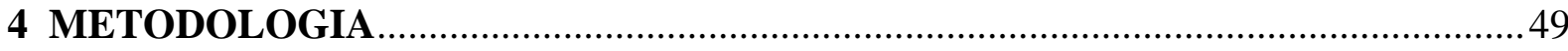

4.1 MEDIDAS POR SENSORIAMENTO REMOTO ………………………………….......4 49

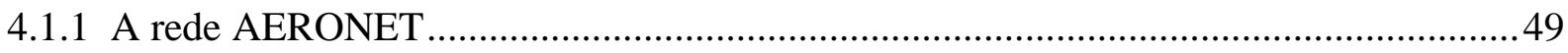

4.1.2 A forçante radiativa como produto da rede AERONET ..................................................51

4.1.3 Descrição das estações da AERONET estudadas .............................................................52

4.1.4 O sistema de análise de dados online NASA-Giovanni ................................................54

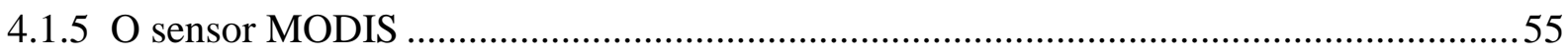

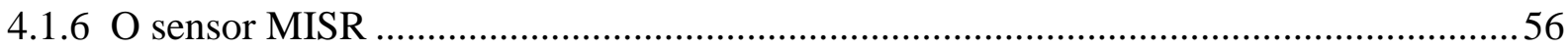

4.2 MEDIDAS IN SITU DE ABSORÇÃO E ESPALHAMENTO …………………………....57

4.2.1 A medida da absorção espectral do aerossol com Aetalômetro ........................................57

4.2.2 A medida da absorção pelo MAAP ...............................................................................59

4.2.3 A medida do espalhamento espectral do aerossol com Nefelômetro ................................60 
5.1 ANÁLISE DAS PROPRIEDADES DE AEROSSOL NA AMAZÔNIA DERIVADAS PELA REDE AERONET

5.2 INFLUÊNCIA DA PLUMA DE POLUIÇÃO PROVENIENTE DE MANAUS SOBRE PROPRIEDADES DE AEROSSOL MEDIDAS PELA REDE AERONET E MEDIDAS IN SITU 72

5.2.1 Análise das propriedades de aerossol derivadas pela rede AERONET 72

5.2.2 Análise do albedo de espalhamento simples obtido a partir de medidas in situ. 76

5.3 INFLUÊNCIA DA PLUMA URBANA DE MANAUS SOBRE PROPRIEDADES DE AEROSSOL E DE NUVENS MEDIDAS POR SENSORIAMENTO REMOTO A PARTIR DE SATÉLITES. 81

6 CONCLUSÕES. 87 


\section{INTRODUÇÃO}

As partículas de aerossol, tanto as emitidas por fontes naturais quanto as emitidas em processos antrópicos, influenciam o clima global e regional através das mudanças que produzem no balanço radiativo terrestre e nas propriedades de nuvens (ANDREAE et al., 2004, 2005). Desde o início da Revolução Industrial, atividades antrópicas, tais como a queima de combustíveis fósseis, as mudanças no uso do solo e os processos industriais, vêm contribuindo consideravelmente para o aumento da concentração de partículas de aerossol e de gases de efeito estufa, tendo como resultado alterações climáticas em larga escala em nosso planeta (IPCC, 2013). Este impacto antrópico excede em muito as alterações provocadas por processos naturais (por exemplo, erupções vulcânicas, mudanças solares e mudanças na órbita terrestre), entretanto, sua quantificação ainda apresenta incertezas significativas (BOUCHER et al., 2013; FORSTER et al., 2007).

A Região Amazônica tem sofrido, nas últimas décadas, importante mudança no padrão de uso do solo através do processo de ocupação humana (ARTAXO et al., 2005). A intensa atividade de desflorestamento, a crescente urbanização e a emissão de grande número de gases e partículas decorrentes da queima de biomassa têm implicações importantes em nível local, regional e global. Um melhor entendimento do papel que as emissões urbanas e de queima de biomassa desempenham no ciclo de vida das partículas de aerossol e das nuvens e, consequentemente, no clima, é essencial para avaliar quantitativamente as mudanças ambientais que a região vem sofrendo (ARTAXO et al., 2009).

\subsection{A REGIÃO AMAZÔNICA}

A Bacia Amazônica se estende por cerca de 6,9 milhões de $\mathrm{km}^{2}$, representando em área cerca de um terço do continente sul-americano, dos quais aproximadamente $80 \%$ é constituído por floresta tropical primária. Abriga entre 10 e $20 \%$ de toda a biodiversidade do planeta (ANDREAE et al., 2015), é o maior e mais produtivo ecossistema, de importância global no que diz respeito ao fluxo de carbono, ao ciclo hidrológico e à regulação do clima (DAVIDSON et al., 2012; NÖLSCHER et al., 2016). No território brasileiro, a Amazônia compreende cerca de 5,5 milhões de $\mathrm{km}^{2}$, com uma participação de $61 \%$ da área do país. $\mathrm{O}$ mapa da Região Amazônica brasileira pode ser visto na Figura 1. 
Figura 1 - Mapa da Amazônia brasileira. Cerca de 80\% da floresta corresponde à floresta tropical primária.

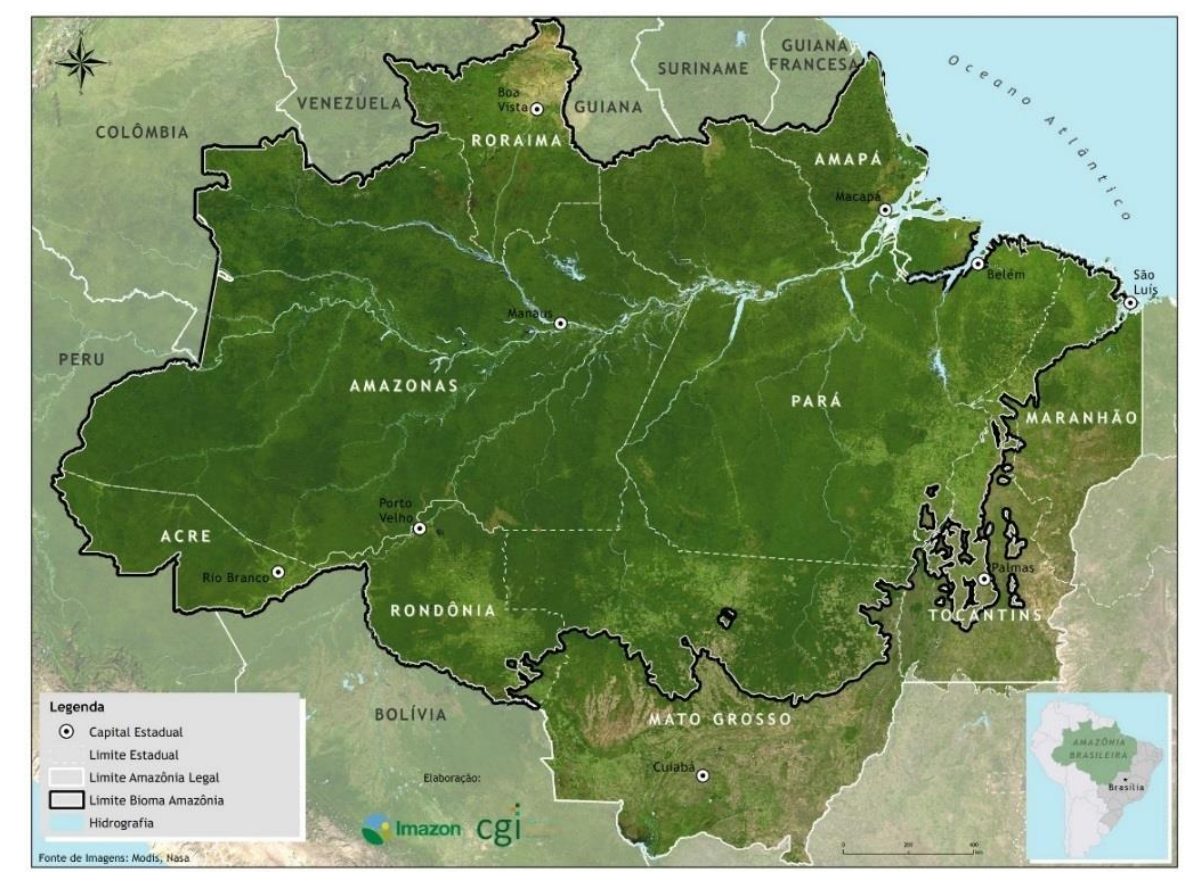

Fonte: Imazon, 2016.

Em razão da sua localização tropical e seu intenso metabolismo, a Floresta Amazônica é uma importante fonte natural de gases traço, aerossol e vapor d'água para a atmosfera global (ARTAXO et al., 2006). Ademais, a floresta fornece a maior parte das partículas que atuam como núcleos de condensação de nuvens (NCN), controlando, assim, os mecanismos de formação de nuvens e precipitação na bacia (ARTAXO; SILVA DIAS; ANDREAE, 2003; ARTAXO et al., 2005, 2006), além de ser uma importante fonte de convecção profunda tropical (ARTAXO et al., 2013).

Durante a estação chuvosa (janeiro a julho), quando predominam as emissões naturais biogênicas, a Bacia Amazônica é uma das regiões continentais com as menores concentrações de gases e partículas do nosso planeta, com concentrações de partículas da ordem de 200 a 300 partículas por $\mathrm{cm}^{3}$, comparável àquela encontrada em regiões oceânicas remotas (ARTAXO et al., 2006). Também na estação chuvosa, a região recebe esporadicamente partículas de aerossol marinho do Oceano Atlântico, poeira mineral do Saara e emissão de queimadas da África através de transporte de longa distância (BAARS et al., 2011; MARTIN et al., 2010). Nestas condições, com concentrações muito baixas de aerossol, concentrações baixas de NCN e com nível de vapor d'água elevado, pequenas variações no número de partículas podem afetar consideravelmente os mecanismos de formação e desenvolvimento de nuvens (ARTAXO et al., 2013). 
Já durante a estação seca (agosto a novembro), a queima de biomassa, principalmente antrópica, é responsável por um aumento significativo na concentração de gases traço e partículas, tendo implicações importantes em nível local, regional e global, inclusive no balanço radiativo atmosférico. A concentração de partículas sobe para 15.000 a 30.000 partículas por $\mathrm{cm}^{3}$, valores comparáveis aos de áreas urbanas muito poluídas (ANDREAE et al., 2015; ARTAXO, 2002; ARTAXO et al., 2006; MARTIN et al., 2010). As queimadas são mais intensas nas regiões sul e leste da Bacia Amazônica, no entanto, como as partículas emitidas pertencem predominantemente à moda fina, e dada a intensa atividade convectiva na região, estão sujeitas ao transporte em larga escala, atingindo, assim, áreas a milhares de quilômetros de distância (ARTAXO et al., 2013; CIRINO et al., 2014; PAULIQUEVIS et al., 2007).

As atividades antrópicas na Amazônia no decorrer dos últimos 50 anos tiveram um impacto expressivo sobre grande parte da região (ARTAXO et al., 2013). Durante as décadas de 70 e 80, a ocupação da Amazônia brasileira foi amplamente incentivada por políticas governamentais e subsídios, o que foi determinante para o crescimento dos desmatamentos. Embora áreas extensas de floresta permaneçam intactas, o desmatamento alterou cerca de $18 \%$ da área de floresta original, principalmente no arco do desflorestamento, área que compreende os estados do Acre, Pará, Maranhão, Mato Grosso, Rondônia e Tocantins (ARTAXO et al., 2013; FEARNSIDE, 2005). Esta mudança no padrão de uso do solo tem sido sobretudo ocasionada pelos grandes projetos de infraestrutura, pela atividade pecuária de grande e médio portes, pelo avanço das plantações de soja e de outras culturas, e pela exploração madeireira (DAVIDSON et al., 2012).

Desde 1988, o Programa de Monitoramento da Floresta Amazônica Brasileira por Satélite (PRODES) do Instituto Nacional de Pesquisas Espaciais (INPE) monitora, via satélite, o desmatamento por corte raso na Amazônia Legal, produzindo taxas anuais de desmatamento que são utilizadas pelo governo para o estabelecimento de políticas públicas, ações de fiscalização, controle e combate aos desmatamentos ilegais (MMA, 2016; INPE, 2016 ). A Figura 2 mostra a série temporal da área desmatada na Amazônia nos últimos 28 anos. Uma grande variabilidade temporal é observada devido a fatores climáticos e socioeconômicos. Até o ano de 2004, as taxas de desmatamento foram em média de $18.400 \mathrm{~km}^{2}$ ao ano. No entanto, nos últimos 10 anos, a região tem presenciado uma queda acentuada nestas taxas, de 27.772 km²/ano em 2004 para $5.831 \mathrm{~km}^{2} /$ ano em 2015, uma queda de aproximadamente 79\%, o que sugere que é possível gerir o avanço do desmatamento na região com políticas públicas adequadas (NEPSTAD et al., 2014). 
Figura 2 - Série temporal das taxas anuais de desmatamento na Amazônia Legal no período de 1988 a 2015.

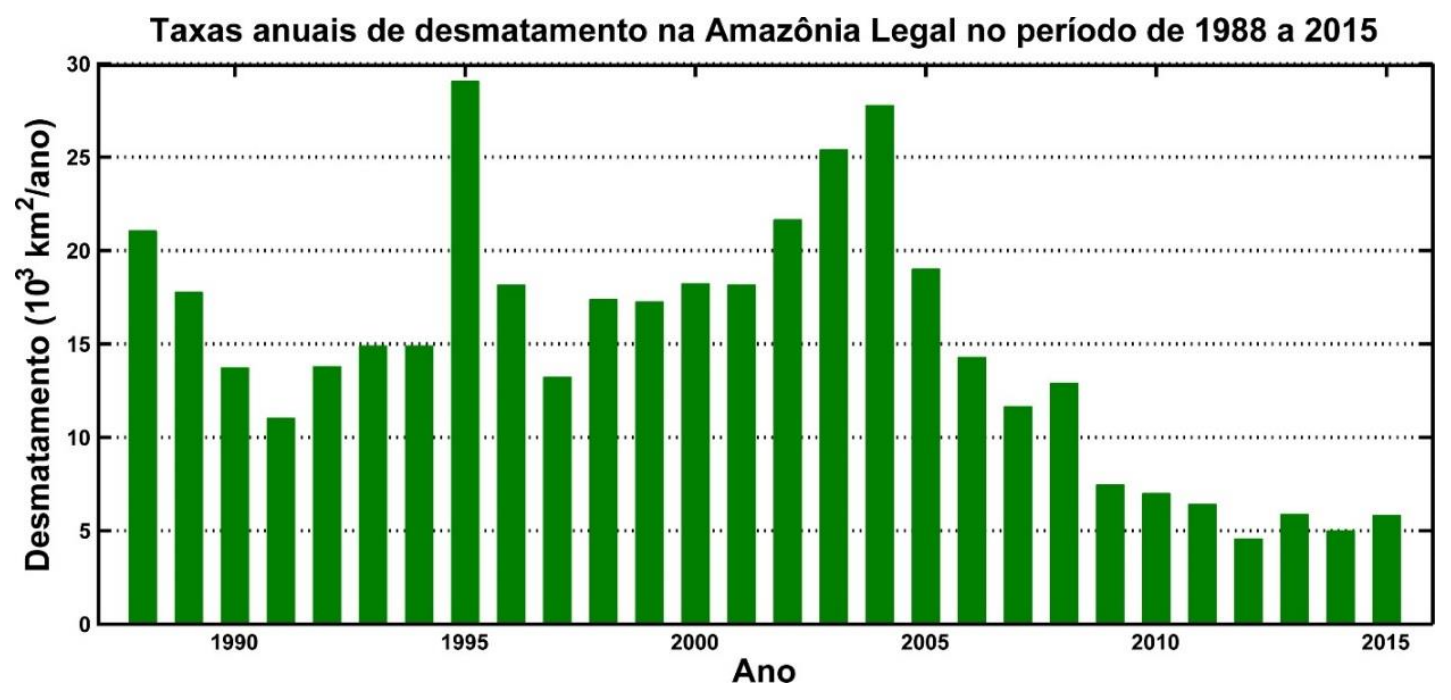

Fonte: INPE, 2016.

Figura 3 - Número de focos de incêndios ativos no Brasil entre os anos de 1998 e 2015.

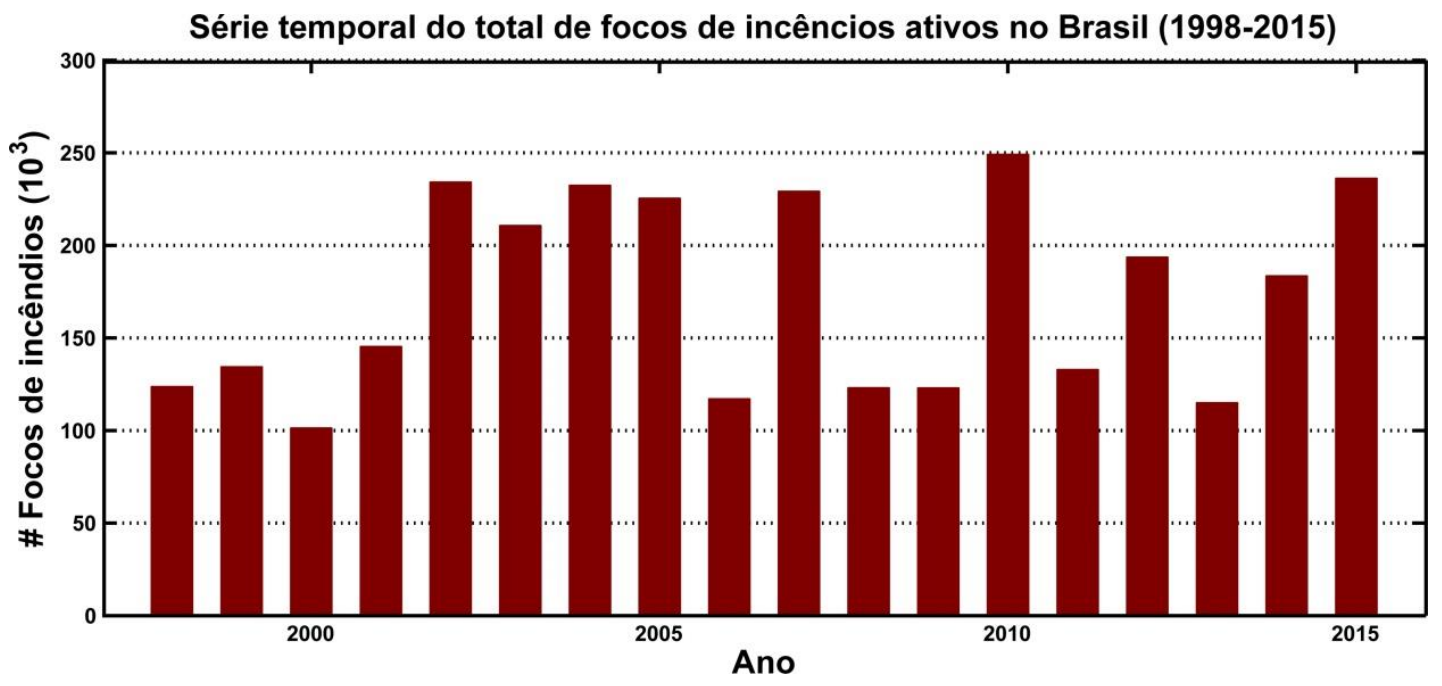

Fonte: INPE, 2016.

Apesar dos progressos feitos pelo Brasil no que diz respeito à redução das taxas de desmatamento, a frequência de ocorrência de focos de incêndios não teve o mesmo comportamento, como mostra a Figura 3. Desde 2004, o Brasil tem conseguido reduções substanciais nas emissões de queimadas associadas ao desmatamento (REDDINGTON et al., 2015), o que indica uma possível mudança no tipo de queima que ocorre na Amazônia, uma transição das queimadas nas regiões de floresta para as regiões de cerrado e regiões já previamente desmatadas (TEN HOEVE et al., 2012). 


\subsection{O BALANÇO RADIATIVO TERRESTRE}

A radiação solar é a principal fonte de energia que rege o clima terrestre. Estima-se que a quantidade de energia solar média por segundo por unidade de área que incide na Terra é de $340 \mathrm{~W} / \mathrm{m}^{2}$, com uma incerteza de $1 \mathrm{~W} / \mathrm{m}^{2}$ (Figura 4). Aproximadamente $30 \%$ deste valor é refletido de volta para o espaço por nuvens, moléculas de gás e partículas $\left(76 \mathrm{~W} / \mathrm{m}^{2}\right)$ e pela superfície terrestre $\left(24 \mathrm{~W} / \mathrm{m}^{2}\right)$. Cerca de $50 \%$ desta radiação incidente é absorvida pela superfície terrestre $\left(161 \mathrm{~W} / \mathrm{m}^{2}\right)$ e outros $20 \%$ são absorvidos pela atmosfera $\left(79 \mathrm{~W} / \mathrm{m}^{2}\right)$. A superfície terrestre transfere ainda parte desta radiação para atmosfera em forma de calor latente, calor sensível e de radiação de ondas longas. Para a manutenção do equilíbrio do balanço radiativo terrestre, a radiação absorvida pela Terra deve ser igual a radiação emitida de volta para o espaço (TRENBERTH et al., 2009).

Figura 4 - Diagrama esquemático do balanço de energia terrestre médio global. Os valores em $W / \mathrm{m}^{2}$ indicam a magnitude dos fluxos de energia juntamente com sua faixa de incerteza, representando as condições climáticas atuais. O fluxo de radiação solar é apresentado em amarelo e o fluxo de radiação terrestre de onda longa é apresentado em laranja.

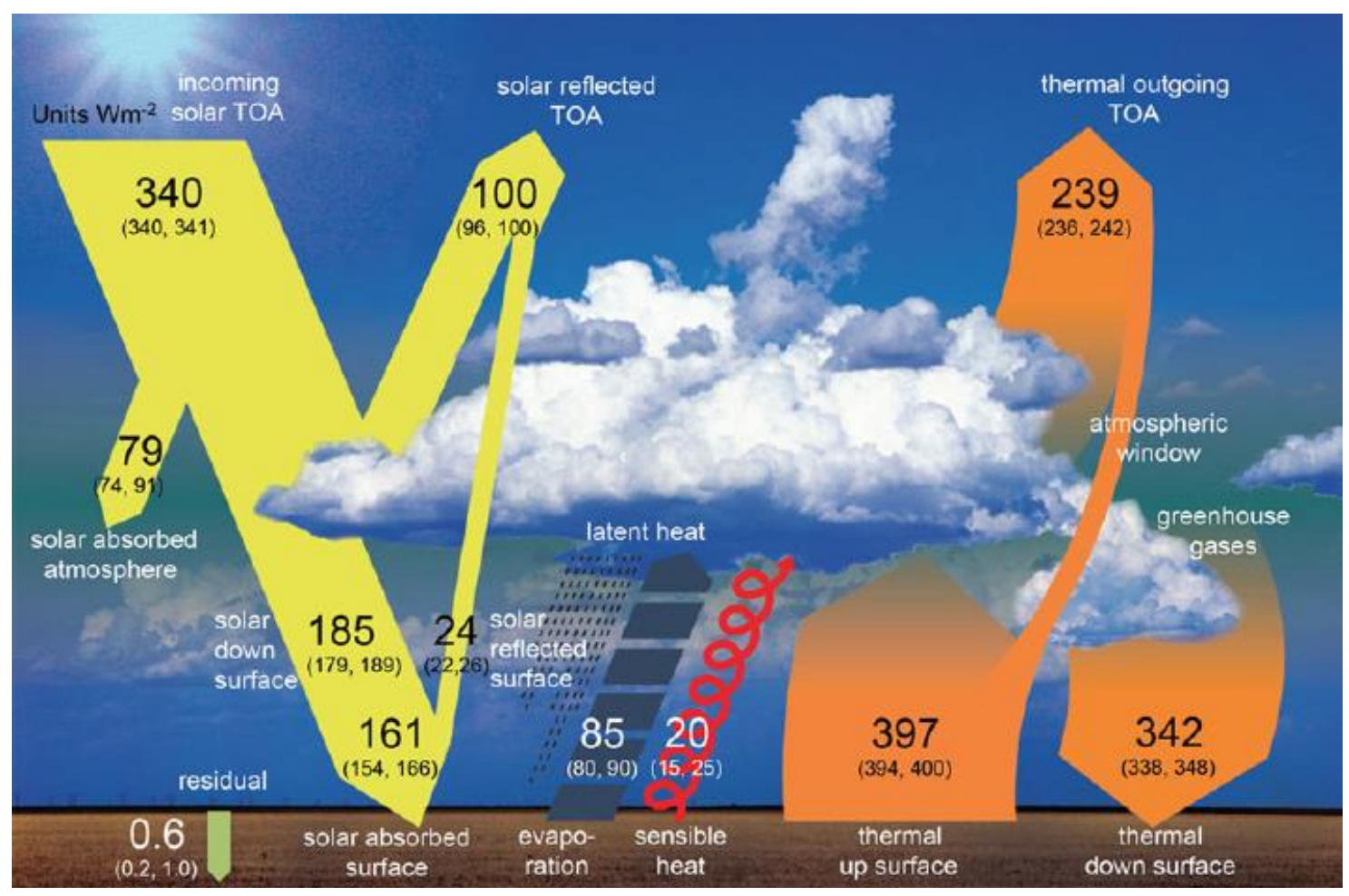

Fonte: WILD et al., 2013.

O balanço radiativo terrestre pode ser perturbado por fatores naturais ou antrópicos. Um exemplo importante de fator antrópico é o aumento da concentração de gases de efeito estufa na atmosfera, o que resulta na diminuição da radiação solar que é emitida de volta para 
o espaço. As altas concentrações de partículas de aerossol também têm impacto fundamental no balanço radiativo terrestre. A influência destes fatores pode ser avaliada em termos de uma grandeza denominada forçante radiativa, que é uma medida de como o balanço radiativo do sistema Terra-atmosfera é influenciado por perturbações externas (FORSTER et al., 2007). O Quinto Relatório de Avaliação do IPCC (IPCC AR5) define o conceito de forçante radiativa como a diferença na irradiância líquida no topo da atmosfera entre um estado de referência e um estado perturbado. $\mathrm{O}$ estado de referência pode ser a ausência de agente climático, ou seu impacto em uma dada situação ou época, como, por exemplo, no início da Revolução Industrial em 1750, estado de referência adotado pelo IPCC (CORREIA et al., 2012; MYHRE et al., 2013). Forçante radiativa positiva indica um efeito líquido de aquecimento sobre o clima, enquanto que forçante radiativa negativa indica um efeito de resfriamento climático.

Figura 5 - Estimativa da média global da forçante radiativa para o ano 2011 em relação a 1750 para os principais fatores que alteram o balanço radiativo terrestre.

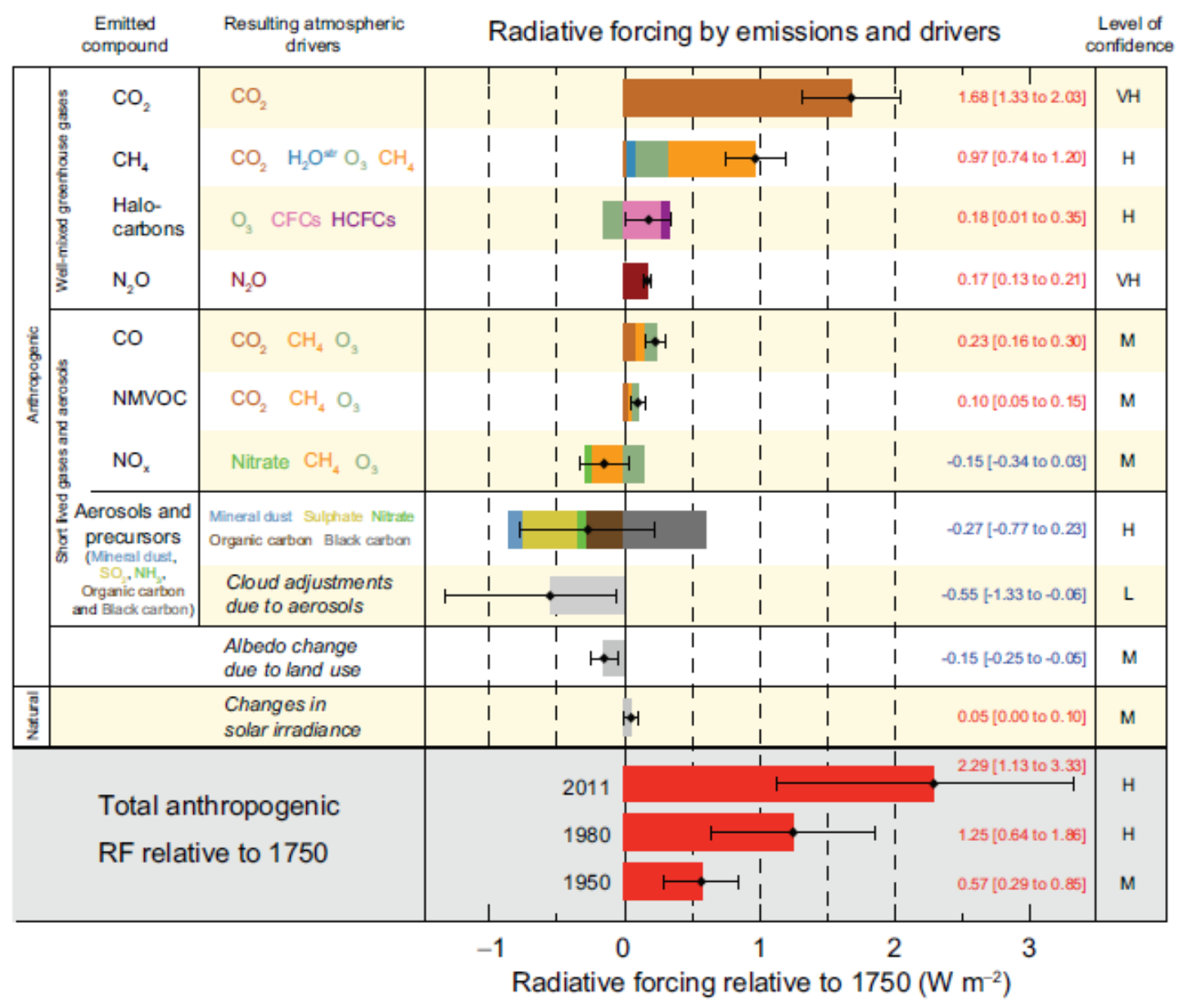

Fonte: IPCC, 2013. 
A Figura 5 mostra a estimativa da média global da forçante radiativa para $2011 \mathrm{em}$ relação a 1750 para os principais fatores responsáveis pelas mudanças no balanço radiativo. Os gases de efeito estufa, em geral, causam um efeito de aquecimento do sistema. Já o aerossol atmosférico, excetuando o black carbon, contribui para um efeito de resfriamento do sistema climático. $\mathrm{O}$ aerossol é responsável ainda por um efeito indireto associado às alterações no albedo de nuvens. É importante ressaltar que os efeitos locais destas partículas de aerossol podem ser muito maiores chegando a centenas de $\mathrm{W} / \mathrm{m}^{2}$, sobretudo em regiões próximas das fontes de emissões de partículas (GARCÍA et al., 2012).

A forçante radiativa do aerossol é a incerteza mais importante das mudanças climáticas globais e regionais, o que ocorre porque as partículas de aerossol têm um tempo de residência curto na atmosfera e sua concentração varia significativamente no espaço e tempo. Isto torna essencial estudar em detalhes as propriedades radiativas das partículas de aerossol e reduzir as incertezas na quantificação do seu papel no balanço radiativo terrestre e na sua representação em modelos climáticos (ARTAXO et al., 2009; WILD et al., 2013).

\subsection{AS PARTÍCULAS DE AEROSSOL ATMOSFÉRICO}

O aerossol atmosférico consiste em um conjunto de partículas sólidas ou líquidas em suspensão na atmosfera (SEINFELD \& PANDIS, 2016). Estas partículas podem ser originadas por fontes naturais, como é o caso da poeira mineral, do aerossol marinho, das emissões vulcânicas e das partículas biogênicas, ou por fontes antrópicas, como, por exemplo, as emissões industriais e produtos da queima de combustível fóssil. Podem ser emitidas diretamente na atmosfera, sendo chamadas de aerossol primário, ou formadas na atmosfera a partir de percursores gasosos, o chamado aerossol secundário.

O efeito das partículas no clima depende de seu tamanho, propriedades ópticas e composição química. Em se tratando do tamanho, as partículas de aerossol podem ser classificadas de acordo com o seu diâmetro, que varia de alguns nanômetros até dezenas de micrômetros. Partículas com diâmetro menor que $2,5 \mu \mathrm{m}$ são pertencentes à chamada moda fina e aquelas com diâmetro maior que $2,5 \mu \mathrm{m}$ são pertencentes à chamada moda grossa. A moda fina pode ser ainda subdividida em moda de nucleação, que compreende as partículas com diâmetro menor que $10 \mathrm{~nm}$; moda de Aitken, que compreende as partículas com diâmetro entre $10 \mathrm{~nm}$ e $100 \mathrm{~nm}(0,1 \mu \mathrm{m})$; e moda de acumulação, que compreende as partículas cujo diâmetro varia entre 0,1 e 2,5 $\mu \mathrm{m}$. Quando na atmosfera, as partículas podem ter seu tamanho 
e composição alterados através da condensação de vapores, evaporação, coagulação com outras partículas, reações químicas ou ativação para formar gotículas de nuvem (RAES et al., 2000). Os processos que influenciam o tamanho das partículas em cada moda são mostrados na Figura 6.

As partículas de aerossol podem ser removidas da atmosfera por processos de deposição seca ou úmida. A deposição seca pode ocorrer por difusão ou sedimentação. A difusão ocorre tanto pela agitação térmica das partículas quanto por processos turbulentos na atmosfera. Já a deposição úmida pode ocorrer no interior das nuvens pelo processo de nucleação das partículas (washout) ou abaixo das nuvens através da interceptação das partículas durante eventos de precipitação (rainout). Ambos os processos de remoção são responsáveis por um tempo de residência das partículas na troposfera relativamente curto, variando de alguns dias a algumas semanas. Juntamente com a distribuição geográfica altamente não-uniforme das fontes de partículas, tais processos contribuem para uma grande variação da concentração e da composição do aerossol na atmosfera terrestre (SEINFELD \& PANDIS, 2016). A variabilidade ao longo da coluna vertical também é expressiva.

Figura 6 - Distribuição de tamanho das partículas de aerossol. Principais modas, fontes e mecanismos de formação e remoção.

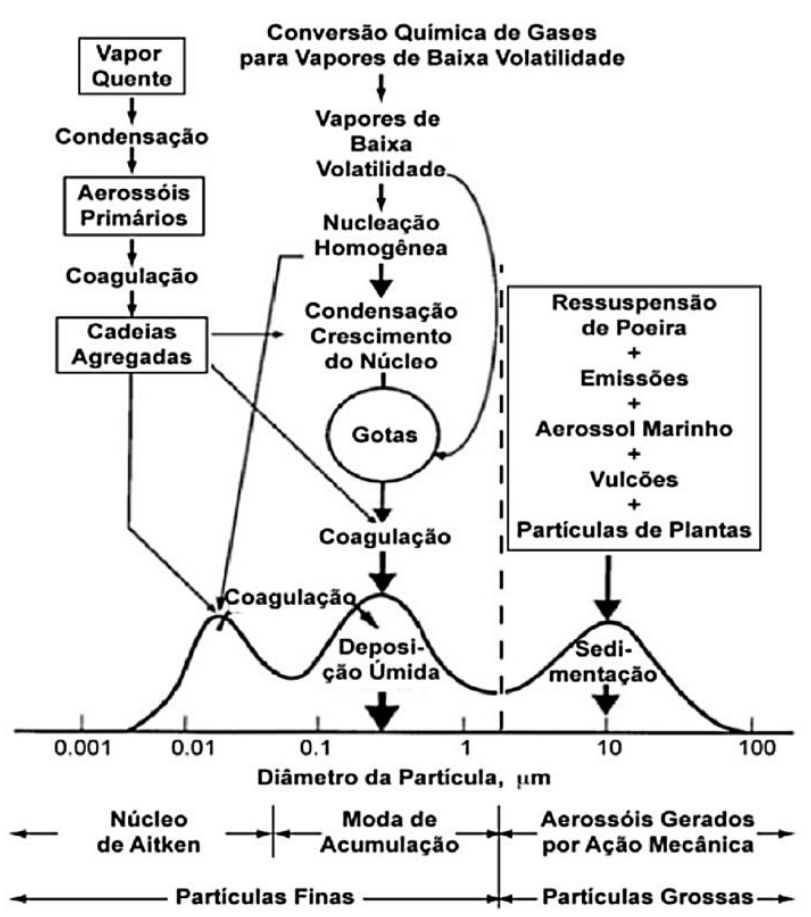

Fonte: Adaptada de SEINFELD \& PANDIS, 2016. 
Quanto ao tempo de residência na atmosfera, partículas com diâmetro menor que 10 nm têm tempo de residência de um dia ou menos, sendo removidas por processos de difusão e de coagulação. As partículas com diâmetros menores que $20 \mu \mathrm{m}$ também têm tempo de residência de um dia ou menos, entretanto, são removidas por deposição seca ou úmida, por processos de sedimentação e de impactação. Por outro lado, partículas com diâmetros entre 0,1 e 2,5 $\mu \mathrm{m}$ tem tempos de residência relativamente maiores, podendo atingir centenas de dias na alta troposfera ou na estratosfera. Embora os processos de remoção nesta faixa de tamanho sejam menos eficientes, a remoção por precipitação e por processos de impactação reduz o tempo de residência a algumas dezenas de dias nas camadas mais baixas da troposfera. É por esta razão que a moda de acumulação está neste intervalo de tamanho (WALLACE \& HOBBS, 2006).

$\mathrm{Na}$ Amazônia, as principais fontes naturais de aerossol são a emissão primária de partículas biogênicas e a oxidação dos compostos orgânicos voláteis (COVs) emitidos pela vegetação, sobretudo isopreno e terpenos (ARTAXO et al., 2009). As partículas biogênicas primárias pertencem principalmente à moda grossa, que tem uma meia vida curta (de algumas horas), e depositam-se rapidamente perto do local de emissão (ARTAXO et al., 2006). São constituídas, por exemplo, por grãos de pólen, bactérias, esporos de fungos e de samambaias, vírus e fragmentos de plantas e animais (ARTAXO et al., 2009; MARTIN et al., 2010; PAULIQUEVIS et al., 2007). A maior parte dessas partículas tem composição orgânica, com traços de potássio, cálcio, magnésio, enxofre, fósforo zinco e outros elementos. Os COVs, por sua vez, são compostos químicos orgânicos que tem pressão de vapor suficientemente alta em condições normais a ponto de vaporizarem e se dispersarem na atmosfera. Uma vez na atmosfera, estão sujeitos a reações que podem converter alguns deles em partículas de aerossol, partículas essas que são chamadas de aerossol orgânico secundário e pertencem à moda fina (PAULIQUEVIS et al., 2007). As emissões antrópicas são oriundas da combinação das emissões da queima de vegetação de cerrado, de pastagens e de florestas primárias e secundárias (ARTAXO et al., 1998), fonte dominante em alguns locais, principalmente durante a estação seca. Tais partículas são pertencentes à moda fina e consistem predominantemente em carbono orgânico, além de black carbon e compostos inorgânicos (MARTIN et al., 2010).

Principalmente durante a estação chuvosa, eventos convectivos produzem grandes quantidades de precipitação que são a principal fonte de remoção de gases e partículas da atmosfera na região. Além disso, dada a perturbação dos ciclos biogeoquímicos por ações antrópicas, a deposição atmosférica pode ser uma importante fonte de remoção de poluentes, 
assim como um significante aporte de nutrientes para o ecossistema amazônico (ARTAXO et al., 2005).

\subsubsection{A componente carbonácea do aerossol}

O carbono é um componente muito importante para o material particulado atmosférico e, em geral, o elemento majoritário. Na natureza, o ciclo de carbono é um dos ciclos biogeoquímicos mais importantes e está presente na forma de substâncias orgânicas e inorgânicas. Estes compostos são importantes devido a sua ocorrência nas modas grossa e fina do aerossol atmosférico e por possuírem propriedades de absorção e espalhamento da radiação (ARANA, 2014).

O carbono orgânico (OC, do inglês, Organic Carbon) é o componente do aerossol carbonáceo em que as moléculas de carbono estão quimicamente combinadas a outros elementos, como hidrogênio ou oxigênio. Pode ser um produto da combustão incompleta, emitido por fontes naturais ou formado a partir da condensação de produtos da foto-oxidação de COVs. O OC é tipicamente tratado como um aerossol puramente espalhador, entretanto, estudos recentes mostram que existe uma fração absorvedora. Esta fração, a qual chamamos de Brown Carbon (BrC), absorve radiação solar principalmente na região do ultravioleta; é produzida principalmente a partir da queima de biomassa ou queima de combustíveis fósseis, mas também pode ser produzida na atmosfera a partir de fontes secundárias. Estudos estimam ainda que o BrC contribui com cerca de 20 a $40 \%$ da absorção do total do aerossol carbonáceo e que seu efeito radiativo direto varia entre $+0,1$ e $+0,6 \mathrm{~W} / \mathrm{m}^{2}$ (WANG et al., 2016). Em geral, o OC representa entre 10 a 40\% das emissões de aerossol orgânico primário, dependendo da fonte, contudo, existe uma dificuldade na quantificação da contribuição das várias fontes devido à complexidade da mistura de compostos orgânicos (SEINFELD \& PANDIS, 2006).

O black carbon (BC) é um dos principais componentes do aerossol atmosférico, com grande influência sobre as mudanças climáticas e sobre a qualidade do ar, no entanto, não existe acordo sobre uma terminologia que considere as propriedades específicas, definições, métodos de medição e incertezas associadas. Em se tratando dos métodos de medição, PETZOLD (2013) sugere que o termo black carbon equivalente (EBC, do inglês, Equivalent Black Carbon) deve ser utilizado em vez de BC para medidas de absorção obtidas a partir de métodos de absorção óptica, em conjunto com o coeficiente mássico de absorção apropriado para a conversão do coeficiente de absorção em concentração de massa. O termo carbono 
elementar (EC, Elemental Carbon) deve ser utilizado em vez de BC para os dados obtidos a partir de métodos termo-ópticos. É sugerido ainda que o termo black carbon refratário (rBC, Refractory Black Carbon) deve ser usado em vez de BC para medidas obtidas a partir de métodos baseados em incandescência, tais como instrumentos do tipo SP2, da Droplet Measurement Technology.

Formalmente, a definição de BC se baseia em sua composição e em suas propriedades de absorção da radiação: é uma substância que absorve radiação na região do visível, com um coeficiente mássico de absorção acima de $5 \mathrm{~m}^{2} / \mathrm{g}$ a um comprimento de onda $\lambda=550 \mathrm{~nm}$ para partículas recém-produzidas; é refratário, ou seja, mantém sua forma mesmo em temperaturas muito elevadas, com uma temperatura de volatilização próxima de $4.000 \mathrm{~K}$; é insolúvel em água, em solventes orgânicos, incluindo metanol e acetona, e em outros componentes do aerossol atmosférico; consiste em agregados de pequenas esférulas de carbono com diâmetro entre 10 e $50 \mathrm{~nm}$; e, adicionalmente, contém uma grande fração de átomos de carbono com ligação do tipo $\mathrm{sp}^{2}$ do mesmo modo que as ligações no grafite (PETZOLD et al., 2013).

$\mathrm{O}$ BC é formado pela combustão incompleta de combustíveis fósseis, biocombustíveis e de biomassa, e é co-emitido com outras partículas e gases, tais como dióxido de enxofre, óxidos de nitrogênio e OC. Quando na atmosfera, o BC tem reatividade química baixa, podendo ser removido por processos de deposição seca, o que resulta em um tempo de vida médio de aproximadamente uma semana.

Como dito anteriormente, o BC tem grande influência sobre o balanço radiativo terrestre. O Quinto Relatório de Avaliação do IPCC estima a forçante radiativa do BC em cerca de $+0,6 \mathrm{~W} / \mathrm{m}^{2}$. Já BOND et al., 2013, estima a forçante do BC em $+1,1(+0,17$ a $+2,10) \mathrm{W} / \mathrm{m}^{2}$, valor muito elevado, como podemos ver na Figura 7. Alguns dos componentes co-emitidos com o BC (sulfatos e OC, principalmente) exercem um efeito de resfriamento sobre o clima compensando parcialmente o efeito de aquecimento do BC. Estes valores mostram que o BC tem grande responsabilidade pelo aquecimento global, com valores de forçante próximos ao do $\mathrm{CO}_{2}$ e do $\mathrm{CH}_{4}$ quando consideramos seus efeitos diretos e indiretos (IPCC, 2013).

A forçante radiativa do $\mathrm{BC}$ sozinho é mais incerta do que a forçante radiativa total do aerossol. Isto pode ser explicado pela hipótese de que toda a absorção é imputada ao BC quando de fato uma fração significativa pode ser devido à absorção pelo aerossol orgânico, pela poeira mineral e pelo chamado BrC. Embora as fontes de poeira mineral possam ser isoladas geograficamente das fontes de BC, o aerossol orgânico é tipicamente co-emitido com o black carbon. O estudo da absorção da radiação pelas diferentes espécies químicas é, portan- 
to, essencial para limitar as grandes incertezas na estimativa da forçante radiativa do BC (FORSTER et al., 2007; HOLANDA, 2015).

Figura 7 - Estimativa da média global da forçante radiativa do black carbon entre 1750 e 2005.

Global climate forcing of black carbon and co-emitted species in the industrial era (1750 - 2005)

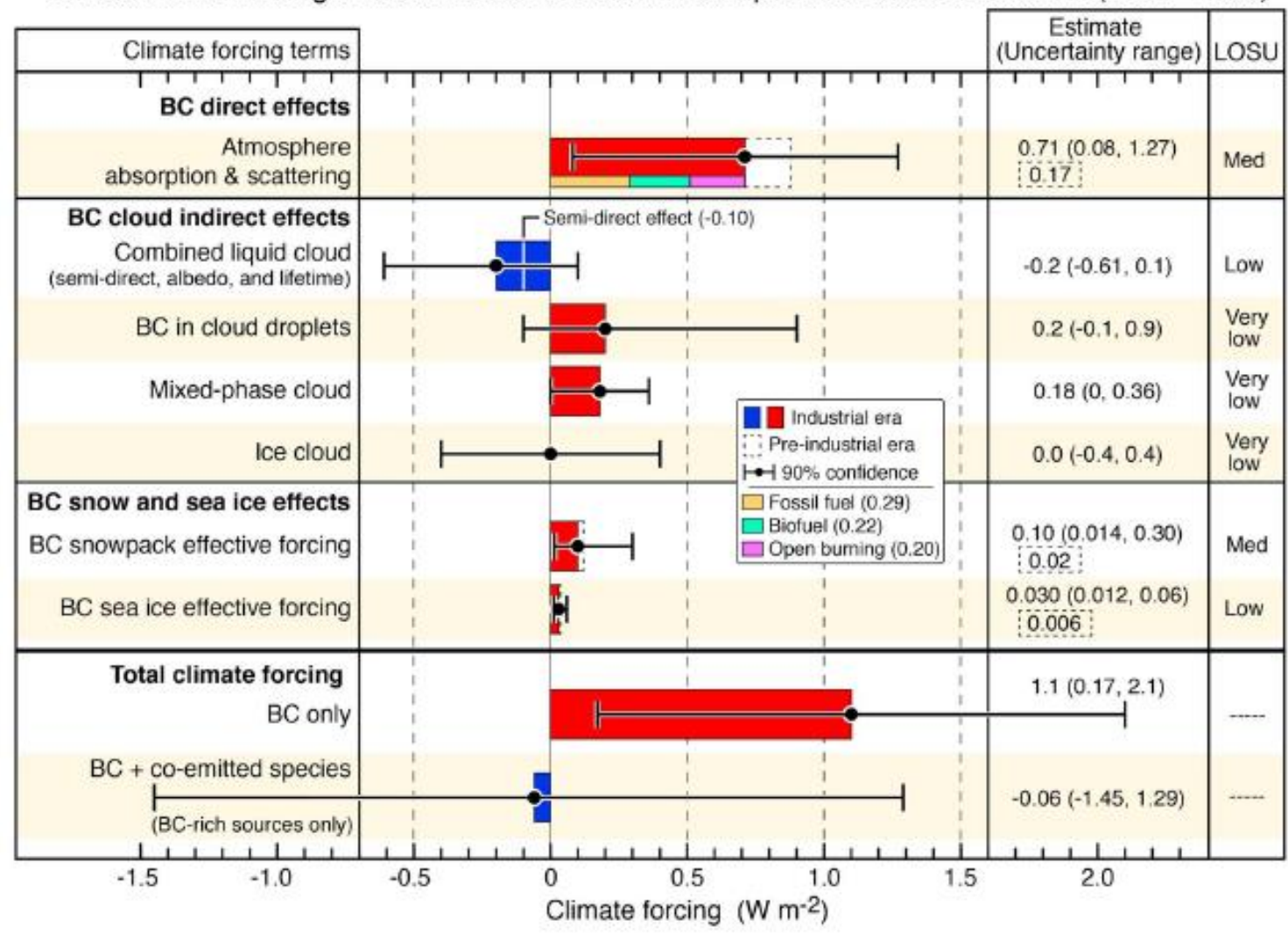

Fonte: BOND et al., 2013.

1.3.2 Os efeitos das partículas aerossol no clima

As partículas de aerossol afetam o clima regional e global através das mudanças que produzem no balanço radiativo terrestre (ANDREAE et al., 2004, 2005). O efeito pode ser tanto direto, através da absorção e espalhamento da radiação solar pelas partículas, mudando os fluxos radiativos líquidos na atmosfera e na superfície; quanto indireto, o que está relacionado com as mudanças provocadas pelo aerossol nas propriedades micro e macrofísicas de nuvens (ARTAXO et al., 2009).

O efeito direto do aerossol no clima depende da concentração das partículas na atmosfera, das suas propriedades ópticas e do seu tamanho, de modo que a interação é mais eficiente quando o tamanho da partícula é da mesma ordem de grandeza do comprimento de onda incidente. Sendo assim, as partículas da moda de acumulação interagem mais eficientemente 
com a radiação solar. Através do espalhamento pelas partículas de aerossol, grande parte da radiação solar incidente é emitida de volta para o espaço, resultando em um efeito de resfriamento da atmosfera, isto é, em uma forçante negativa. Em contrapartida, quando a radiação é absorvida pelas partículas, parte de sua energia é convertida em energia térmica, causando um efeito de aquecimento, logo, uma forçante positiva. Ademais, a absorção da radiação está intimamente ligada à concentração de black carbon e ao estado de mistura dos componente nãoabsorvedores em uma população de partículas (DE LUCCA, 2009; DUBOVIK et al., 2002a; HOLANDA, 2015).

O efeito indireto do aerossol está associado à sua atuação como núcleos de condensação de nuvens (NCN). O aumento no número de partículas de aerossol ocasiona um aumento da concentração de gotículas de nuvens para uma mesma quantidade de vapor d'água. Sendo o conteúdo de água líquida constante, este aumento de gotículas implica em uma diminuição do seu tamanho médio. Gotículas menores refletem mais radiação solar de volta para o espaço (nuvens mais brilhantes), reduzindo a quantidade de radiação solar que alcança a superfície terrestre e levando a um efeito de resfriamento no solo (RAMANATHAN, 2001; TWOMEY, 1977). O aumento da concentração de partículas também pode afetar a taxa de precipitação e o tempo de vida das nuvens. Além disso, as partículas de aerossol podem afetar propriedades termodinâmicas da atmosfera, tais como o perfil de temperatura e a variabilidade da umidade relativa sobre grandes áreas, efeitos chamados de efeitos semidiretos.

\subsection{O EXPERIMENTO GOAMAZON2014/5}

O experimento GoAmazon2014/5 (Green Ocean Amazon 2014/5) foi realizado entre os anos de 2014 e 2015 com o objetivo de entender como o ciclo de vida das partículas de aerossol e das nuvens em condição natural é também influenciado pelas emissões urbanas de Manaus. A proposta buscou entender a suscetibilidade das interações nuvem-aerossol-radiaçãoprecipitação e os feedbacks entre o funcionamento da biosfera e atmosfera e as atividades antrópicas na Amazônia Central (ARTAXO et al., 2014). Neste sentido, a pluma de poluição proveniente de Manaus funcionou como um laboratório para a investigação das perturbações a processos naturais (MARTIN et al., 2015). O estudo dos processos atmosféricos em tais condições é relevante para a compreensão das mudanças climáticas regionais e globais.

Manaus é a capital do estado do Amazonas, com uma população de mais de 2 milhões de habitantes (IBGE, 2015) e uma frota veicular de cerca de 650 mil veículos (DENATRAN, 
2016). É uma área urbana isolada em meio a Bacia Amazônica com alto nível de poluição onde se identifica o efeito ilha urbana de calor, resultando em uma diferença de mais ou menos $3^{\circ} \mathrm{C}$ entre a área urbana e a floresta (CARVALHO et al., 2013; DE SOUZA \& DOS SANTOS ALVALÁ, 2014). As emissões veiculares contribuem significativamente para os níveis de poluição da pluma urbana, além da contribuição das atividades industriais na região e das emissões de usinas termoelétricas que utilizam combustível com alto teor de enxofre, ainda que esteja havendo um crescimento do uso de gás natural na geração de energia elétrica (MARTIN et al., 2015). O número de partículas e as concentrações em massa são de 10 a 100 vezes maiores na pluma de poluição em comparação com a condição natural (MARTIN et al., 2010).

Figura 8 - Sítios de amostragem em operação durante o experimento GoAmazon2014/5.

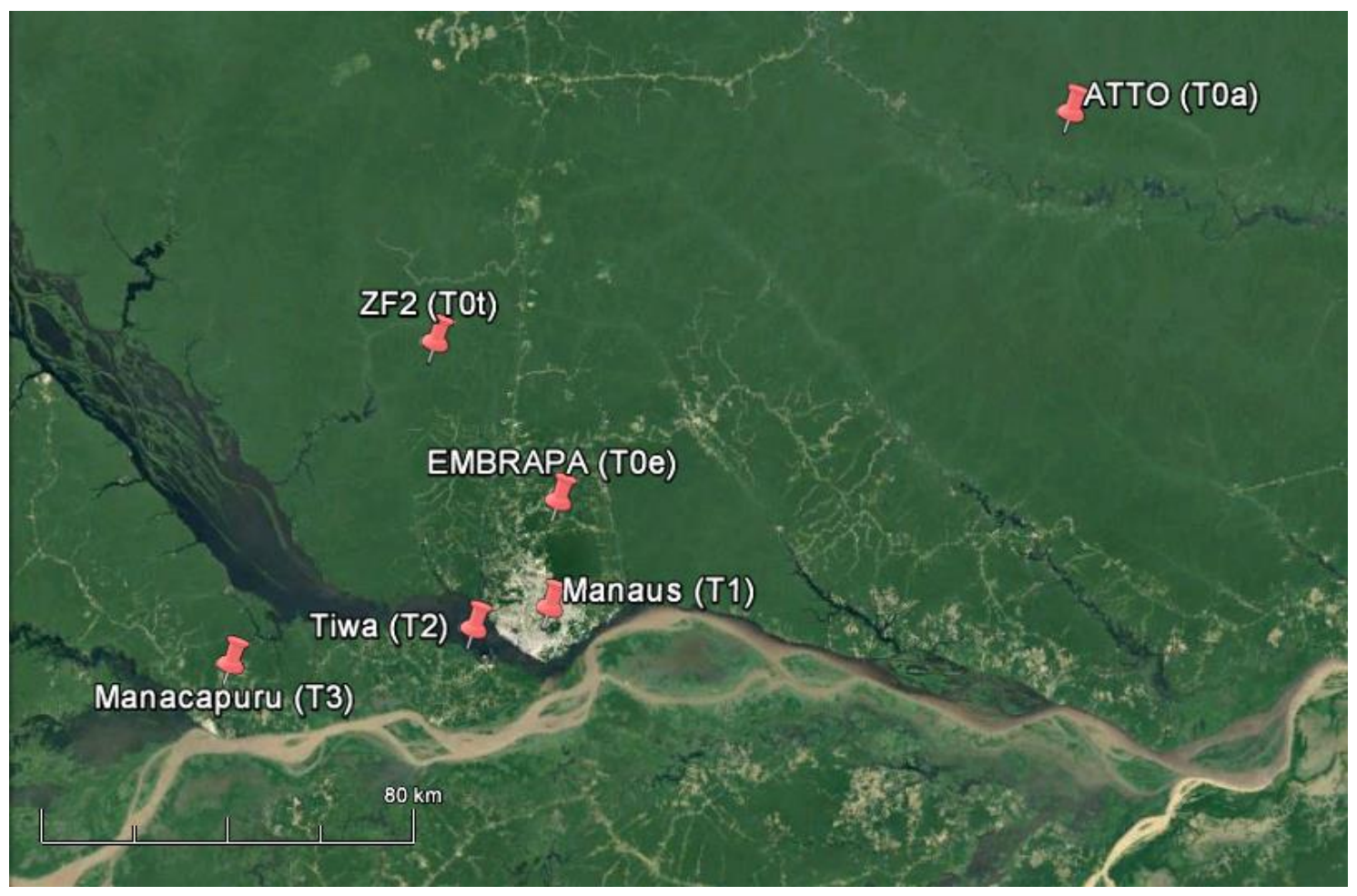

Fonte: Adaptada de MARTIN, 2015.

Para a realização do experimento, foram operadas estações em 6 diferentes sítios de amostragem (Figura 8). Em três sítios foram medidas propriedades atmosféricas vento acima da pluma de Manaus: ATTO (T0a), ZF2 (T0t) e EMBRAPA (T0e). Em dois sítios foram realizadas medições vento abaixo de Manaus: Tiwa (T2) e Manacapuru (T3). Além disto, um sítio de amostragem operou no campus do Instituto Nacional de Pesquisas da Amazônia (INPA), em Manaus. Neste trabalho, foram analisadas as medições realizadas no ATTO (T0a), na 
EMBRAPA (T0e) e em Manacapuru (T3). As coordenadas geográficas dos sítios são listadas na Tabela 1.

Tabela 1 - Coordenadas geográficas dos sítios de amostragem em operação durante o experimento GoAmazon2014/5.

\begin{tabular}{lcccc}
\hline & Sítios & \multicolumn{2}{c}{ Localização } & \multirow{2}{*}{ Descrição } \\
\multicolumn{2}{c}{ GoAmazon2014/5 } & Latitude & Longitude & Floresta vento acima de Manaus \\
\hline T0a & ATTO & $-2,1466^{\circ}$ & $-59,0050^{\circ}$ & Pastagem vento acima de Manaus \\
T0e & EMBRAPA & $-2,8942^{\circ}$ & $-59,9718^{\circ}$ & Pastagem vento abaixo de Manaus \\
T3 & Manacapuru & $-3,2133^{\circ}$ & $-60,5987^{\circ}$ & Paut \\
\hline
\end{tabular}

Fonte: Adaptada de MARTIN, 2015.

O ATTO (Amazonian Tall Tower Observatory) está localizado a cerca de $150 \mathrm{~km}$ a nordeste da cidade de Manaus na Reserva de Desenvolvimento Sustentável (RDS) do Uatumã, na Amazônia Central. Vento acima do sítio, no sentido do vento dominante (nordeste), o sítio ATTO recebe massas de ar que passam por grandes áreas cobertas por florestas não perturbadas, ao longo de centenas de quilômetros. À Nordeste, a região mais próxima com densa atividade antrópica se encontra na região costeira das Guianas e do estado do Amapá, a cerca de $1.100 \mathrm{~km}$ de distância. Na direção leste, estão cidades menores dispersas e as cidades de Santarém e Belém, a uma distância de cerca de 500 e 900 km, respectivamente. A origem das massas de ar no ATTO muda ao longo do ano conforme as mudanças sazonais na Zona de Convergência Intertropical (ZCIT) sobre a Bacia Amazônia, resultando em diferenças significativas nas condições meteorológicas e na composição da atmosfera. Na estação chuvosa, as massas de ar chegam predominantemente de nordeste ao longo de uma região de floresta tropical com baixa concentração de partículas. Durante este período, devido ao transporte de longa distância do Atlântico e da África, é possível observar episódios de aerossol marinho, poeira do Saara, aerossol de queimada da África Ocidental e, possivelmente, até mesmo poluição da América do Norte e da Europa. Este padrão muda abruptamente no final de maio, quando a ZCIT se desloca para norte do sítio ATTO. Esta mudança marca o início da estação seca, um período em que o sítio experimenta massas de ar vindos de leste e sudeste, sendo influenciado pela queima de biomassa e outras atividades antrópicas no nordeste do Brasil. A Figura 9 ilustra a rosa dos ventos para a estação seca (15 de junho - 30 de novembro) e para a estação chuvosa ( 1 de dezembro - 14 de junho), indicando a predominância do vento vindo de leste. Uma ligeira mudança da direção do vento em direção a ENE (lés-nordeste) é observada 
na estação chuvosa, enquanto que na estação seca os fluxos são principalmente de leste (ANDREAE et al., 2015).

Figura 9 - Rosa dos ventos para (a) estação seca (15 de junho - 30 de novembro) e (b) estação chuvosa (1 de dezembro - 14 de junho) com base em médias de meia hora da velocidade e da direção do vento medidas a $81 \mathrm{~m}$ AGL no período de 18 de outubro de 2012 e 23 de julho de 2014 no ATTO (T0a).
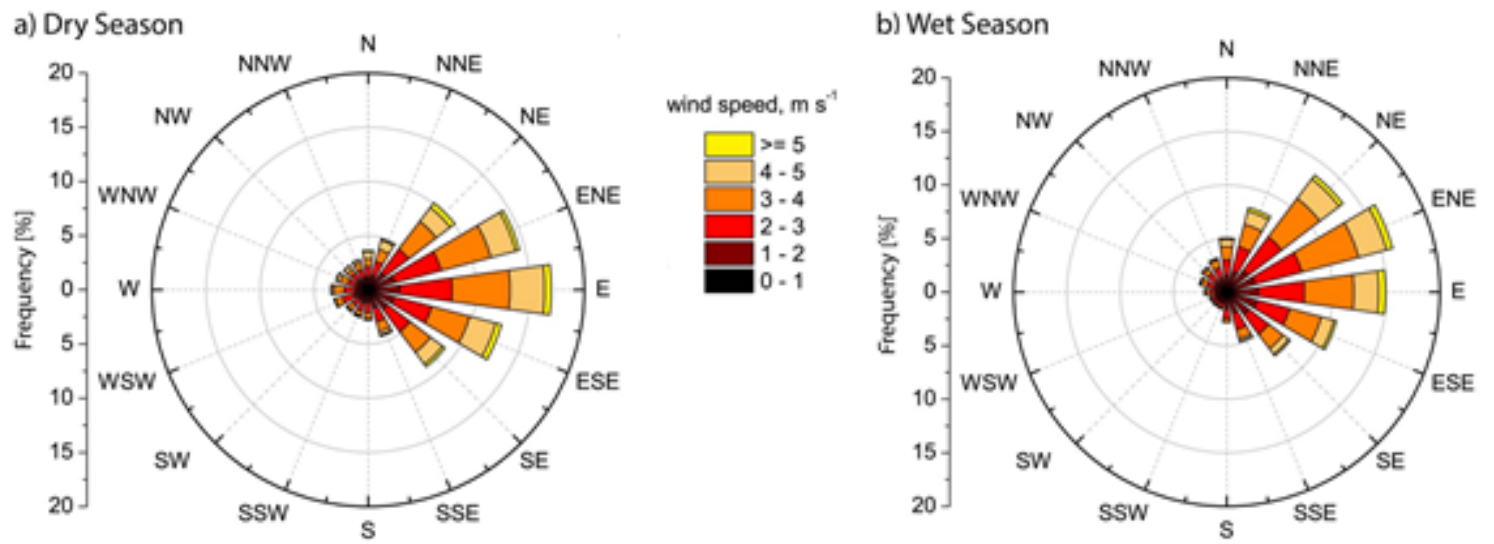

Fonte: ANDREAE et al., 2015.

O sítio ATTO está em operação desde meados de 2012, realizando medições contínuas da composição da atmosfera em condições de background, com pouca ou nenhuma influência da pluma de Manaus na região. Medidas de absorção, espalhamento, distribuição de tamanho, NCN e composição química foram realizadas pelo Instituto de Física da Universidade de São Paulo em parceria com o Instituto Max Planck, que mediu parâmetros similares com outra instrumentação, além de compostos gasosos (O3, CO, CH4, CO2, $\mathrm{N} 2 \mathrm{O}$ e outros gases) (ARTAXO et al., 2014). Em setembro de 2014, foi iniciada a construção de uma torre de 325 m no local para a realização de medições micrometeorológicas, caracterização de aerossol e monitoramento contínuo de gases traço, e sua inauguração se deu em agosto de 2015. Em vista disso, durante o experimento GoAmazon2014/5, as medições neste sítio foram realizadas a partir de duas torres de altura intermediária $(80 \mathrm{~m})$ em operação.

O sítio T0e foi implementado em 2011 na Empresa Brasileira de Pesquisas Agropecuárias (EMBRAPA), cerca de $10 \mathrm{~km}$ ao norte do limite da área metropolitana de Manaus, para a operação do sistema Raman Lidar. Neste sítio foram operados, além do Raman Lidar, um fotômetro da rede AERONET, disdrômetros e radiômetros para a medida do conteúdo de vapor d'água na atmosfera, entre outros instrumentos, permitindo o estudo dos mecanismos de feedback e interações entre umidade, convecção, nuvens e aerossol (BARBOSA et al., 2014).

O sítio experimental T3 foi instalado a $70 \mathrm{~km}$ vento abaixo de Manaus, o que representa, dependendo da velocidade de vento, um período de algumas horas até que a massa de 
ar proveniente de Manaus atinja a região. Está situado em uma área de pastagem a $2 \mathrm{~km}$ a norte da estrada AM-070, que liga Manaus à cidade de Manacapuru. Este sítio experimenta duas condições extremas que variam de acordo com as condições meteorológicas: uma atmosfera com baixa concentração de aerossol com a predominância de aerossol biogênico, e uma atmosfera afetada pela pluma urbana de Manaus que atinge o local regularmente. Ademais, durante a noite o sítio pode ser impactado por fontes locais, como, por exemplo, as olarias localizadas na região, e na estação seca é pouco impactado por emissões de queimadas locais, sofrendo influência do transporte em larga escala. Cerca de 19 containers foram instalados em Manacapuru de modo a possibilitar medidas de propriedades de aerossol, nuvens e gases traços.

Os instrumentos utilizados neste trabalho, assim como o período de análise em cada sítio, são apresentados na Tabela 2.

Tabela 2 - Instrumentos utilizados neste trabalho e o período de análise no ATTO (T0a), na EMBRAPA (T0e) e em Manacapuru (T3).

\begin{tabular}{|c|c|c|c|}
\hline GoA & $\begin{array}{l}\text { Sítios } \\
\text { mazon2014/5 }\end{array}$ & Instrumento & $\begin{array}{l}\text { Período de } \\
\text { Análise }\end{array}$ \\
\hline T0a & ATTO & $\begin{array}{l}\text { MAAP (modelo Thermo Scientific-5012) } \\
\text { Nefelômetro (modelo TSI-3563) } \\
\text { Nefelômetro (modelo Aurora Ecotech 3000) }\end{array}$ & $\begin{array}{l}\text { Set/2011 - Dez/2015 } \\
\text { Ago/2012 - Dez/2013 } \\
\text { Fev/2014 - Out/2015 }\end{array}$ \\
\hline T0e & EMBRAPA & Fotômetro da rede AERONET & Mar/2011 - Dez/2015 \\
\hline $\mathrm{T} 3$ & Manacapuru & $\begin{array}{l}\text { Aetalômetro (modelo AE31) } \\
\text { Nefelômetro (TSI-3563) } \\
\text { Fotômetro da rede AERONET }\end{array}$ & $\begin{array}{c}\text { Jan/2014 - Set/2015 } \\
\text { Jan/2014 - Ago/2015 } \\
\text { Jan/2014 - Nov/2015 }\end{array}$ \\
\hline
\end{tabular}





\section{OBJETIVOS}

Este trabalho tem como objetivo analisar as propriedades ópticas do aerossol na Amazônia Central, em particular, separando as três componentes presentes: 1) aerossol urbano associado às emissões da cidade de Manaus; 2) aerossol emitido a partir da queima de biomassa e 3) aerossol biogênico natural predominante na estação chuvosa. Para atender a estes objetivos propõe-se:

1) Quantificar a influência da pluma urbana de Manaus sobre propriedades de aerossol e de nuvens medidas por sensoriamento remoto a partir de satélites vento acima e vento abaixo da cidade entre os anos de 2003 e 2015;

2) Caracterizar a influência dos eventos anuais de queima de biomassa nas propriedades físicas do aerossol medidas pela rede AERONET ao longo de mais de 15 anos em diferentes regiões da Amazônia;

3) Avaliar as propriedades de absorção e de espalhamento e sua dependência espectral a partir de medidas por sensoriamento remoto e medidas in situ realizadas no entorno de Manaus nos anos de 2014 e 2015.

O primeiro objetivo visa utilizar dados dos satélites Terra e Aqua em longa série temporal para investigar se a pluma de aerossol de Manaus pode ser observada com os sensores MODIS e MISR em termos de aerossol e nuvens. Dadas as longas séries temporais de cerca de 15 anos, a observação em regiões vento acima e abaixo pode auxiliar na determinação do impacto das emissões de Manaus e sua variabilidade ao longo do tempo. O segundo objetivo lida com medidas de propriedades ópticas de aerossol através da rede AERONET coletadas ao longo dos últimos 15 anos em várias localidades da Amazônia. Esta rica base de dados auxilia no entendimento do impacto da componente de queimadas na Amazônia Central, que é um dos objetivos do terceiro tópico. No experimento GoAmazon2014/5, fotômetros, modelo CIMEL Eletronic 318A, foram operados antes de depois da cidade de Manaus, buscando analisar o impacto da pluma urbana na profundidade óptica de aerossol e suas componentes. As medidas in situ realizadas nos vários sítios experimentais do GoAmazon2014/5 também integram este trabalho; são medidas detalhadas em solo que permitem complementar as medidas integradas na coluna atmosférica. 



\section{FUNDAMENTAÇÃO TEÓRICA}

Neste capítulo são descritos resumidamente os conceitos básicos de transferência radiativa na atmosfera e da interação das partículas de aerossol com a radiação.

\subsection{TRANSFERÊNCIA RADIATIVA NA ATMOSFERA}

O mais importante processo responsável pela transferência de energia na atmosfera é a interação da radiação eletromagnética com gases, nuvens e partículas (LIOU, 2002). A radiação eletromagnética pode ser caracterizada pelo comprimento de onda $(\lambda)$, pela frequência $(\tilde{v})$ e pelo número de onda $(v)$. O número de onda é inversamente proporcional ao comprimento de onda, $v=1 / \lambda$, e $\lambda=c / \tilde{v}$, onde $c=2,998 \times 10^{8} \mathrm{~m} / \mathrm{s}$ é a velocidade da luz no vácuo. $\mathrm{O}$ chamado espectro eletromagnético é divido em regiões, como pode ser visto na Figura 10. A região do visível se estende de 0,4 a $0,7 \mu \mathrm{m}$. A região do ultravioleta se estende de $0,01 \mu \mathrm{m}$ a $0,4 \mu \mathrm{m}$ e a região do infravermelho se estende de $0,7 \mu \mathrm{m}$ a $100 \mu \mathrm{m}$. É conveniente ainda subdividir a região do infravermelho em duas outras regiões: a região do infravermelho próximo, entre $0,7 \mu \mathrm{m}$ e $4 \mu \mathrm{m}$, e a região do infravermelho térmico, entre $4 \mu \mathrm{m}$ e $100 \mu \mathrm{m}$.

Figura 10 - Representação do espectro eletromagnético em seus vários comprimentos de onda.

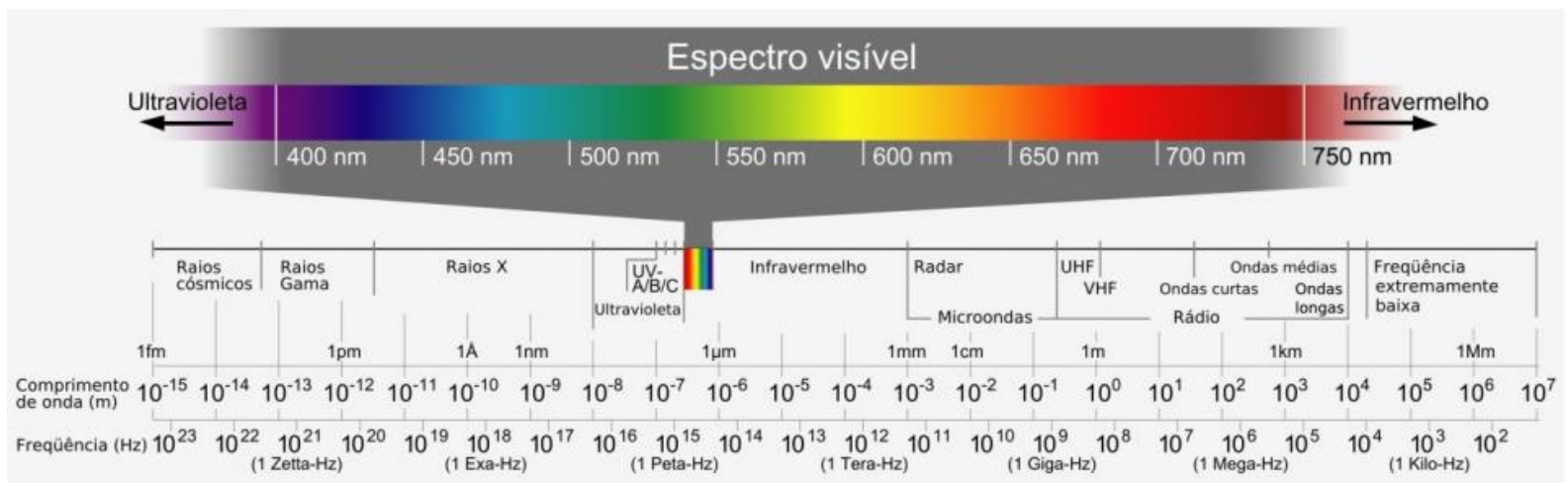

Fonte: Adaptada de ARANA, 2014.

O Sol emite radiação eletromagnética ao longo das regiões do ultravioleta, do visível e do infravermelho próximo, embora a maior parte da radiação emitida esteja concentrada na região do visível, em cerca de $0,5 \mu \mathrm{m}$. A radiação emitida nesta região corresponde a emissão de um corpo negro a uma temperatura aproximada de $5.780 \mathrm{~K}$. A Terra também emite radiação como um corpo negro, mas a uma temperatura de cerca de $255 \mathrm{~K}$, na região do infravermelho térmico, com um pico próximo a $10 \mu \mathrm{m}$. 
A intensidade da radiação emitida por um corpo negro $B_{\lambda}(T)\left[W m^{-2} s r^{-1} \mu m^{-1}\right]$ é dada pela Função de Planck:

$$
B_{\lambda}(T)=\frac{2 h c^{2}}{\lambda^{5}\left[\exp \left(h c / \lambda k_{b} T\right)-1\right]},
$$

onde $k_{b}$ é a constante de Boltzmann $\left(1,3806 \times 10^{-23} J K^{-1}\right), h$ é a constante de Planck $\left(6,626 \times 10^{-34} J s\right)$ e $T$ é a temperatura absoluta. O espectro de emissão de um corpo negro a 5.780 K (Sol) e a 255 K (Terra) é mostrado na Figura 11.

Figura 11 - Espectro normalizado de emissão de um corpo negro a $5.780 \mathrm{~K}$ (Sol) e a $255 \mathrm{~K}$ (Terra) em escala logarítmica. A ordenada foi multiplicada pelo comprimento de onda a fim de manter a proporcionalidade entre as áreas sob a curva e a intensidade da radiação.

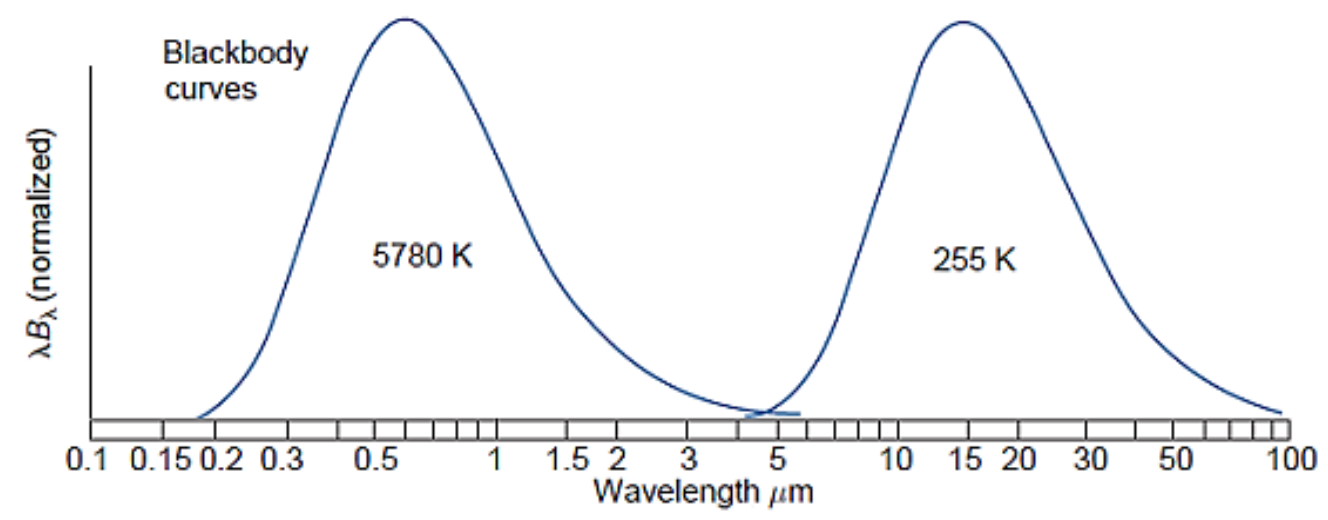

Fonte: Adaptada de WALLACE \& HOBBS, 2006.

Diferenciando a Equação (1) e igualando a zero é possível determinar o comprimento de onda no qual a emissão é máxima:

$$
\frac{\partial B_{\lambda}(T)}{\partial \lambda}=0 \rightarrow \lambda_{m}=\frac{a}{T}
$$

em que $a=2.897 \mu m K$. A Equação (2) é chamada Lei de Deslocamento de Wien.

A irradiância espectral total emitida por um corpo negro $F\left[W m^{-2} \mu m^{-1}\right]$ é obtida integrando a Função de Planck em todo o espectro, $\operatorname{com} \lambda$ variando de 0 a $\infty$ :

$$
B(T)=\int_{0}^{\infty} B_{\lambda}(T) d \lambda=b T^{4}
$$


Considerando a radiação emitida pelo corpo negro como isotrópica, ou seja, independente da direção, a irradiância é, então,

$$
E(T)=\pi B(T)=\sigma T^{4},
$$

sendo $\sigma$ a constante de Stefan-Boltzmann $\left(5,67 \times 10^{-8} \mathrm{Wm}^{-2} \mathrm{~K}^{-4}\right)$. A Equação (4), conhecida como Lei de Stefan-Boltzmann, mostra que a irradiância emitida por um corpo negro depende apenas da temperatura absoluta.

Um corpo (ou um meio) pode absorver radiação em um comprimento de onda específíco e emiti-la em vários comprimentos de onda. A taxa com a qual este corpo emite radiação é função tanto da temperatura quanto do comprimento de onda. Em equilíbrio termodinâmico, caracterizado por temperatura uniforme e radiação isotrópica, a radiação absorvida pelo corpo deve ser igual à radiação emitida em todos os comprimentos de onda. Desta forma, a Lei de Kirchhoff afirma que a emissividade $\varepsilon_{\lambda}$ (razão entre a irradiância emitida pelo corpo e a irradiância emitida pelo corpo negro) é igual à absortância $\alpha_{\lambda}$ (razão entre a irradiância absorvida pelo corpo e a irradiância absorvida pelo corpo negro),

$$
\varepsilon_{\lambda}=\alpha_{\lambda}
$$

No caso de um corpo negro, a absorção é máxima, assim como a emissão, de modo que

$$
\varepsilon_{\lambda}=\alpha_{\lambda}=1
$$

A Terra como um todo não está em equilíbrio termodinâmico, no entanto, para altitudes menores que aproximadamente $40 \mathrm{~km}$, com uma boa aproximação, podemos considerar que a temperatura é uniforme e a radiação isotrópica, e aplicar a Lei de Kirchhoff localmente (YAMASOE \& CORRÊA, 2016).

\subsubsection{Absorção e espalhamento da radiação por partículas e gases}

A absorção e o espalhamento da radiação por gases e partículas contribuem substancialmente para a extinção da radiação terrestre e solar na atmosfera (WALLACE \& HOBBS, 2006). Quando um feixe de luz incide sobre uma partícula (ou molécula de gás), as cargas elétricas da partícula são excitadas, descrevendo movimentos oscilatórios. As cargas excitadas emitem radiação eletromagnética em todas as direções (espalhamento) e podem também con- 
verter uma parte da radiação incidente em energia térmica (absorção) (SEINFELD \& PANDIS, 2016).

A Figura 12 mostra a diferença entre a irradiância no topo da atmosfera e ao nível do mar. Em determinados intervalos de comprimentos de onda, as chamadas banda de absorção, a radiação solar é absorvida pelos constituintes da atmosfera, o que ocasiona uma diminuição da energia solar que incide na superfície terrestre. $\mathrm{O}$ oxigênio $\left(\mathrm{O}_{2}\right)$ e o ozônio $\left(\mathrm{O}_{3}\right)$ são responsáveis por praticamente toda a absorção da radiação de comprimento de onda menor que $0,29 \mu \mathrm{m}$. O ozônio interage ainda com a radiação acima de $0,4 \mu \mathrm{m}$, na região do visível. Em contrapartida, entre 0,3 e $0,8 \mu \mathrm{m}$, a absorção da radiação solar não é significativa, o que constitui uma "janela" no espectro que permite que quase toda a radiação seja transmitida. Além disso, o vapor d'água $\left(\mathrm{H}_{2} \mathrm{O}\right)$ e o dióxido de carbono $\left(\mathrm{CO}_{2}\right)$ são responsáveis pela absorção da radiação terrestre na região do infravermelho. A região espectral entre 0,7 e 1,3 $\mu$ m constitui uma outra "janela" em que cerca de $80 \%$ da radiação terrestre é transmitida para o espaço.

Figura 12 - Irradiância solar espectral no topo da atmosfera (linha sólida) e ao nível do mar (área sombreada). A linha pontilhada corresponde à irradiância de um corpo negro a uma temperatura de $6.000 \mathrm{~K}$. São indicados ainda os gases responsáveis pela absorção da radiação na atmosfera. As regiões do ultravioleta, do visível e do infravermelho próximo também são mostradas.

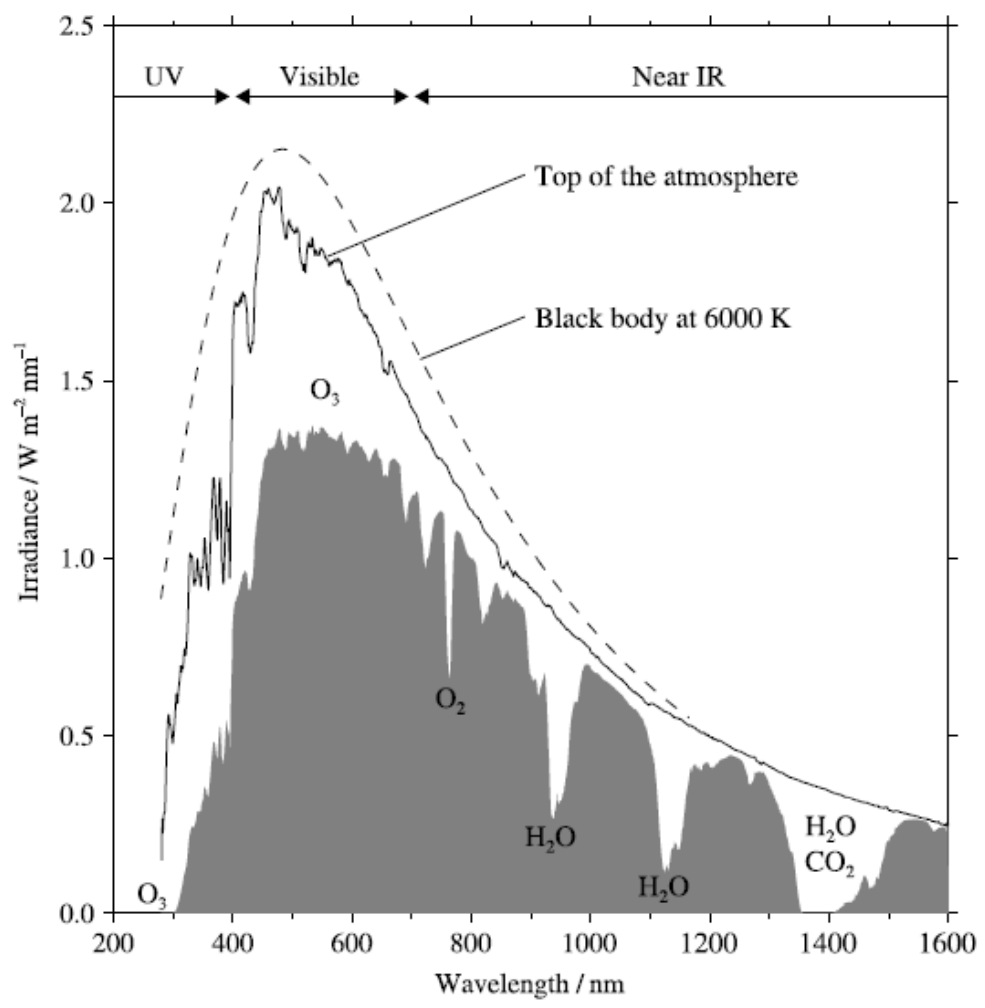

Fonte: ANDREWS, 2010. 
O espalhamento da radiação é ponderado por um termo físico denominado parâmetro de tamanho $x$ e pelo índice de refração complexo das partículas $(m=n+k i)$. Para uma partícula esférica de raio $r, x$ é a razão entre a circunferência da partícula e o comprimento de onda incidente (LIOU, 2002):

$$
x=\frac{2 \pi r}{\lambda}
$$

Para partículas com $x \ll 1$, ou seja, partículas pequenas em relação ao comprimento de onda incidente, o regime de espalhamento é Rayleigh. Para partículas com $x \cong 1$, ou seja, partículas com tamanho próximo ao comprimento de onda incidente, o espalhamento é determinado pela teoria de espalhamento Mie. E para partículas $\operatorname{com} x \gg 1$, ou seja, partículas grandes em relação ao comprimento de onda incidente, o espalhamento é determinado com base na óptica geométrica. A Figura 13 mostra a relação entre o parâmetro de tamanho, o raio da partícula e o comprimento de onda da radiação incidente.

Figura 13 - Parâmetro de tamanho $x$ como função do comprimento de onda da radiação incidente $\lambda$ e do raio da partícula $r$.

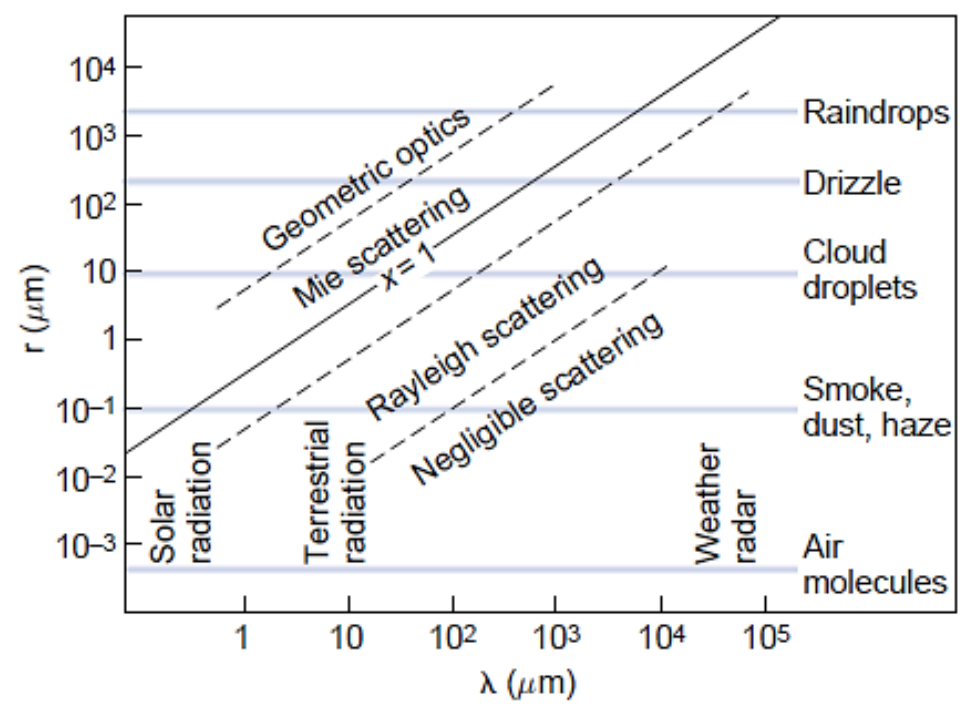

Fonte: WALLACE \& HOBBS, 2006.

A teoria de espalhamento Mie prevê tanto o espalhamento quanto a absorção da radiação por partículas esféricas homogêneas. A parte real do índice de refração corresponde ao espalhamento e a parte imaginária corresponde à absorção. 


\subsubsection{A Lei de Beer-Lambert-Bouguer}

A Lei de Beer-Lambert-Bouguer descreve a atenuação da radiação eletromagnética ao atravessar um meio homogêneo (Figura 14); expressa a variação da intensidade da radiação em razão da extinção causada tanto pela absorção quanto pelo espalhamento da mesma.

Figura 14 - Representação da atenuação da radiação eletromagnética ao atravessar um meio homogêneo.

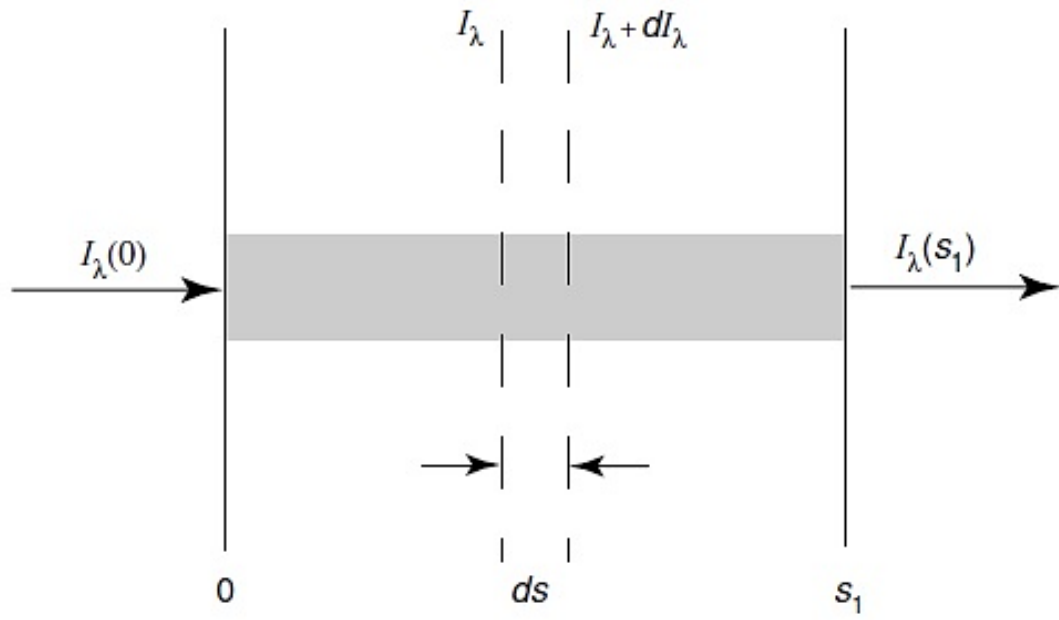

Fonte: LIOU, 2002

Sendo a intensidade da radiação incidente igual a $I_{\lambda}$ e a intensidade da radiação após atravessar um meio material de espessura $d s$ igual a $I_{\lambda}+d I_{\lambda}$, e negligenciando a radiação difusa produzida por espalhamento múltiplo,

$$
d I_{\lambda}=-b_{\text {ext }}(s, \lambda) I_{\lambda} d s .
$$

$\mathrm{O}$ coeficiente linear de extinção $b_{\text {ext }}(s, \lambda)$ é proporcional à densidade do material do meio e pode ser definido como o produto entre a seção de choque de extinção de uma partícula $k_{\lambda}$ e a densidade numérica de partículas $u$ :

$$
b_{\text {ext }}(s, \lambda)=k_{\lambda} u \text {. }
$$

Como a absorção e o espalhamento ocorrem simultaneamente na atmosfera, uma vez que todas as partículas (e moléculas) absorvem e espalham a radiação (SEINFELD \& PANDIS, $2016), b_{\text {ext }}(s, \lambda)$ pode ser expresso ainda como a soma do coeficiente de absorção $b_{a b s}(s, \lambda)$ e do coeficiente de espalhamento $b_{e s p}(s, \lambda)$ :

$$
b_{\text {ext }}(s, \lambda)=b_{a b s}(s, \lambda)+b_{\text {esp }}(s, \lambda) \text {. }
$$


Integrando a Equação (8) entre $s=0$ e $s=s_{1}$, obtemos

$$
I_{\lambda}\left(s_{1}\right)=I_{\lambda}(0) \exp \left(-\int_{0}^{s_{1}} b_{\text {ext }}(s, \lambda) d s\right)
$$

e ainda

$$
I_{\lambda}\left(s_{1}\right)=I_{\lambda}(0) \exp \left(-\delta_{\text {ext }}(s, \lambda)\right)
$$

onde

$$
\delta_{\text {ext }}(\lambda)=\int_{0}^{s_{1}} b_{\text {ext }}(s, \lambda) d s
$$

é denominada espessura óptica de extinção. A Equação (12) é conhecida como Lei de BeerLambert-Bouguer, e mostra que a radiação sofre uma atenuação exponencial ao atravessar um meio homogêneo.

A espessura óptica de extinção é uma grandeza adimensional e representa a quantidade de partículas absorvedoras e espalhadoras presente nos meios responsáveis pela extinção da radiação ao longo do caminho óptico $d s$. Analogamente à Equação $(10), \delta_{\text {ext }}(\lambda)$ é a soma da espessura óptica de absorção $\delta_{a b s}(\lambda)$ e da espessura óptica de espalhamento $\delta_{\text {esp }}(\lambda)$ :

$$
\delta_{\text {ext }}(\lambda)=\delta_{a b s}(\lambda)+\delta_{\text {esp }}(\lambda)
$$

Em se tratando da interação da radiação solar com a atmosfera, considerando a aproximação de uma atmosfera plano-paralela, isto é, um conjunto de camadas verticalmente estruturadas e horizontalmente homogêneas (Figura 15), podemos definir a profundidade óptica de extinção $\tau_{\text {ext }}(\lambda)$ como a espessura óptica de extinção medida verticalmente:

$$
\tau_{\text {ext }}(\lambda)=\delta_{\text {ext }}(\lambda) \cos \theta
$$

sendo $\theta$ o ângulo zenital solar. Assim como $\delta_{\text {ext }}(\lambda)$, podemos escrever $\tau_{\text {ext }}(\lambda)$ como a soma da profundidade óptica de absorção $\tau_{a b s}(\lambda)$ e a profundidade óptica de espalhamento $\tau_{e s p}(\lambda)$ :

$$
\tau_{\text {ext }}(\lambda)=\tau_{\text {abs }}(\lambda)+\tau_{\text {esp }}(\lambda)
$$

Por definição, $\tau_{\text {ext }}(\lambda)=0$ no topo da atmosfera em razão da ausência de partículas e moléculas de gás. 
Figura 15 - Sistema de coordenadas para uma atmosfera plano-paralela. $\theta$ e $\phi$ representam os ângulos zenital e azimutal, respectivamente, e $s$ é o caminho óptico.

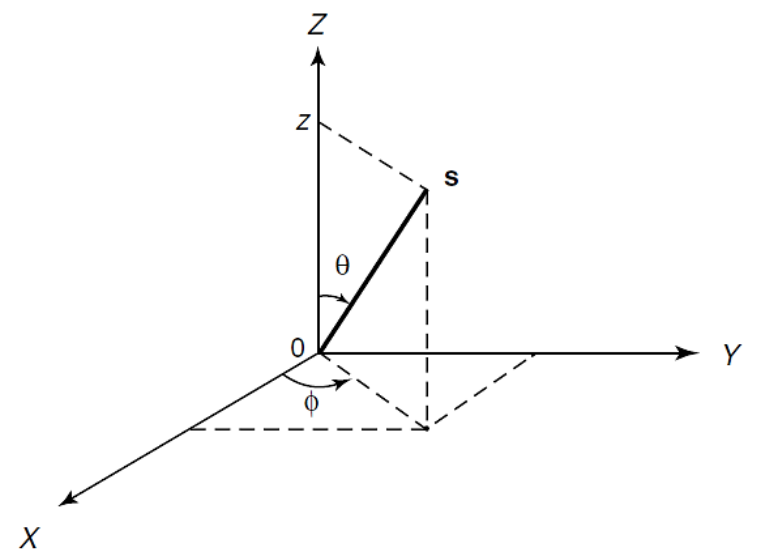

Fonte: LIOU, 2002.

Neste trabalho, usaremos AOD (Aerosol Optical Depth) para nos referirmos a profundidade óptica de extinção. De modo semelhante, usaremos AAOD (Absorption Aerosol Optical Depth) e SAOD (Scattering Aerosol Optical Depth) para nos referirmos à profundidade óptica de absorção e à profundidade óptica de espalhamento, respectivamente.

\subsection{PROPRIEDADES INTENSIVAS DAS PARTÍCULAS DE AEROSSOL}

As propriedades intensivas das partículas de aerossol são propriedades que independem da quantidade de partículas, dependendo apenas de suas propriedades intrínsecas. Neste trabalho, foram analisados o albedo de espalhamento simples e os expoentes Ångström de absorção e de espalhamento, que serão descritos a seguir.

O albedo de espalhamento simples $\omega_{0}$ é definido como a razão entre o coeficiente de espalhamento e o coeficiente de extinção:

$$
\omega_{0}(s, \lambda)=\frac{b_{\text {esp }}(s, \lambda)}{b_{\text {ext }}(s, \lambda)} .
$$

É uma medida da importância relativa do espalhamento e da absorção na extinção da radiação. Quando consideramos a aproximação de uma atmosfera plano-paralela, $\omega_{0}$ é calculado utilizando-se a profundidade óptica de absorção e a profundidade óptica de espalhamento:

$$
\omega_{0}(\lambda)=\frac{\tau_{\text {esp }}(\lambda)}{\tau_{\text {ext }}(\lambda)}
$$


Isto posto, se $\omega_{0}$ se aproxima de 1 , a extinção da radiação pelas partículas é majoritariamente devido ao espalhamento (por exemplo, sulfato de amônio); se $\omega_{0}$ se aproxima de 0 , a extinção é majoritariamente devido à absorção. Observações in situ de $\omega_{0}$ para aerossol seco mostram valores variando tipicamente entre 0,80 e 0,98 para aerossol urbano e entre 0,72 e 0,88 para partículas recém-emitidas na queima de biomassa (RIZZO et al., 2013). Para partículas de poeira mineral, o albedo de espalhamento simples tem uma dependência espectral característica, com maior absorção da radiação na região do ultravioleta.

Neste trabalho, usaremos SSA (do inglês, Single Scattering Albedo) para nos referirmos ao albedo de espalhamento simples.

O expoente Ångström $(\alpha)$ descreve a dependência espectral do coeficiente de extinção ou da profundidade óptica de extinção através de uma expressão empírica apresentada por Ångström em 1929:

$$
\tau_{\text {ext }}=B \cdot \lambda^{-\alpha}
$$

onde $\lambda$ é o comprimento de onda e $B$ é o coeficiente de turbidez. A partir da Equação (19), podemos ainda relacionar a dependência espectral em dois comprimentos de onda, $\lambda_{1}$ e $\lambda_{2}$ :

$$
\alpha=-\frac{\log \left(\tau_{\text {ext }}\left(\lambda_{1}\right) / \tau_{\text {ext }}\left(\lambda_{2}\right)\right)}{\log \left(\lambda_{1} / \lambda_{2}\right)} .
$$

De modo análogo, podemos calcular o expoente Ångström de absorção $\left(\alpha_{a b s}\right)$ e o expoente Ångström de espalhamento $\left(\alpha_{e s p}\right)$ :

$$
\begin{gathered}
\alpha_{a b s}=-\frac{\log \left(\tau_{a b s}\left(\lambda_{1}\right) / \tau_{a b s}\left(\lambda_{2}\right)\right)}{\log \left(\lambda_{1} / \lambda_{2}\right)} . \\
\alpha_{e s p}=-\frac{\log \left(\tau_{e s p}\left(\lambda_{1}\right) / \tau_{e s p}\left(\lambda_{2}\right)\right)}{\log \left(\lambda_{1} / \lambda_{2}\right)} .
\end{gathered}
$$

que representam a dependência espectral da absorção e do espalhamento, respectivamente.

$\mathrm{O} \alpha_{a b s}$ está relacionado com as propriedades físicas e químicas do aerossol (RIZZO et al., 2011), podendo fornecer informação sobre o tipo de aerossol absorvedor predominante em 
uma mistura de partículas de aerossol. O BC segue tipicamente uma dependência espectral $\lambda^{-1}$, ou seja, $\alpha_{a b s}$ igual a 1 . O carbono orgânico presente no aerossol de queima de biomassa e a poeira mineral contribuem para a absorção da radiação na região do ultravioleta e regiões espectrais do azul, resultando em um $\alpha_{a b s}$ maior que 1, que varia de acordo com os comprimentos de onda utilizados para o cálculo. Valores de $\alpha_{a b s}$ maiores que 1,5 têm sido, então, utilizados para caracterizar o aerossol que tem uma maior absorção em comprimentos de onda mais curtos, como a poeira mineral e o OC. Valores menores que 1,5 caracterizam uma grande influência do EC, levando a misturas mais complexas.

Por outro lado, o $\alpha_{e s p}$ fornece informação sobre a moda de tamanho predominante em uma mistura de aerossol. Valores menores indicam a predominância de partículas pertencentes à moda grossa, tais como poeira mineral; valores maiores que 1,5 estão associados a partículas pertencentes à moda fina (EC e OC), levando novamente a misturas complexas (CAZORLA et al., 2013).

Neste trabalho, o expoente Ångström de absorção e expoente Ångström de espalhamento serão referidos como AAE (do inglês, Absorption Ångström Exponent) e SAE (Scattering Ångström Exponent), respectivamente. 


\section{METODOLOGIA}

\subsection{MEDIDAS POR SENSORIAMENTO REMOTO}

As propriedades de aerossol na Amazônia têm sido estudadas com o auxílio de sensoriamento remoto em solo, como, por exemplo, a rede AERONET, e de sensoriamento remoto a partir de sensores em operação em satélites, como os sensores MODIS e MISR a bordo do satélite Terra (ARTAXO et al., 2006; MOREIRA, 2007).

As medidas por sensoriamento remoto em solo têm papel essencial na caracterização das propriedades ópticas e microfísicas das partículas de aerossol, assim como na determinação de cargas de aerossol e dos efeitos radiativos que estas partículas tem sobre locais específicos (BIBI et al., 2015). Embora o sensoriamento remoto em solo tenha uma cobertura espacial fixa, as medidas feitas em vários ângulos e bandas espectrais distintas fornecem medidas importantes, confiáveis e contínuas (DUBOVIK et al., 2002a).

As medidas por sensoriamento remoto a partir de satélites também são de extrema importância para caracterizar as propriedades ópticas de aerossol em escala local e global. No entanto, como a radiância medida depende da refletância da superfície, é necessário um cuidado com a validação das propriedades obtidas (KING et al., 1999).

\subsubsection{A rede AERONET}

A rede AERONET (Aerosol Robotic Network) é uma rede de monitoramento de aerossol por sensoriamento remoto em solo estabelecida no início dos anos 90 pela NASA e pela LOA-PHOTONS (CNRS). Consiste em mais de 400 fotômetros solares que fornecem medidas de propriedades ópticas, radiativas e microfísicas de aerossol integradas na coluna atmosférica. Os dados podem ser acessados facilmente através da página da AERONET http://aeronet.gsfc.nasa.gov/.

Os fotômetros solares, modelo CIMEL Eletronic 318A, realizam medições tanto da radiância solar direta quanto da radiância solar difusa. As medições da radiância solar direta são feitas em oito bandas espectrais centradas em 340, 380, 440, 500, 670, 870, 940 e 1020 $\mathrm{nm}$, em intervalos de 15 minutos e com um campo de visão de $1,2^{\circ}$. O canal de $940 \mathrm{~nm}$ é utilizado para determinar a coluna de vapor d'água precipitável uma vez que o vapor d'água tem um máximo de absorção nesse comprimento de onda (KOGAN; POWELL; FEDOROV, 
2011). Os demais canais são utilizados para derivar a AOD a partir da extinção da radiação solar calculada de acordo com a lei de Beer-Lambert-Bouguer (Equação (12)). A profundidade óptica devido ao vapor d'água, ao espalhamento Rayleigh e a outros gases residuais são calculadas e removidas a fim de reportar apenas a AOD.

A radiância solar difusa é medida em quatro bandas espectrais (440, 670, 870 e 1020 $\mathrm{nm}$ ), em intervalos de uma hora ao longo do plano principal e do almucântara, como é mostrado na Figura 16. Para medições no plano principal, varia-se o ângulo zenital $(\theta)$ e o ângulo azimutal $\left(\varphi=\varphi_{0}\right)$ é fixo no Sol. Já para medições no almucântara, varia-se o ângulo azimutal $(\varphi)$ e o ângulo zenital de observação $(\theta)$ é igual ao ângulo zenital solar $\left(\theta_{0}\right)$. A partir destas medidas, propriedades importantes de aerossol, como a distribuição de tamanho e o índice de refração complexo, são derivadas (DUBOVIK et al., 2000).

Figura 16 - Esquema do posicionamento do fotômetro solar para a realização de medições no plano principal e no almucântara.

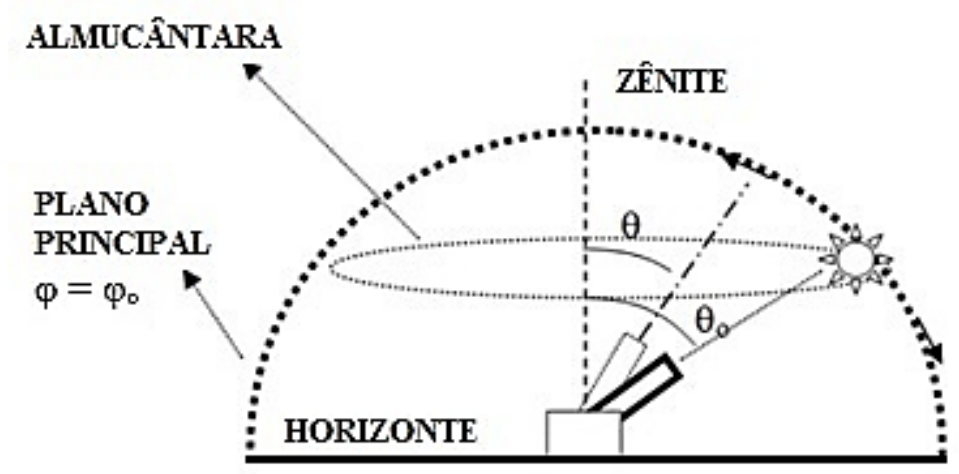

Fonte: Adaptada de CASTANHO, 2005.

O algoritmo de inversão da AERONET calcula propriedades das partículas de aerossol integradas na coluna atmosférica a partir das medidas de radiância direta e difusa. Estes cálculos são feitos assumindo-se, primeiramente, que as partículas de aerossol estão divididas em duas componentes: esférica e não-esférica. A componente esférica é modelada por um conjunto de esferas polidispersas e homogêneas com o mesmo índice de refração complexo (DUBOVIK; KING, 2000). A componente não-esférica é uma mistura de esferoides polidispersos, homogêneos e orientados aleatoriamente (DUBOVIK et al., 2002b, 2006). Além disso, assume-se que a atmosfera é plano-paralela e que a distribuição vertical de aerossol é homogênea para a inversão no almucântara, e em duas camadas para a inversão no plano principal. A refletância na superfície é aproximada pela BRDF (Bidirectional Reflectance Distribution Function) obtidas a partir do sensor MODIS. 
O algoritmo deriva a distribuição volumétrica de tamanho para 22 faixas equidistantes na escala logarítmica, variando o raio da partícula entre 0,05 e $15 \mu \mathrm{m}$, e deriva o índice de refração complexo para os comprimentos de onda correspondentes às medidas de radiância difusa. A partir destas propriedades são determinados o SSA, a função de fase para os 83 ângulos de espalhamento, e o fator de assimetria para cada função de fase.

Os dados da AERONET estão disponíveis em três níveis de processamento. Os dados brutos correspondem ao nível 1.0, unscreened. No nível 1.5, cloud screened, são eliminadas as medidas contaminadas pela presença de nuvens. No nível de qualidade máxima, nível 2.0 chamado quality assured -, os dados são avaliados pré e pós-calibração quando o fotômetro retorna para a NASA, geralmente uma vez por ano. Neste nível, os parâmetros são derivados apenas para ângulo zenital solar maior que $50^{\circ}$. Além disso, para o SSA e o índice de refração complexo, a AOD em $440 \mathrm{~nm}$ deve ser maior ou igual a 0,4 (HOLBEN et al., 2006). Este limite inferior de AOD em 0,4 tem impacto importante sobre as medidas reportadas na Amazônia uma vez que exclui valores de AOD muito baixos (AOD < 0,4). A incerteza da AOD, devido principalmente à incerteza de calibração, varia entre 0,01 e 0,02 e depende do comprimento de onda, com erros maiores no ultravioleta (ECK et al., 1999; SCHAFER, 2002; SCHAFER et al., 2008). Por outro lado, a incerteza do SSA é de 0,03 e diminui à medida que a AOD aumenta (SCHAFER et al., 2008). Neste trabalho, serão utilizadas medidas da AERONET dados de nível 1.5 e 2.0 .

\subsubsection{A forçante radiativa como produto da rede AERONET}

A forçante radiativa direta do aerossol $\Delta F$ derivada pela AERONET é definida como a diferença entre a irradiância, com ou sem a presença de aerossol, tanto na superfície da atmosfera (BOA, Bottom of Atmosphere) quanto no topo da atmosfera (TOA, Top of Atmosphere):

$$
\begin{gathered}
\Delta F_{B O A}=F_{B O A}^{\downarrow}-F_{B O A}^{\downarrow 0} \\
\Delta F_{T O A}=-\left(F_{T O A}^{\uparrow}-F_{T O A}^{\uparrow 0}\right),
\end{gathered}
$$

sendo $F$ e $F^{0}$ as irradiância com e sem aerossol, respectivamente. As setas indicam a direção do fluxo: $\downarrow$ indica fluxo descendente e $\uparrow$ indica fluxo ascendente. A escolha dos sinais é tal que os valores negativos de $\Delta F$ estão associados a um efeito de resfriamento e os valores positivos estão associados a um efeito de aquecimento. 
As irradiâncias ascendentes e descendentes na faixa espectral de 0,2 a 4,0 $\mu \mathrm{m}$ são estimadas utilizando-se as propriedades calculadas pelo algoritmo de inversão da AERONET. Especificamente, as irradiâncias são calculadas a partir do código de transferência radiativa GAME (Global Atmospheric Model) (GARCÍA et al., 2012). Neste trabalho, a forçante radiativa será referida como RF (do inglês, Radiative Forcing).

\subsubsection{Descrição das estações da AERONET estudadas}

A primeira parte deste trabalho foi baseada em medições realizadas em sete sítios onde foram operados fotômetros da rede AERONET (Figura 17), em algumas estações durante um período de mais de 15 anos. As coordenadas geográficas de todas as estações são listadas na Tabela 3.

Figura 17 - Mapa com a localização dos fotômetros da rede AERONET.

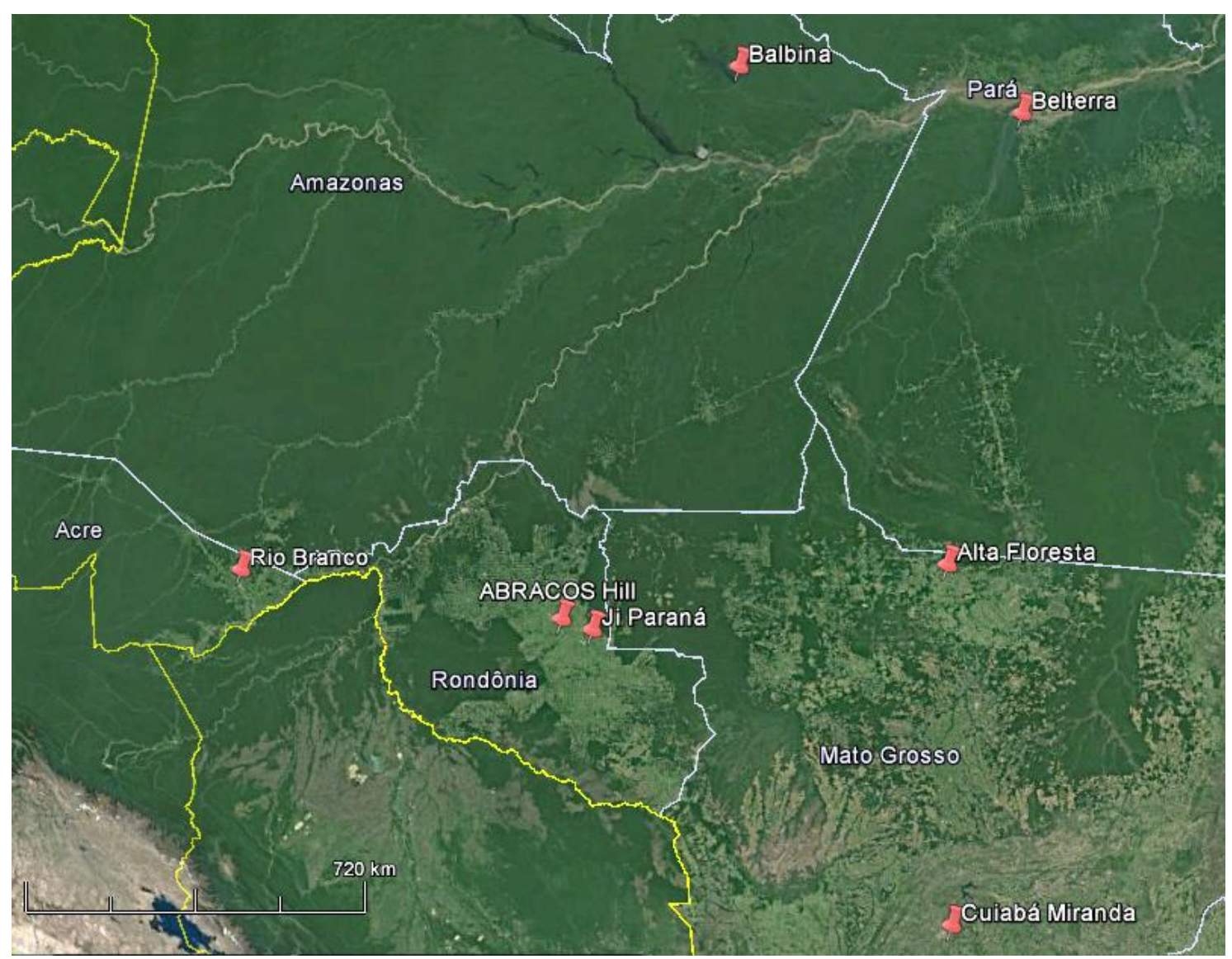

Os sítios de Balbina (AM) e Belterra (PA) representam o Norte da Amazônia e correspondem a regiões com baixa carga atmosférica de aerossol, muito úmidas, com atmosfera pouco influenciada pelas queimadas dada à proximidade da área de floresta natural, e com 
baixo impacto populacional; são áreas sujeitas à influência do transporte de poeira mineral do deserto do Saara e de aerossol marinho do Oceano Atlântico. A estação chuvosa ocorre de dezembro a maio e a estação seca começa em junho, se estendendo até novembro, sendo, então, tardia em relação à região do arco do desflorestamento.

Alta Floresta (MT), ABRACOS Hill (RO), Ji Paraná (RO) e Rio Branco (AC) fazem parte da região chamada arco do desflorestamento. No ano de 2005, a estação de ABRACOS Hill foi desativada e os instrumentos foram realocados na cidade de Ji Paraná. Considerando que os dois sítios distam apenas $60 \mathrm{~km}$, trataremos ambos como um único sítio, Ji ParanáRondônia.

A região do arco do desflorestamento é uma região com grande influência de queimadas, mudanças no uso do solo e representa a expansão da fronteira agrícola. A estação seca ocorre de maio a outubro de forma bem pronunciada, com períodos sem ocorrência chuva, e a estação chuvosa ocorre de novembro a abril.

A região do Cerrado é representada pelo sítio de Cuiabá Miranda (MT), região caracterizada por vegetação rasteira e clima seco, e afetada ocasionalmente por queimadas locais geralmente menos extensas do que as ocorridas no arco do desflorestamento -, que tem sido em grande parte convertida em terras agrícolas (HOLBEN et al., 2001). Sua atmosfera é influenciada pelo transporte de aerossol de queimadas emitidos na região do arco do desflorestamento, aerossol "envelhecido". A estação seca começa em abril e se estende até setembro, sendo a incidência de precipitação inconstante durante todo o ano.

Tabela 3 - Coordenadas geográficas das estações da rede AERONET.

\begin{tabular}{lccl}
\hline \multicolumn{1}{c}{ Estação da AERONET } & \multicolumn{2}{c}{ Localização } & Período de análise \\
\hline ABRACOS Hill (RO) & $-10,7600^{\circ}$ & $-62,3583^{\circ}$ & Abr/1999 - Set/2005 \\
Alta Floresta (MT) & $-9,8713^{\circ}$ & $-56,1044^{\circ}$ & Fev/1999 - Fev/2015 \\
Balbina (AM) & $-1,9170^{\circ}$ & $-59,4868^{\circ}$ & Out/1999 - Set/2002 \\
Belterra (PA) & $-2,6485^{\circ}$ & $-54,9516^{\circ}$ & Set/1999 - Nov/2004 \\
Cuiabá Miranda (MT) & $-15,7295^{\circ}$ & $-56,0208^{\circ}$ & Abr/2001 - Nov/2014 \\
Ji Paraná (RO) & $-10,9342^{\circ}$ & $-61,8515^{\circ}$ & Jun/2006 - Jan/2015 \\
Rio Branco (AC) & $-9,9575^{\circ}$ & $-67,8693^{\circ}$ & Abr/1999 - Jan/2015 \\
\hline
\end{tabular}

Fonte: AERONET, 2016.

No contexto das análises da profundidade óptica de aerossol do experimento GoAmazon2014/5, foram analisadas as medições feitas em duas estações da AERONET: Manaus- 
EMBRAPA, vento acima da pluma de Manaus, e ARM-Manacapuru, vento abaixo da pluma. Neste trabalho, tais estações serão referidas como EMBRAPA e Manacapuru, respectivamente. Tais sítios foram descritos em detalhes na Seção 1.4.

4.1.4 O sistema de análise de dados online NASA-Giovanni

O Giovanni (Goddard Interactive Online Visualization and Analysis Infrastructure), desenvolvido pela Goddard Earth Sciences Data and Information Services Center (GES DISC), é um sistema de análise de dados online que desde 2003 possibilita o acesso a dados de sensoriamento remoto, especialmente de satélites, de maneira simples e intuitiva sem que o usuário precise fazer o download desses dados. Embora apresente limitações na resolução temporal e espacial, o sistema garante uma harmonização dos procedimentos, o que resulta em uma coerência nos resultados qualquer que seja o usuário.

Na própria página do sistema, http://giovanni.gsfc.nasa.gov, o usuário é capaz de selecionar a sua região de interesse ou inserir manualmente as coordenadas que vão definir a caixa delimitadora. É necessário também selecionar o intervalo de tempo, as variáveis e o tipo de saída desejado: perfis verticais, mapas, animações, séries temporais, comparações entre variáveis. Tanto os mapas quanto os gráficos gerados pelo Giovanni podem ser baixados pelo usuário assim como os dados em formato ASCII (ACKER et al., 2014; SCHAAP et al., 2009).

Com o auxílio do Giovanni, os produtos de AOD em $550 \mathrm{~nm}$, de temperatura e pressão do topo da nuvem e de raio efetivo de gotículas de nuvem derivados do MODIS foram obtidos a partir dos dados mensais MOD08 M3.6 (Terra) e MYD08 M3.6 (Aqua) com uma resolução espacial de $1^{\circ}$ x $1^{\circ}$. Do MISR, o produto de AOD em $555 \mathrm{~nm}$ foi obtido a partir dos dados mensais MIL3MAE.4 com resolução espacial de $0,5^{\circ}$ x $0,5^{\circ}$. O período de tempo analisado foi de 2003 a 2015. Os valores dos produtos obtidos foram valores médios na área selecionada (Figura 18). As coordenadas geográficas das áreas selecionadas no Giovanni e o valor da área são mostrados na Tabela 4. 
Figura 18 - Área selecionada no sistema NASA-Giovanni vento acima e vento abaixo de Manaus.

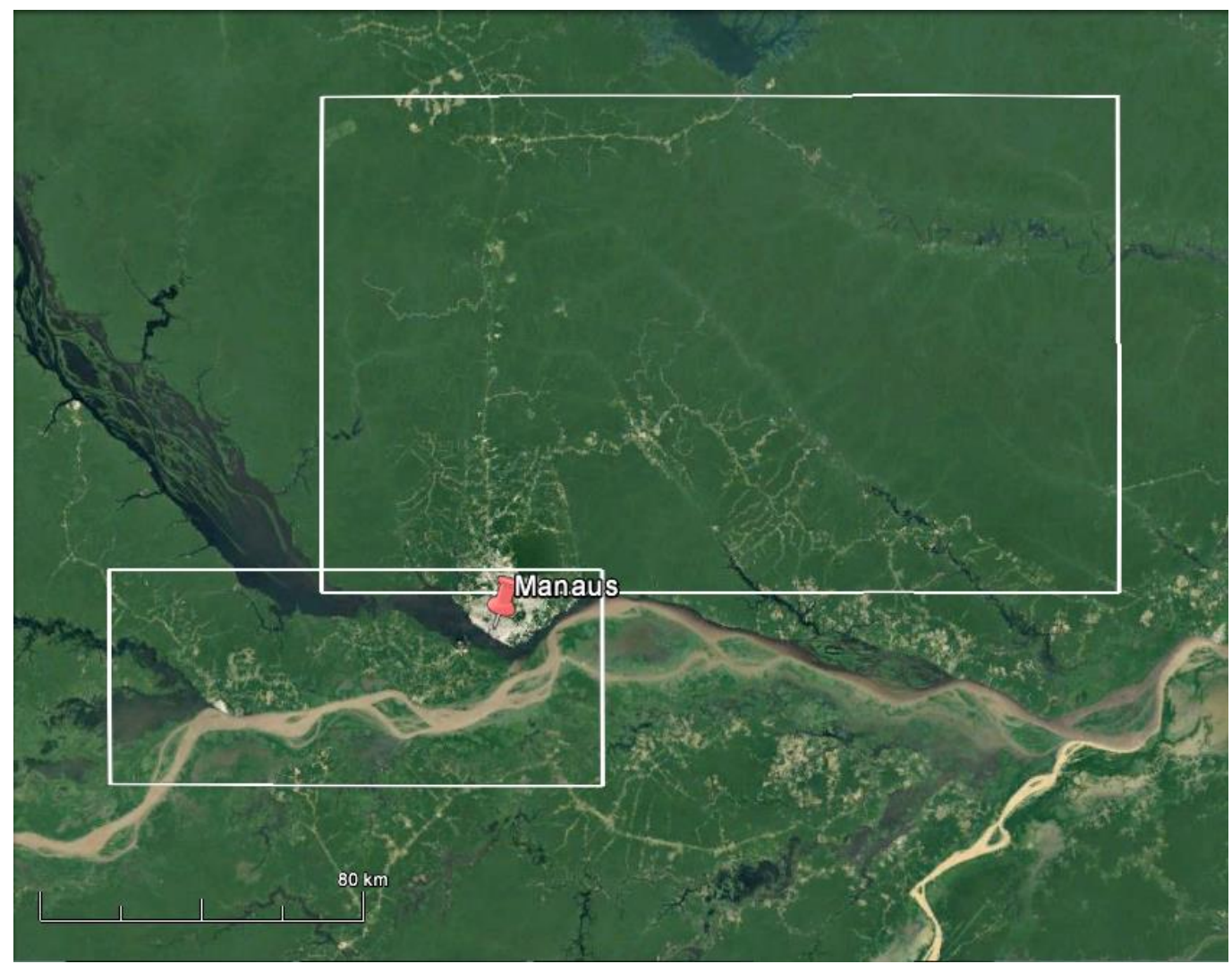

Tabela 4 - Coordenadas geográficas das áreas selecionadas no Giovanni vento acima e vento abaixo de Manaus.

\begin{tabular}{cccccc}
\hline & \multicolumn{4}{c}{ Coordenadas } & \multicolumn{2}{c}{ Área } \\
& Oeste & Sul & Leste & Norte & \\
\hline Vento acima & $-60,4028^{\circ}$ & $-3,0418^{\circ}$ & $-58,6560^{\circ}$ & $-1,9552^{\circ}$ & $\sim 23.500 \mathrm{~km}^{2}$ \\
Vento abaixo & $-60,8752^{\circ}$ & $-3,4641^{\circ}$ & $-59,7864^{\circ}$ & $-2,9919^{\circ}$ & $\sim 6.360 \mathrm{~km}^{2}$ \\
\hline
\end{tabular}

Foram selecionadas uma área vento acima de Manaus e uma área vento abaixo com o objetivo de estudar a influência da pluma urbana sobre as propriedades ópticas de aerossol e de nuvens medidas por sensoriamento remoto a partir de satélites. Como o valor da profundidade óptica é baixo e a possível contaminação por nuvens é alta, selecionamos regiões extensas para cobrir uma média que pudesse ser significativa, tanto antes da pluma de Manaus quanto na região de Manacapuru, área impactada pela pluma.

\subsubsection{O sensor MODIS}

O sensor MODIS (Moderate Resolution Imaging Spectroradiometer) é um espectrômetro de resolução moderada que opera a bordo de dois satélites do sistema EOS (Earth Ob- 
serving System), os satélites Terra e Aqua, lançados em 1999 e 2002, respectivamente (KING et al., 2003). Ambos os satélites operam em órbita polar em sincronia com o sol e a uma altitude de $705 \mathrm{~km}$, com um horário de passagem no Equador em torno das 10h30min para o Terra (órbita descendente) e em torno das 13h30min para o Aqua (órbita ascendente). Os satélites repetem a sua órbita a cada 16 dias. O sensor varre a superfície terrestre a uma faixa de 2.330 $\mathrm{km}$ de largura, faixa suficientemente ampla para fornecer uma cobertura global quase completa a cada um ou dois dias dependendo da latitude - diária a norte da latitude $30^{\circ}$ e a cada dois dias para latitudes inferiores a $30^{\circ}$ (JUSTICE et al., 2002).

O MODIS mede a radiância no topo da atmosfera em 36 bandas espectrais, entre 0,415 e 14,235 $\mu \mathrm{m}$, com resolução espacial de $250 \mathrm{~m}$ (bandas 1-2), $500 \mathrm{~m}$ (bandas 3-7) e $1.000 \mathrm{~m}$ (bandas 8-36). 7 destas bandas, entre 0,47 e 2,13 $\mu \mathrm{m}$, estão na região do espectro solar e são utilizadas para derivar propriedades de aerossol a partir de dois algoritmos distintos: um para aerossol sobre continentes e outro para aerossol sobre oceanos. Estes algoritmos são descritos em detalhes por KAUFMAN et al., 1997, TANRÉ et al., 1997 e REMER et al., 2005. Utilizam-se ainda outros comprimentos de onda para identificar a contaminação por nuvens (PETZOLD; SCHÖNLINNER, 2004).

O sensor MODIS possibilita uma maior compreensão acerca das propriedades da atmosfera, propriedades de nuvens e de aerossol, de suas variações espaciais e temporais, além de permitir o estudo da interação e do impacto do homem sobre meio ambiente (KING et al., 1992).

\subsubsection{O sensor MISR}

O sensor MISR (Multi-angle Imaging SpectroRadiometer), também a bordo do satélite Terra, é um instrumento imageador que realiza medições em quatro bandas espectrais centradas em $0,446,0,558,0,672$ e $0,866 \mu \mathrm{m}$ a partir de 9 ângulos de visada (nadir, $\pm 26,1, \pm 45,6$, $\pm 60,0$ e \pm 70.5 graus), levando 7 minutos para observar um ponto da Terra em todos os 9 ângulos (Figura 19). O sensor varre a superfície terrestre a uma faixa limitada em comparação com o MODIS - cerca de $380 \mathrm{~km}$ de largura - fornecendo uma cobertura global a cada 9 dias no Equador e a cada 2 dias na proximidade dos pólos (DINER et al., 1998). Possui resolução espacial de $250 \mathrm{~m}$ (para o nadir) e de $275 \mathrm{~m}$ para os outros ângulos. 
Figura 19 - Representação dos 9 ângulos de visada e das 4 bandas espectrais nos quais o sensor MISR realiza medições de propriedades de aerossol e de superfície.

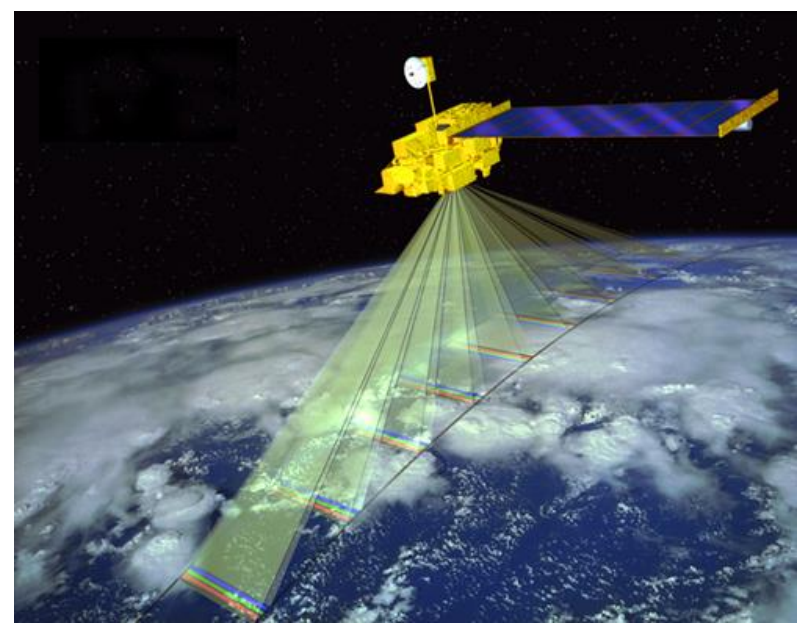

Fonte: NASA Space Place, 2016

O MISR, combinando alta resolução espacial, grande variedade de ângulos de visada ao longo da trajetória e calibração e estabilidade radiométricas de alta precisão, tem sido utilizado para derivar propriedades de aerossol de modo a melhorar a compreensão de processos atmosféricos e o impacto do aerossol no clima (DINER et al., 1998).

\subsection{MEDIDAS IN SITU DE ABSORÇÃO E ESPALHAMENTO}

As medidas in situ são essenciais para o estudo das propriedades de aerossol na Amazônia, especialmente no solo, onde há uma maior concentração de aerossol. Possibilitam ainda a obtenção de uma informação mais precisa sobre as tendências locais (CALVELLO et al., 2010). A partir destas medidas, é possível validar e estimar as incertezas nas propriedades de aerossol obtidas a partir de sensoriamento remoto e verificar se as medidas in situ são representativas das medidas integradas ao longo da coluna atmosférica.

\subsubsection{A medida da absorção espectral do aerossol com Aetalômetro}

O Aetalômetro é um instrumento que utiliza a análise óptica para determinar a concentração de BC em tempo real. Para as análises deste trabalho foi utilizado o Aetalômetro modelo AE31, que realizou medições em sete comprimentos de onda $(370,430,470,520,565,700$ e $880 \mathrm{~nm}$ ) no T3. O desenho esquemático do Aetalômetro pode ser visto na Figura 20. 
Figura 20 - Desenho esquemático do Aetalômetro. O ar ambiente é bombeado para dentro do sensor (A) e é, então, conduzido até o filtro (D). Uma fonte de luz (B) emite um feixe de luz com um ou vários comprimentos de onda (dependendo do modelo). $I_{0}$ é intensidade de luz transmitida através do filtro limpo (C) e $I$ é a intensidade de luz após a amostragem (D). Um feixe de referência (E) é conduzido diretamente até o fotodetector (F). A fita de filtro $(\mathrm{G})$ avança automaticamente para uma nova amostragem.

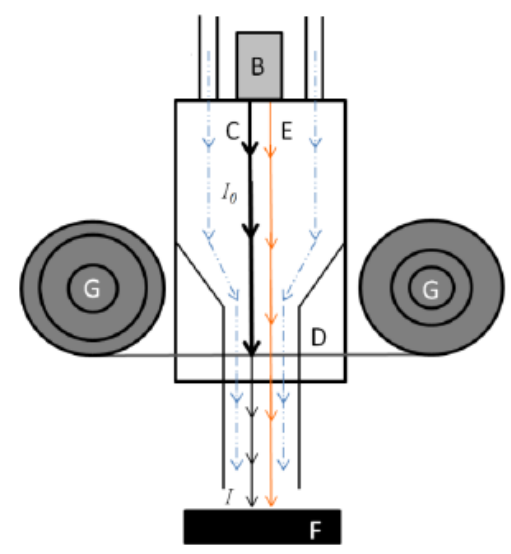

Fonte: MARTINSSON, 2013.

O método óptico empregado consiste em medir a atenuação de um feixe de luz transmitido através de um filtro que coleta continuamente uma amostra de partículas de aerossol. Definindo $I_{0}$ como a intensidade de luz transmitida através do filtro limpo e $I$ como a intensidade de luz transmitida após a amostragem, a atenuação óptica (ATN) é dada por

$$
A T N=100 \cdot \ln \left(\frac{I_{0}}{I}\right)
$$

O coeficiente de atenuação $\sigma_{A T N}$ é calculado a partir da variação da atenuação $\triangle A T N$, da área do filtro $A$, da taxa de fluxo volumétrico $Q$ e do tempo $\Delta t$ :

$$
\sigma_{A T N} \equiv \frac{A}{Q} \frac{\Delta A T N}{\Delta t}
$$

$\mathrm{O}$ instrumento fornece, então, a concentração em massa de BC determinada da seguinte maneira:

$$
[B C]_{A T N}=\frac{\sigma_{A T N}}{\sigma_{1 / \lambda}}
$$

onde $\sigma_{1 / \lambda}=14625 / \lambda\left[\mathrm{m}^{2} \mathrm{~g}^{-1}\right]$ é a seção de choque de absorção óptica e [BC] é a concentração de black carbon $\left[\mathrm{ng} \mathrm{m}^{-3}\right]$.

Assim sendo, para obter o coeficiente de absorção $\sigma_{a b s}\left[\mathrm{Mm}^{-1}\right]$, as medidas do coeficiente da atenuação foram corrigidas para efeito de espalhamento múltiplo e efeito de filter 
loading - que resulta da não-linearidade da relação entre a transmissão da luz através do filtro e a quantidade de material absorvedor presente no filtro -, segundo SCHMID, 2006 e RIZZO, 2011.

A concentração em massa de BC é calculada a partir da mudança na atenuação óptica a $880 \mathrm{~nm}$ no intervalo de tempo selecionado e utilizando $\sigma_{1 / \lambda}$ igual a $16,6 \mathrm{~m}^{2} / \mathrm{g}$ (no caso do Aetalômetro modelo AE31), isto porque, neste comprimento de onda, outras partículas de aerossol - carbonáceos ou minerais - absorvem consideravelmente menos radiação, de modo que a absorção pode ser atribuída unicamente ao BC. As medições em regiões espectrais distintas permitem a análise espectral dos dados. Por exemplo, a análise da dependência da absorção com o comprimento de onda pode ser importante para a detecção de poeira mineral ao considerarmos a dependência do albedo de espalhamento simples com o comprimento de onda (DRINOVEC et al., 2015).

\subsubsection{A medida da absorção pelo MAAP}

O MAAP (Multi Angle Absorption Photometer - modelo Thermo Scientific-5012) é um instrumento que determina o coeficiente de absorção do aerossol a partir de técnicas de transferência radiativa. Baseia-se na medição simultânea da atenuação óptica e do espalhamento de luz por partículas de aerossol depositadas em um filtro de fibra de vidro (PETZOLD et al., 2005). Ou seja, além da medição da luz transmitida, a luz espalhada é medida com fotodetectores posicionados em $\theta_{1}=130^{\circ}$ e $\theta_{2}=165^{\circ}$ (HYV ÄRINEN et al., 2013), como pode ser visto na Figura 21. Para derivar o coeficiente de absorção das partículas depositadas, o MAAP calcula a transferência radiativa através do filtro e desconta o espalhamento óptico.

Figura 21 - Diagrama esquemático do MAAP. A luz transmitida é medida com o fotodetector em $\theta_{0}=0^{\circ}$, e a luz espalhada com os fotodetectores em $\theta_{1}=130^{\circ}$ e $\theta_{2}=165^{\circ}$.

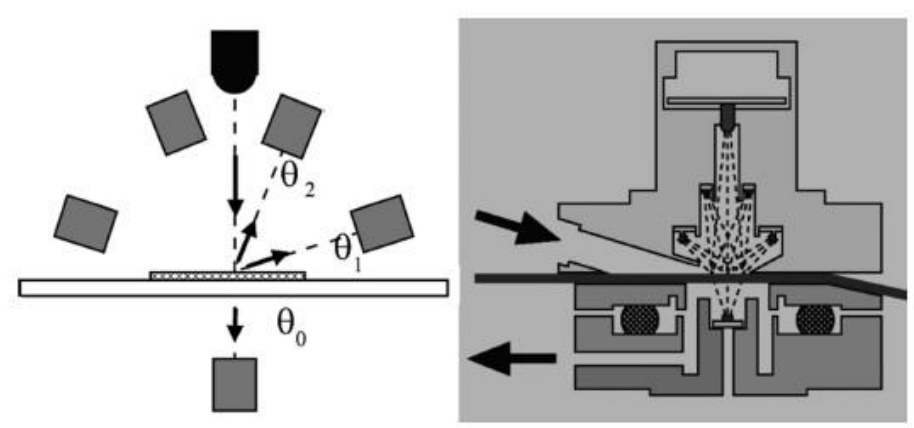

Fonte: HYVÄRINEN, 2013. 
Os valores reportados pelo instrumento são valores de concentração de BC em $670 \mathrm{~nm}$ convertidos em coeficiente de absorção assumindo-se um coeficiente mássico de absorção de 6,6 $\mathrm{m}^{2} / \mathrm{g}$. No entanto, segundo MÜLLER (2011), o comprimento de onda do MAAP é, na verdade, de $637 \pm 1 \mathrm{~nm}$ ao invés do seu comprimento de onda nominal, $670 \mathrm{~nm}$. Como o coeficiente de absorção em $637 \mathrm{~nm}$ deve ser cerca de 5\% maior, os valores referentes a $670 \mathrm{~nm}$ foram corrigidos através da multiplicação por um fator 1,05.

\subsubsection{A medida do espalhamento espectral do aerossol com Nefelômetro}

O Nefelômetro é um instrumento que mede o coeficiente de espalhamento devido à presença de partículas de aerossol atmosférico. Para a realização deste trabalho, foram utilizados dois modelos: o modelo TSI-3563, que mediu o espalhamento nos comprimentos de onda de 450, 550 e $700 \mathrm{~nm}$ no T0a e no T3, e o modelo Aurora Ecotech 3000, que mediu o espalhamento em 450, 525 e $635 \mathrm{~nm}$ no T0a. A Figura 22 mostra o diagrama interno de um Nefelômetro TSI-3563.

Figura 22 - Esquema interno do Nefelômetro de três comprimentos de onda, modelo TSI-3563.

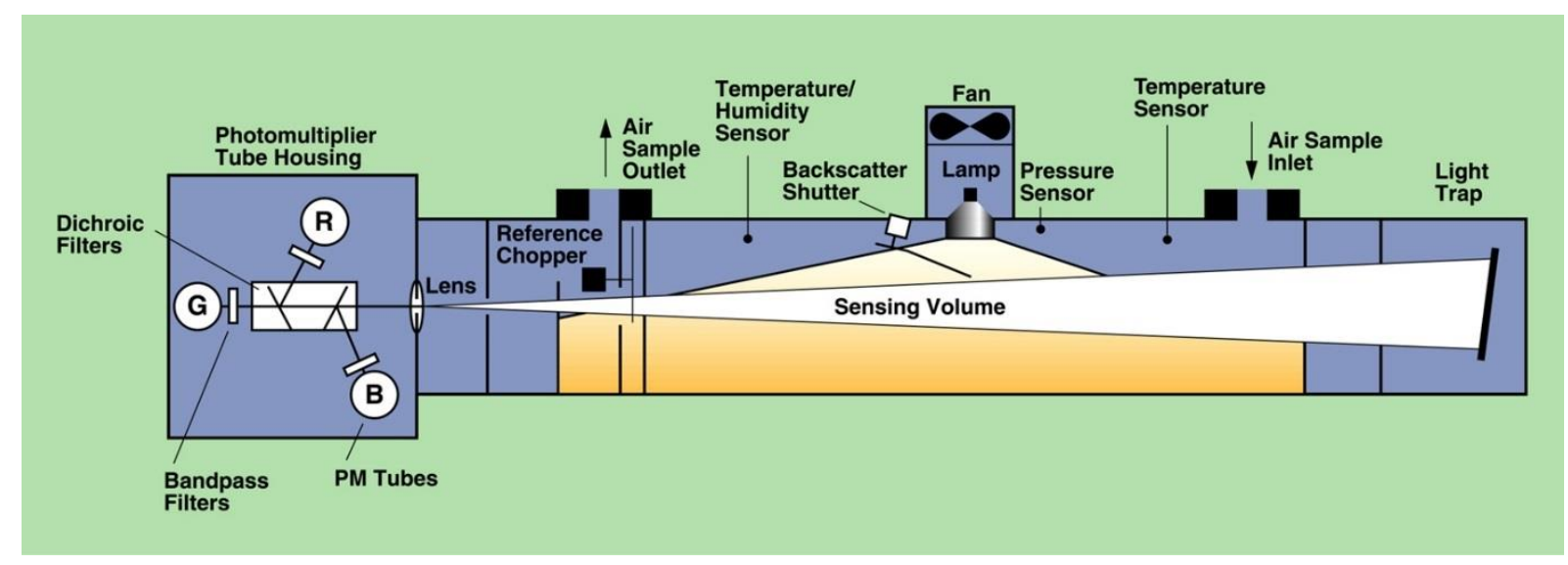

Fonte: Earth System Research Laboratory, 2016

Durante a operação do instrumento, a amostra de aerossol é bombeada através do inlet para a câmara volumétrica de análise. Em seguida, a amostra é iluminada ao longo de um intervalo angular de 7 a 170 graus por uma lâmpada halogênica. $\mathrm{O}$ volume amostrado passa, então, por uma série de obturadores ao longo do eixo principal do instrumento, sendo posteriormente analisado por três tubos fotomultiplicadores (azul, verde e vermelho) localizados em sua extremidade. O espalhamento do aerossol é observado em um anteparo que absorve a luz emitida com alta eficiência, minimizando, assim, a possibilidade de espalhamento pelas pare- 
des internas do instrumento. Periodicamente, uma válvula automatizada posicionada no inlet é ativada para drenar toda a amostra de aerossol do interior do instrumento, o que possibilita a medição do sinal de ar limpo do ambiente. Este sinal é subtraído do sinal original de modo que o espalhamento medido seja devido apenas à amostra de aerossol (RIZZO, 2006). 



\section{RESULTADOS E DISCUSSÃO}

Neste capítulo são apresentados e discutidos os principais resultados obtidos a partir da análise das propriedades ópticas de aerossol urbano e de queimadas na Amazônia utilizando diferentes técnicas. Medidas realizadas pela rede AERONET ao longo de mais de 15 anos permitiram a caracterização da influência do aerossol de queimadas sobre as propriedades de aerossol em diferentes regiões. No que concerne ao experimento GoAmazon2014/5, buscouse quantificar os efeitos da pluma de poluição proveniente de Manaus nas propriedades ópticas do aerossol vento abaixo da cidade. Foram analisadas as propriedades medidas in situ e medidas pela rede AERONET. Finalmente, o impacto da pluma urbana foi avaliado com base em medidas por sensoriamento remoto a partir de satélites.

\subsection{ANÁLISE DAS PROPRIEDADES DE AEROSSOL NA AMAZÔNIA DERIVADAS PELA REDE AERONET}

As medidas contínuas realizadas pela rede AERONET ao longo de mais de 15 anos permitiram o estudo da influência dos eventos anuais de queima de biomassa sobre as propriedades de aerossol em diferentes regiões da Amazônia. As análises apresentadas nesta seção foram feitas a partir de dados de nível 2.0 da AERONET.

A profundidade óptica do aerossol diz respeito à quantidade de partículas opticamente ativas na coluna atmosférica e é uma propriedade importante para a determinação da forçante radiativa. A Figura 23 mostra a série temporal de todos os dados de profundidade óptica do aerossol (AOD) em 500 nm disponíveis para Alta Floresta, Balbina, Belterra, Cuiabá Miranda, Rio Branco e Ji Paraná-Rondônia. Todos os sítios estudados apresentam tendências sazonais similares nas medidas de AOD. A estação chuvosa (janeiro a julho), período com altas taxas de precipitação, é caracterizada por AOD em torno de 0,1 em todas as regiões, o que é consistente com os valores de background, ou seja, valores que indicam emissões sobretudo biogênicas. Entre os meses de agosto e novembro, na estação seca, é observado um aumento no valor de AOD devido às emissões de queimadas, que variam temporal e espacialmente, como também indica a Figura 23. 
Figura 23 - Série temporal de todos os valores da profundidade óptica do aerossol (AOD) em $500 \mathrm{~nm}$ disponíveis entre os anos de 1999 e 2014.

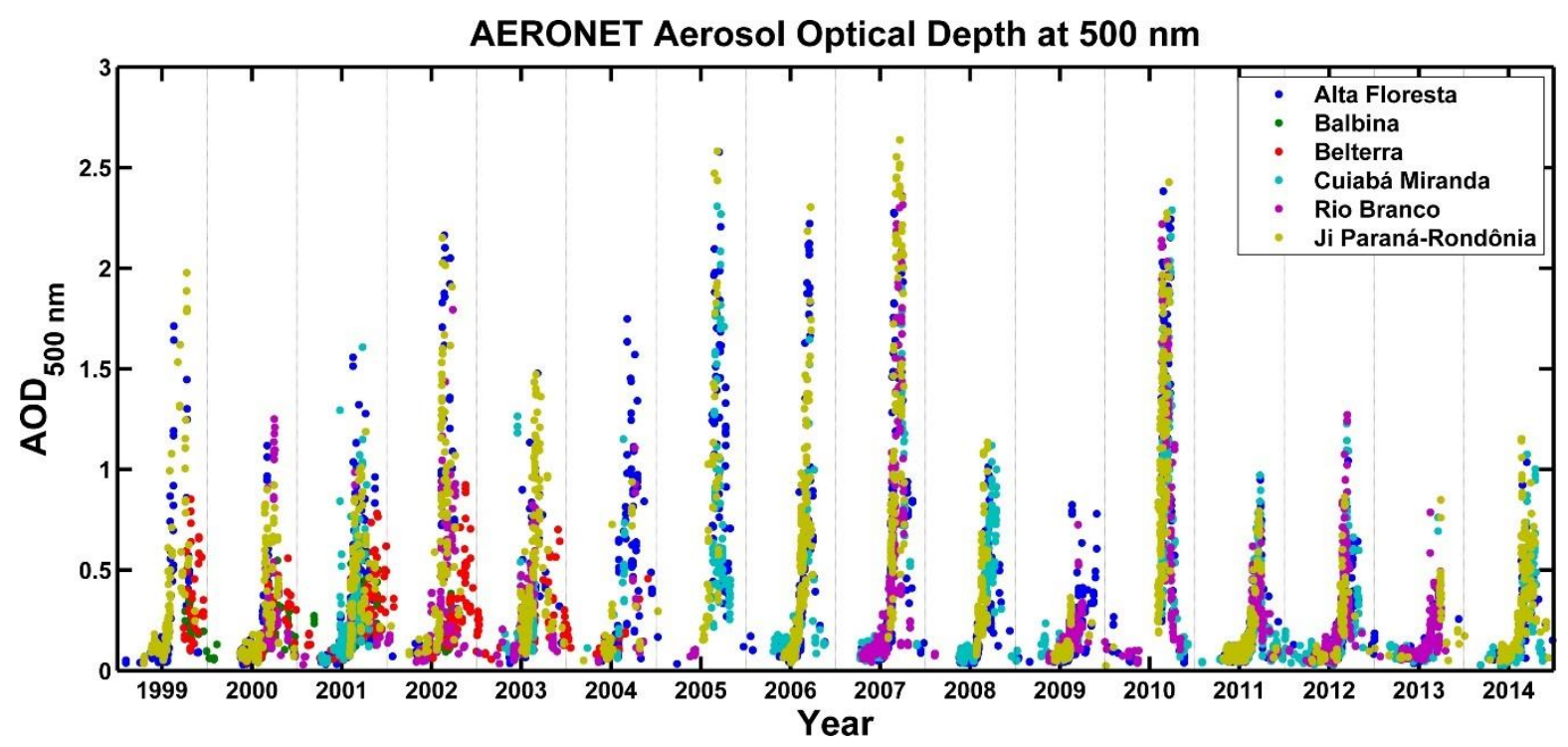

Os sítios localizados no arco do desflorestamento - Alta Floresta, Rio Branco e Ji Paraná-Rondônia -, região com grande influência de queimadas e mudanças no uso do solo, apresentam uma grande carga de aerossol, principalmente nos meses de agosto e setembro. Nos sítios localizados no Norte da Amazônia, Balbina e Belterra, a presença de aerossol de queimadas se dá por transporte, ou seja, são menos impactados por emissões diretas de queimadas locais, e a AOD atinge seus valores máximos em outubro e novembro, com uma defasagem em relação aos sítios ao longo do arco do desflorestamento, como já observado por PAIXÃO (2011) e SCHAFER (2008). Cuiabá Miranda, na região do Cerrado, também apresenta grande carga de aerossol na estação seca, sendo influenciada tanto por queimadas locais quanto pelo transporte de aerossol de queimadas emitido na região do arco do desflorestamento.

É possível observar também que os máximos valores de AOD ocorreram em 2005, 2007 e 2010, anos em que foram detectadas as secas mais severas e um grande número de focos de incêndio na região da Amazônia (ARTAXO et al., 2013; REDDINGTON et al., 2015; TEN HOEVE et al., 2012). 
Figura 24 - Médias da distribuição volumétrica de tamanho do aerossol na estação chuvosa (esquerda) e na estação seca (direita) entre os anos de 1999 e 2014. Diferentes escalas nas duas estações.
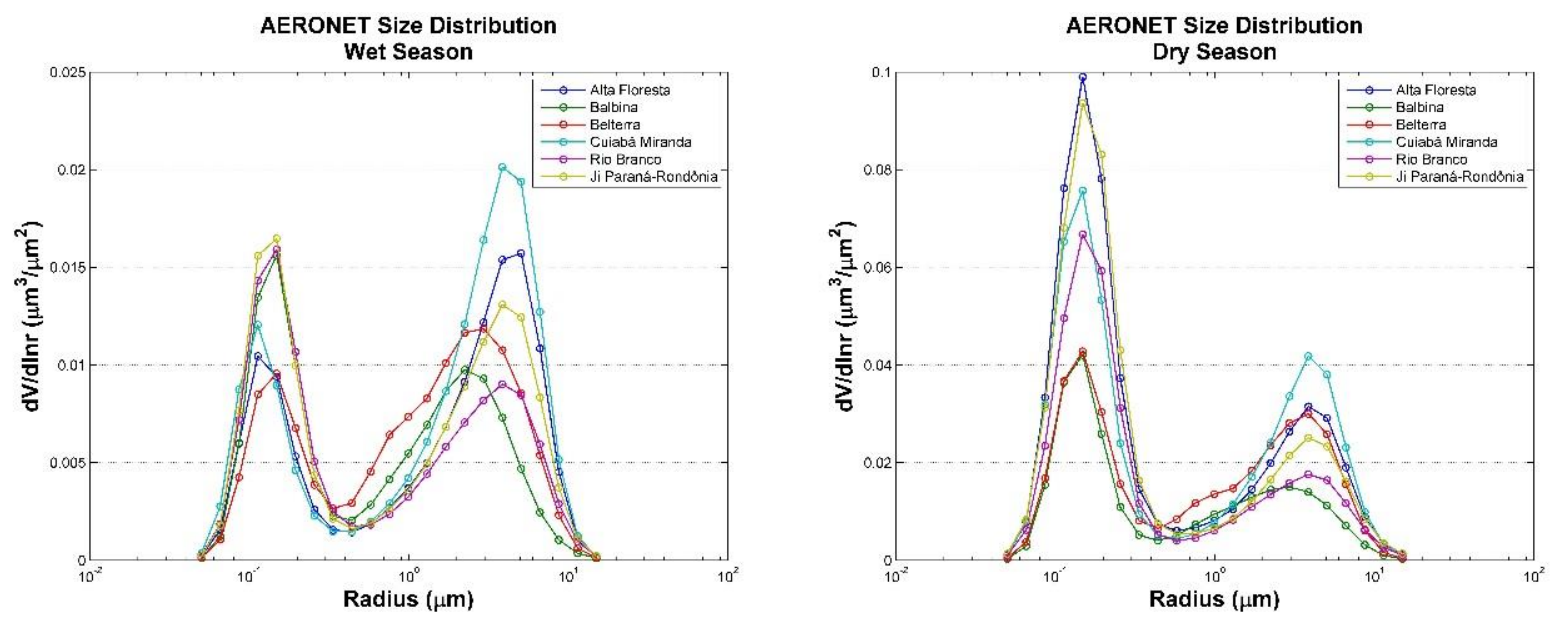

A influência das emissões de queimadas também pode ser observada na distribuição volumétrica de tamanho das partículas de aerossol, que fornece informação sobre dominância das fontes de emissão. A Figura 24 mostra a distribuição volumétrica de tamanho nas estações chuvosa e seca para os sítios estudados. A distribuição é fortemente bimodal e nota-se um aumento significativo no volume de partículas da moda fina durante a estação seca, principalmente nos sítios localizados na região do arco do desflorestamento, o que está associado ao fato de que as partículas oriundas da queima de biomassa são pertencentes à moda fina (MARTIN et al., 2010). O volume de partículas na moda fina também pode ser atribuído ao aerossol orgânico secundário formado a partir da oxidação dos COVs emitidos pela vegetação, contudo, este aparece em baixas concentrações (PAULIQUEVIS et al., 2007).

A moda grossa, composta em sua maioria por partículas biogênicas e mais suscetível a emissões locais, não sofre grandes alterações da estação chuvosa para a estação seca. No sítio de Cuiabá Miranda, esta moda é bastante acentuada, o que pode ser explicado pela cobertura do solo. Em áreas de pastagem, com vegetação menos densa, o solo é mais exposto e acaba contribuindo com uma maior quantidade de partículas de ressuspensão de solo na atmosfera. É importante ressaltar que Balbina e Belterra são ainda impactadas esporadicamente na estação chuvosa por poeira mineral do deserto do Saara e aerossol marinho do Oceano Atlântico, que também contribuem para a moda grossa, principalmente nos meses de março e abril (ARTAXO et al., 2009). Ainda que o número de medidas seja pequeno nestes dois sítios $\left(\mathrm{N}_{\text {Balbina }}=24\right.$ e $\left.\mathrm{N}_{\text {Belterra }}=106\right)$, a distribuição volumétrica de tamanho está dentro do esperado para esta região. 
Apesar da enorme variabilidade espacial, a similaridade do raio volumétrico médio (Tabela 5) é grande nos diferentes sítios experimentais, sempre em torno de $0,15 \mu \mathrm{m}$ na moda fina para todos os sítios e para as duas estações, seca e chuvosa. O raio médio da moda grossa varia entre os sítios (2 a $3 \mu \mathrm{m}$ ), mas ainda em uma faixa estreita levando em conta a variabilidade geográfica dos diferentes locais de medidas.

Tabela 5 - Valores médios do raio volumétrico médio $(\mu \mathrm{m})$ da moda fina e da moda grossa medidos na estação chuvosa e na estação seca entre os anos de 1999 e 2014.

\begin{tabular}{lcccc}
\hline \multicolumn{1}{c}{ Estação da } & \multicolumn{2}{c}{ Estação Chuvosa } & \multicolumn{2}{c}{ Estação Seca } \\
\multicolumn{1}{c}{ AERONET } & Moda Fina & Moda Grossa & Moda Fina & Moda Grossa \\
\hline Alta Floresta & $0,14 \pm 0,01$ & $3,10 \pm 0,35$ & $0,15 \pm 0,02$ & $3,15 \pm 0,45$ \\
Balbina & $0,15 \pm 0,01$ & $2,09 \pm 0,18$ & $0,15 \pm 0,02$ & $2,22 \pm 0,39$ \\
Belterra & $0,16 \pm 0,02$ & $2,19 \pm 0,36$ & $0,16 \pm 0,02$ & $2,39 \pm 0,47$ \\
Cuiabá Miranda & $0,13 \pm 0,01$ & $3,09 \pm 0,28$ & $0,14 \pm 0,02$ & $3,22 \pm 0,29$ \\
Rio Branco & $0,15 \pm 0,02$ & $2,77 \pm 0,41$ & $0,16 \pm 0,02$ & $2,91 \pm 0,53$ \\
Ji Paraná-Rondônia & $0,15 \pm 0,02$ & $2,92 \pm 0,36$ & $0,15 \pm 0,02$ & $3,23 \pm 0,49$ \\
\hline
\end{tabular}

O albedo de espalhamento simples (SSA) expressa a importância relativa do espalhamento na extinção da radiação, fornecendo informação sobre a natureza intrínseca das partículas. A Figura 25 mostra a dependência espectral do SSA nas estações chuvosa e seca. O número pequeno de medidas para estação chuvosa, sobretudo para áreas menos perturbadas por emissões de queimadas como o Norte da Amazônia, deve-se à condição de AOD em $440 \mathrm{~nm}$ maior que 0,4 requerida para derivar o SSA, valor maior do que o valor médio obtido, além da contaminação pela presença de nuvens. Isto significa que as medidas aqui analisadas são mais representativas da estação seca. Os valores médios assim como o número de medidas para o SSA em 675 nm são mostrados Tabela 6. 
Figura 25 - Dependência espectral do albedo de espalhamento simples (SSA) na estação chuvosa (esquerda) e na estação seca (direita) entre os anos de 1999 e 2014.
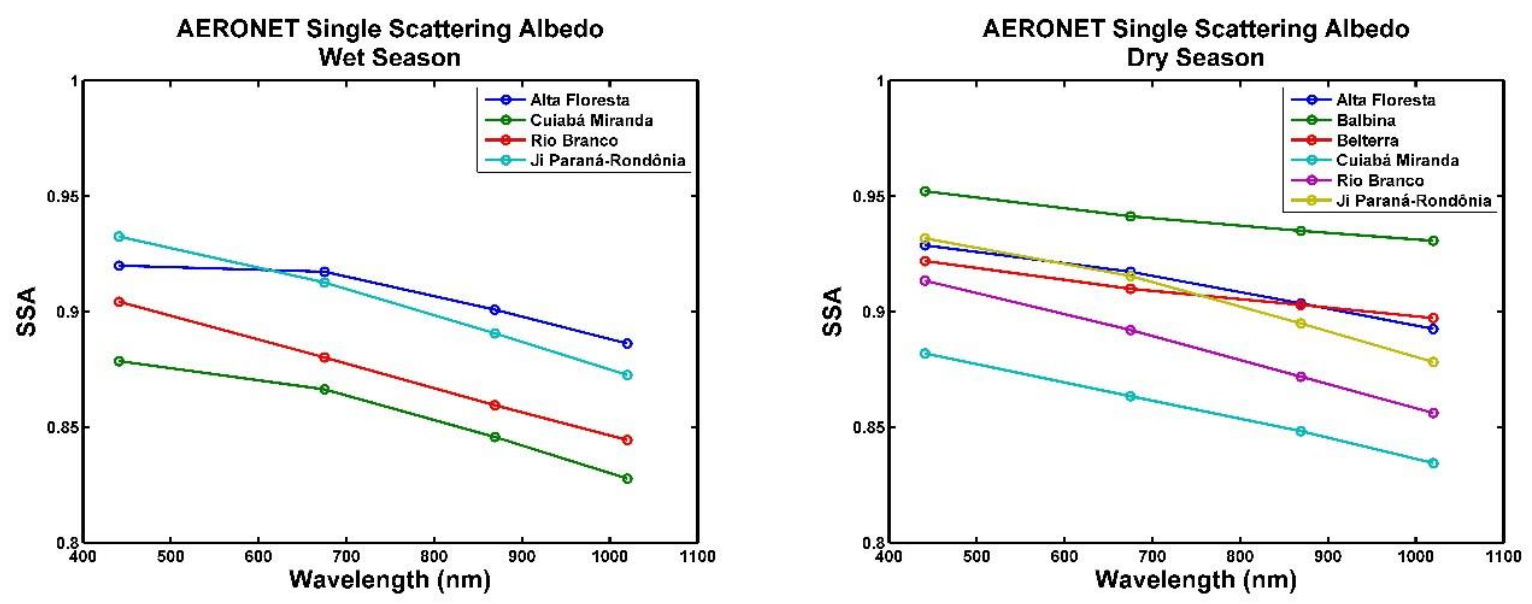

Tabela 6 - Valores médios do albedo de espalhamento simples em 675 nm medidos na estação chuvosa e na estação seca.

\begin{tabular}{lcccc}
\hline \multicolumn{5}{c}{ Albedo de espalhamento simples (SSA) em 675 nm } \\
\hline & \multicolumn{2}{c}{ Estação Chuvosa } & \multicolumn{2}{c}{ Estação Seca } \\
& Média & $\mathrm{N}$ & Média & $\mathrm{N}$ \\
\hline Alta Floresta & $0,92 \pm 0,023$ & 1449 & $0,92 \pm 0,03$ & 1154 \\
Balbina & - & - & $0,94 \pm 0,03$ & 168 \\
Belterra & - & - & $0,91 \pm 0,03$ & 261 \\
Cuiabá Miranda & $0,87 \pm 0,07$ & 842 & $0,86 \pm 0,06$ & 1146 \\
Rio Branco & $0,88 \pm 0,03$ & 574 & $0,89 \pm 0,04$ & 906 \\
Ji Paraná-Rondônia & $0,91 \pm 0,02$ & 845 & $0,92 \pm 0,03$ & 1405 \\
\hline
\end{tabular}

Na estação seca, o valor médio do SSA em 675 nm obtido para Balbina foi de 0,94 \pm 0,03 e para Belterra foi de 0,91 $\pm 0,03$, indicando a presença de um aerossol altamente espalhador. Na estação chuvosa nenhuma medida foi obtida. Para os sítios localizados no arco do desflorestamento, Alta Floresta, Rio Branco e Ji Paraná-Rondônia, os valores médios obtidos na estação seca foram de $0,92 \pm 0,03,0,89 \pm 0,04$ e 0,92 $\pm 0,03$, respectivamente. Na estação chuvosa, os valores médios foram 0,92 \pm 0,02 para Alta Floresta, 0,88 \pm 0,03 para Rio Branco e 0,91 \pm 0,02 para Ji Paraná-Rondônia. RIZZO (2013) sugere que o valor médio compatível nas duas estações apesar do aumento de partículas absorvedoras provenientes de emissões de queimadas na estação seca pode ser em parte explicado pelo fato de que tanto a absorção quanto o espalhamento aumentam em igual proporção na estação seca, a depender da fase da queima, do envelhecimento da pluma e dos processos atmosféricos sofridos pela mesma. 
O valor médio do SSA em Cuiabá Miranda na estação seca é de 0,86 $\pm 0,06$ e na estação chuvosa é de 0,87 \pm 0,07. Como colocado por SCHAFER et al., 2008, na estação seca, a região do Cerrado é afetada pela queima de savana regional, uma combustão mais eficiente (fase flaming), com maior quantidade de black carbon, o que explica o menor valor médio do SSA em comparação com o arco do desflorestamento. A variabilidade dos valores também é maior neste sítio. Isto se deve ao fato de que a região não só é afetada pela queima de savana regional, como também é afetada pelo aerossol "envelhecido" oriundo da queima de floresta, que é transportado à longa distância de regiões de desflorestamento, como do norte do estado do Mato Grosso. Na prática, como pode ser visto na Figura 26, a queima de savana regional está associada a valores moderados de AOD (0,4-0,7), o que leva a um valor médio de SSA mais baixo $(0,85 \pm 0.06)$ dada a maior quantidade de BC emitido na fase flaming dos incêndios. Os valores mais altos de AOD $(\mathrm{AOD}>1,0)$ são atribuídos às queimadas de longa distância, que produzem um maior número de partículas, e resultam em um valor médio de SSA mais elevado $(0,90 \pm 0,03)$, valor este compatível com o obtido para os sítios localizados na região do arco do desflorestamento. Este valor mais elevado está relacionado às maiores emissões de carbono orgânico em incêndios de florestas.

Figura 26 - Histograma normalizado das medidas de albedo de espalhamento simples (SSA) em $675 \mathrm{~nm}$ para AOD entre 0,4 e 0,7 (azul) e para AOD maior que 1,0 (vermelho) em Cuiabá Miranda.

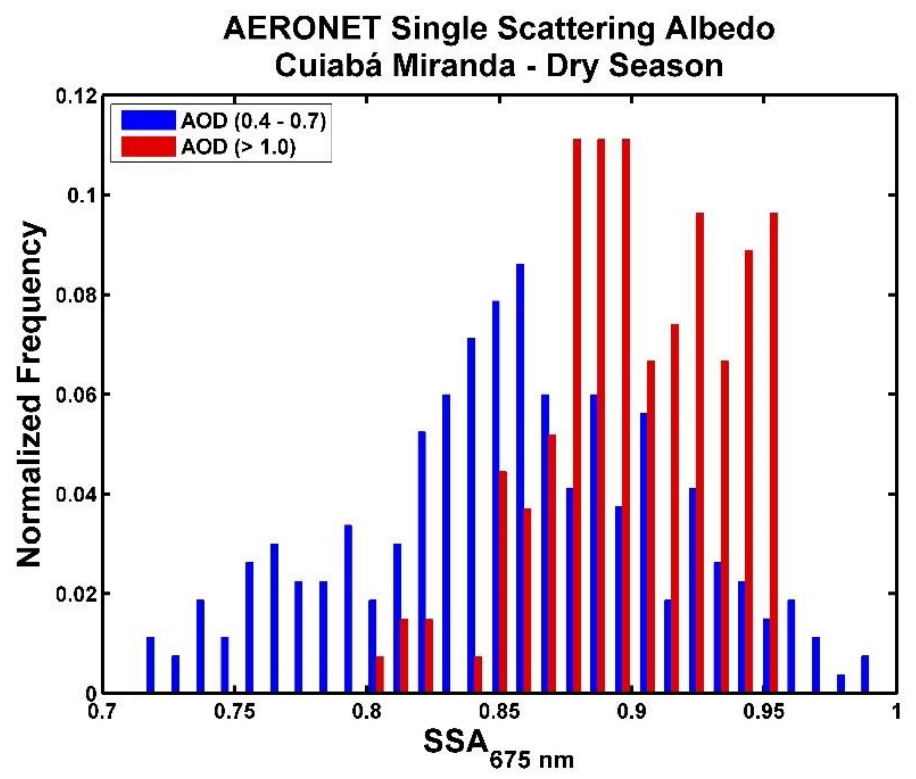

A Tabela 7 apresenta valores médios do SSA obtidos a partir da AERONET encontrados na literatura, para fins de comparação. Os valores de SSA obtidos no presente trabalho são compatíveis com estudos anteriores dentro do desvio padrão. 
Tabela 7 - Valores médios do albedo de espalhamento simples obtidos a partir da AERONET encontrados na literatura.

\begin{tabular}{cccc}
\hline Referência & Região & Período & SSA \\
\hline HOLANDA, 2015 & Alta Floresta, MT & $2000-2014$ & $0,91 \pm 0,03$ \\
SCHAFER et al., 2008 & Norte da Amazônia & $1999-2006$ & $0,91 \pm 0,04$ \\
SCHAFER et al., 2008 & Arco do desflorestamento & $1999-2006$ & $0,93 \pm 0,03$ \\
SCHAFER et al., 2008 & Cerrado & $1999-2006$ & $0,89 \pm 0,04$ \\
PAIXÃO, 2011 & Alta Floresta, MT & $1999-2010$ & $0,92 \pm 0,03$ \\
PAIXÃO, 2011 & Balbina/AM & $1999-2002$ & $0,92 \pm 0,02$ \\
PAIXÃO, 2011 & Belterra/PA & $1999-2005$ & $0,90 \pm 0,06$ \\
PAIXÃO, 2011 & Cuiabá/MT & $2001-2010$ & $0,88 \pm 0,06$ \\
PAIXÃO, 2011 & Ji Paraná/RO & $2006-2010$ & $0,92 \pm 0,03$ \\
PAIXÃO, 2011 & Rio Branco/AC & $2000-2010$ & $0,88 \pm 0,04$ \\
\hline
\end{tabular}

Como dito na Seção 1.3.2, as partículas de aerossol afetam o clima global e regional através das mudanças que produzem no balanço radiativo terrestre. A quantificação deste impacto requer informação não apenas sobre a quantidade de aerossol, mas também sobre outras características, tais como distribuição de tamanho das partículas, composição química, e como elas se relacionam com as propriedades ópticas (RUSSELL et al., 2010).

Neste trabalho, com o objetivo de estimar os tipos de aerossol absorvedor a partir de suas propriedades ópticas, utilizamos o método descrito por CAZORLA (2013). Neste método, o expoente Ångström de absorção (AAE) é utilizado como um indicador da composição química do aerossol e um gráfico AAE vs. SAE, chamado de Matriz Ångström, agrupa em diferentes regiões os diferentes tipos de aerossol absorvedor. AAE e SAE foram calculados a partir das equações (21) e (22), respectivamente, com $\lambda_{1}=440 \mathrm{~nm}$ e $\lambda_{2}=675 \mathrm{~nm}$. A relação entre o AAE e o SAE e as propriedades do aerossol foram descritas na Seção 3.2.

A principal vantagem deste método é que, em uma situação ideal, separa-se as espécies absorvedoras em EC, OC e poeira mineral. No caso da Região Amazônica, podemos atribuir a região de Coated Large Particles do gráfico às partículas biogênicas, que pertencem à moda grossa e mostram uma maior absorção da radiação na região do visível (HOLANDA, 2015). Inicialmente, as medidas que representam poeira mineral e o aerossol biogênico são separadas ao longo do eixo SAE, uma vez que são encontradas principalmente na moda grossa, ao contrário do aerossol carbonáceo, que pertence principalmente à moda fina e ultrafina perto da fonte de emissão. Em seguida, o EC, que é um absorvedor eficiente em todos os 
comprimentos de onda, é separado do OC, que é um absorvedor eficiente apenas em comprimentos de onda mais curtos, ao longo do eixo AAE (CAZORLA et al., 2013).

Com o propósito de melhorar o entendimento do impacto de cada tipo de aerossol absorvedor no balanço radiativo, acrescentamos à Matriz Ångström a forçante radiativa direta no topo da atmosfera $\left(\mathrm{RF}_{\mathrm{TOA}}\right)$ derivada pela AERONET. Para que fosse possível comparar os valores da forçante em condições observacionais semelhantes, só foram utilizadas medidas para ângulo zenital solar entre $50^{\circ}$ e $65^{\circ}$ (GARCÍA et al., 2012). A Figura 27 mostra a Matriz Ångström para Alta Floresta, Cuiabá Miranda, Rio Branco e Ji Paraná-Rondônia; e a Figura 28 mostra a Matriz Ångström para Balbina e Belterra. Nesta análise, a condição de AOD maior que 0,4 não foi aplicada aos dados.

Figura 27 - Matriz Ångström de absorção e espalhamento para os sítios de Alta Floresta, Cuiabá Miranda, Rio Branco e Ji Paraná-Rondônia.
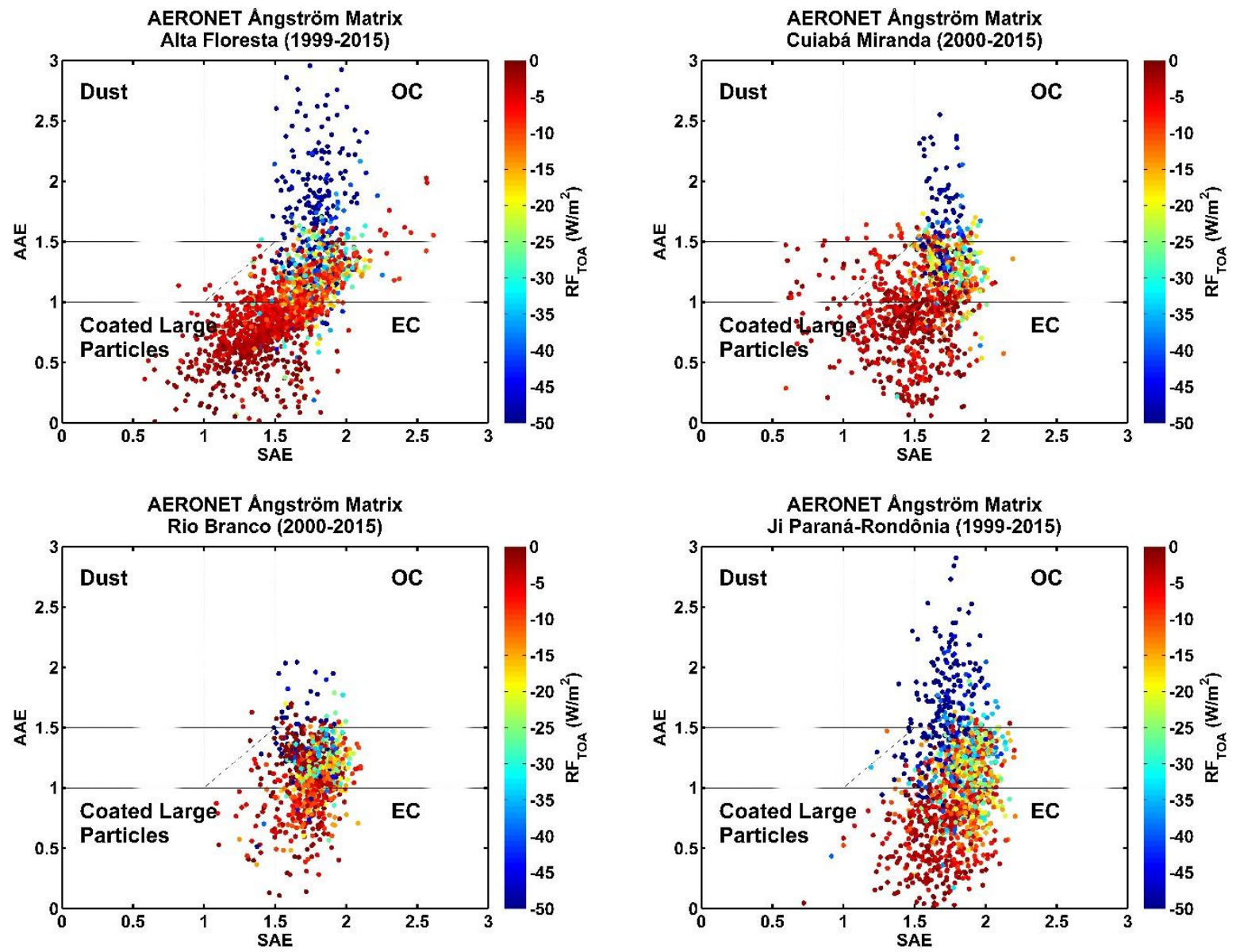

Para Alta Floresta, Cuiabá Miranda e Ji Paraná-Rondônia, as medidas classificadas como OC apresentaram forçantes mais negativas, com elevados valores, variando entre $-51,5$ e $-35,8 \mathrm{~W} / \mathrm{m}^{2}$. Isto mostra que o OC é um componente altamente espalhador e provoca um 
forte efeito de resfriamento no topo da atmosfera. Os valores mais positivos estão associados ao EC e às partículas biogênicas, que são componentes absorvedoras. Os valores da $\mathrm{RF}_{\mathrm{TOA}}$ variaram entre $-10,7$ e $-5,6 \mathrm{~W} / \mathrm{m}^{2}$ para o EC e entre $-6,6$ e $-3,8 \mathrm{~W} / \mathrm{m}^{2}$ para as partículas biogênicas, que absorvem muito eficientemente a radiação, em parte devido à sua morfologia e composição elementar, com a presença de substâncias húmicas, e podem apresentar uma eficiência de absorção maior do que as partículas emitidas por queima de biomassa (ARTAXO et al., 2009). Um comportamento semelhante era esperado para o sítio de Rio Branco. No entanto, um menor número de medidas foi obtido neste sítio e apenas para o EC foi possível estimar o valor da forçante com uma estatística razoável $\left(-9,1 \pm 8,6 \mathrm{~W} / \mathrm{m}^{2}\right)$. Rio Branco é um sítio rodeado de florestas, situa-se no Oeste da Amazônia e apresenta altas taxas de precipitação e nebulosidade. Isto faz com que a estatística de medidas na estação chuvosa seja pequena, impossibilitando uma análise similar à de outros sítios experimentais.

Apenas Cuiabá Miranda apresentou valores que podem ser classificados como Dust. Apesar do número baixo de medidas classificadas como tal, como já foi colocado, em áreas de pastagem o solo é mais exposto e acaba contribuindo com uma maior quantidade de partículas de ressuspensão de solo na atmosfera. HOLANDA (2015) enfatiza que medidas nesta região do gráfico também eram esperadas para os outros sítios dado o conhecido transporte anual de poeira do Saara, sobretudo durante a estação chuvosa. Ainda segundo HOLANDA (2015), a ausência destas medidas pode estar relacionada à condição de céu nublado, que limita a disponibilidade de dias com condições adequadas para a realização de medidas de qualidade no almucântara, e ao fato de que as emissões do deserto do Saara atravessam o Oceano Atlântico e cerca de $1.500 \mathrm{~km}$ de floresta antes de serem observadas na Amazônia, o que leva a misturas internas entre poeira mineral, aerossol biogênico e aerossol marinho, dificultando a identificação unívoca.

$\mathrm{Na}$ estação chuvosa, os valores da $\mathrm{RF}_{\mathrm{TOA}}$ variaram entre $-5,0$ e $-3,8 \mathrm{~W} / \mathrm{m}^{2}$, sendo atribuídos à baixa quantidade de aerossol espalhador, baixos valores de AOD, e à predominância de aerossol biogênico. Já na estação seca, os valores variaram entre $-31,3$ e -20,6 W/m², mostrando um maior efeito de resfriamento apesar do aumento da concentração de partículas absorvedoras provenientes da emissão de queimadas. Isto indica que o OC é a fração dominante na estação seca, como já apontado por estudos anteriores (BRITO et al., 2014; HOLANDA, 2015; MAYOL-BRACERO, 2002). 
Figura 28 - Matriz Ångström de absorção e espalhamento para os sítios de Balbina e Belterra.
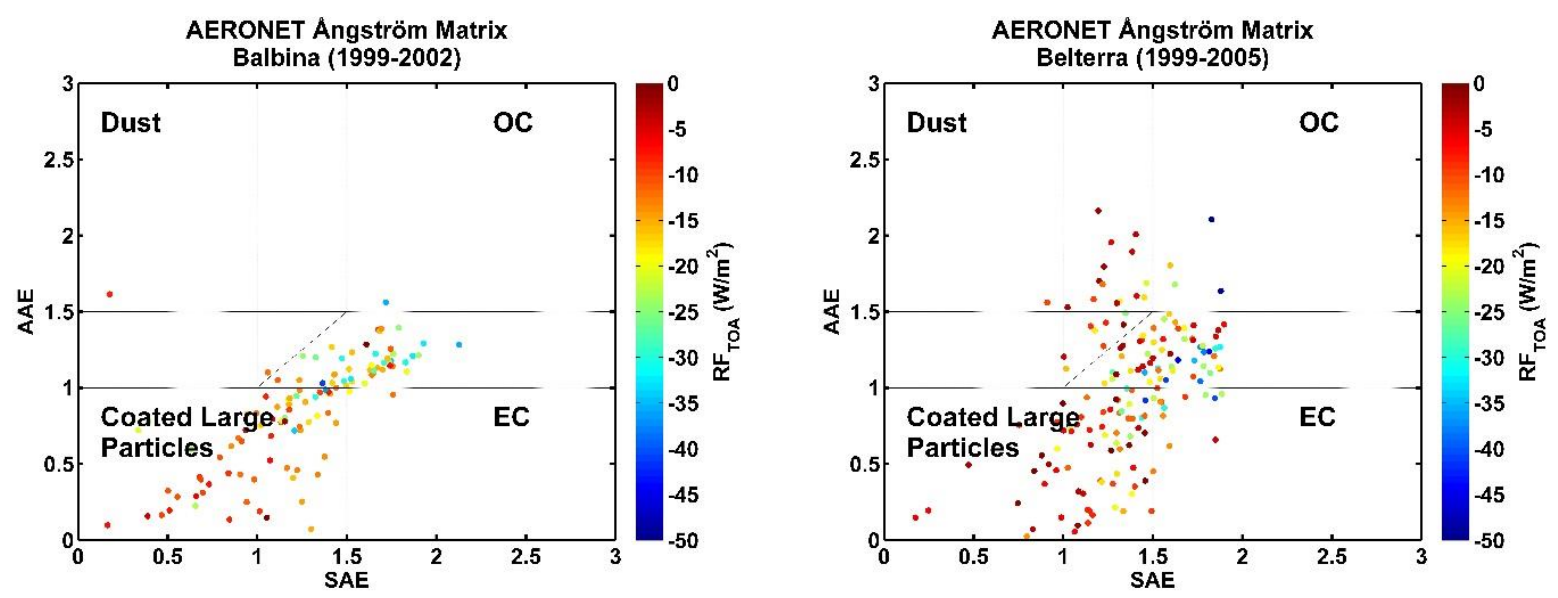

Para os sítios localizados no Norte de Amazônia, como já mencionado, o número de valores determinados é muito pequeno e não foi possível obter uma estatística razoável. Entretanto, os gráficos mostram que o impacto das partículas grossas é mais significativo nesta região, o que está de acordo com o impacto maior de aerossol biogênico e os episódios esporádicos de poeira mineral do Saara na região Norte da Amazônia.

\subsection{INFLUÊNCIA DA PLUMA DE POLUIÇÃO PROVENIENTE DE MANAUS SOBRE PROPRIEDADES DE AEROSSOL MEDIDAS PELA REDE AERONET E MEDIDAS IN SITU}

No âmbito do experimento GoAmazon2014/5, foram analisadas medidas obtidas a partir da rede AERONET e medidas in situ com o objetivo de entender melhor como as propriedades de aerossol natural da Amazônia são influenciadas pelas emissões urbanas de Manaus. As análises aqui apresentadas foram feitas a partir dos dados de nível 1.5 da AERONET. Tanto as propriedades ópticas medidas pela AERONET quanto as propriedades ópticas medidas in situ foram interpoladas usando a Equação (20) de modo a garantir que estivessem em 637 nm (comprimento de onda reportado pelo MAAP) e, consequentemente, garantir coerência na comparação.

5.2.1 Análise das propriedades de aerossol derivadas pela rede AERONET

Em um primeiro momento, a análise focou nas medições das propriedades de aerossol realizadas em duas estações da rede AERONET: EMBRAPA, localizada vento acima da plu- 
ma de Manaus, e Manacapuru, localizada vento abaixo da pluma. A Figura 29 mostra as médias mensais da profundidade óptica do aerossol em $637 \mathrm{~nm}$ medida pela rede AERONET na EMBRAPA e em Manacapuru nos anos de 2014 e 2015. Os dois sítios apresentam tendências sazonais similares nas medidas de AOD, com uma maior carga de aerossol na estação seca devido ao transporte de aerossol de queimadas. Durante a estação chuvosa, com o aumento das taxas de precipitação e as baixas concentrações de aerossol na atmosfera, os valores de AOD ficam em torno de 0,1. Através das medidas de AOD não foi possível observar a influência da pluma urbana de Manaus em Manacapuru neste período. A figura deixa claro que não é possível distinguir estatisticamente os valores nos dois sítios. Isto significa que, apesar da influência da pluma de poluição proveniente de Manaus, os valores de AOD são representativos do aerossol regional e do transporte em larga escala, que afeta os dois sítios de maneira similar (CIRINO, 2015; HOLANDA, 2015; PROCÓPIO, 2005).

Figura 29 - Médias mensais da profundidade óptica do aerossol (AOD) em 637 nm medida na EMBRAPA, vento acima da pluma de Manaus, e em Manacapuru, vento abaixo da pluma, nos anos de 2014 e 2015.

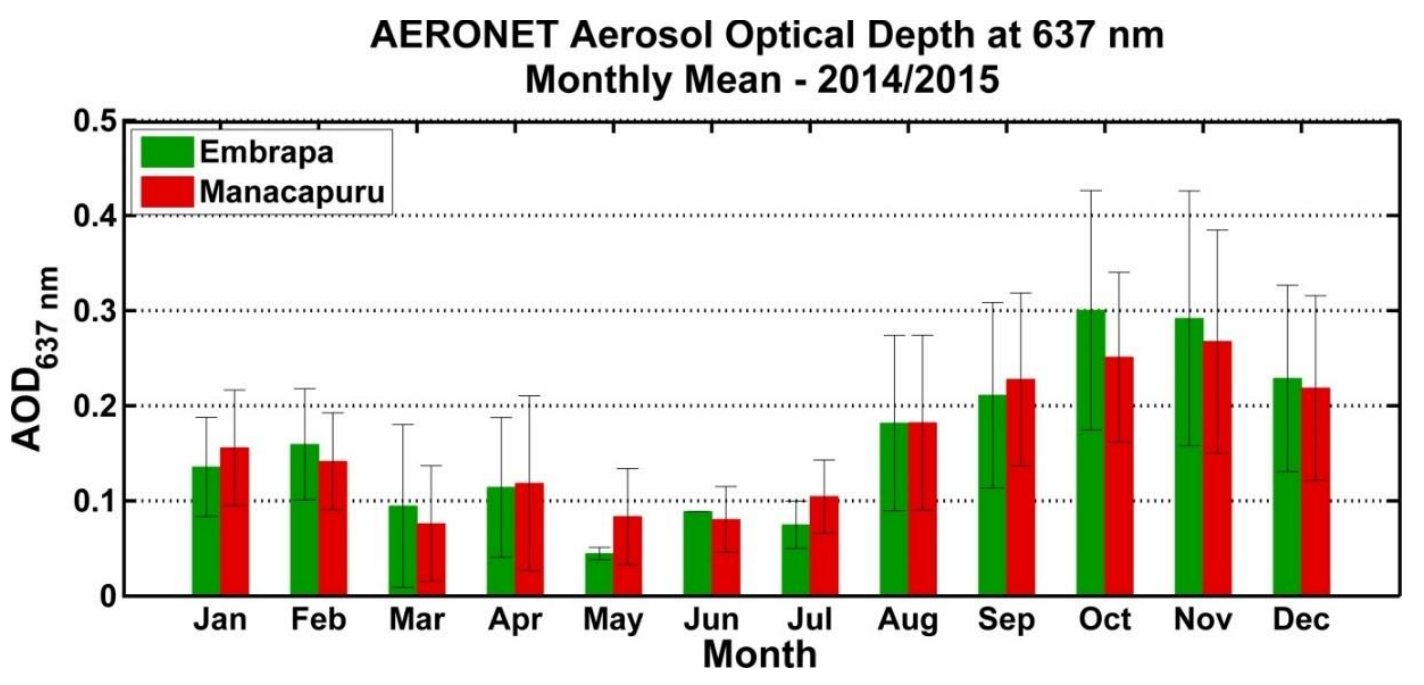

Também na distribuição volumétrica de tamanho do aerossol (Figura 30) observou-se uma similaridade entre os sítios nas duas estações. Na estação seca, tanto as emissões de queimadas quanto a pluma urbana contribuem para o aumento da moda fina do aerossol em relação à estação chuvosa, dificultando a distinção entre o impacto das duas fontes vento abaixo da pluma. 
Figura 30 - Médias da distribuição volumétrica de tamanho do aerossol para EMBRAPA e Manacapuru nas estações chuvosa e seca, nos anos de 2014 e 2015.
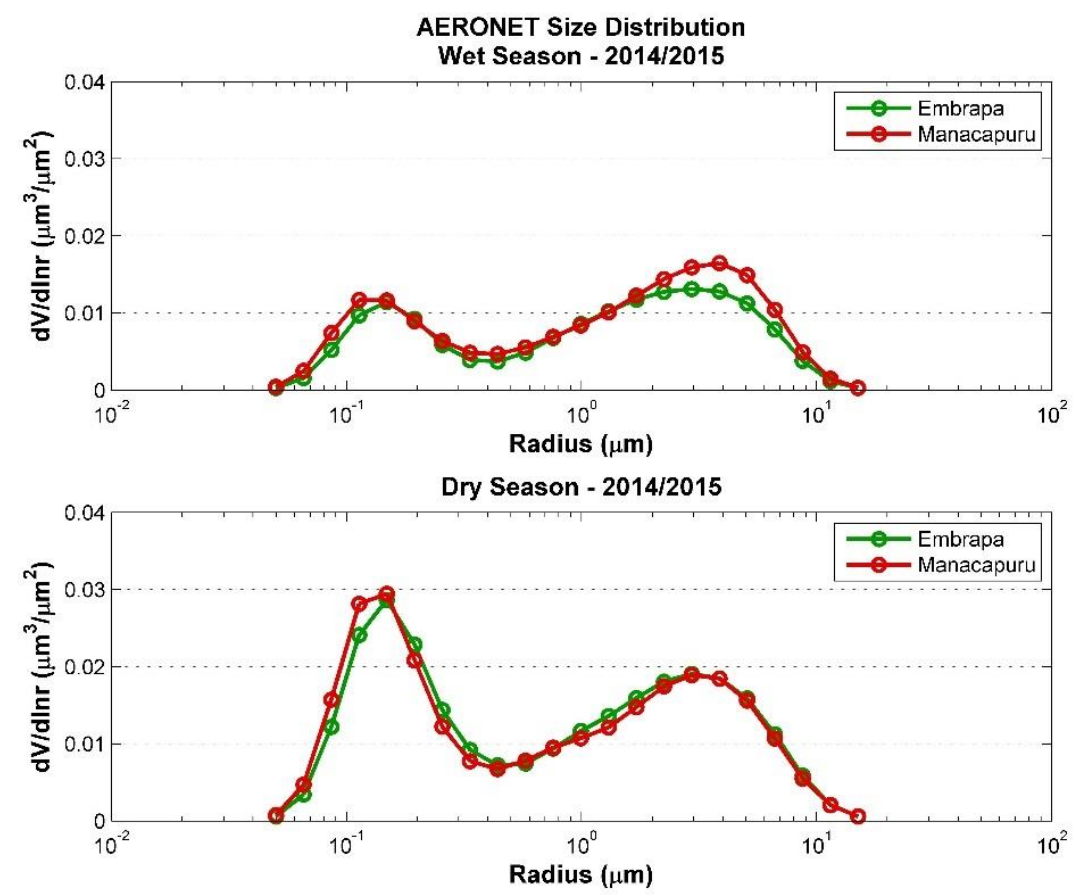

A Figura 31 mostra a dependência espectral do albedo de espalhamento simples obtido pela rede AERONET nos dois sítios na estação chuvosa e na estação seca nos anos de 2014 e 2015. Existe uma diferença significativa nos valores de SSA vento acima e vento abaixo da pluma de Manaus, evidenciando, assim, a presença de um aerossol mais absorvedor em Manacapuru em relação à EMBRAPA nos dois períodos. Esta diferença na absorção também pode ser vista na Figura 32, onde temos as médias mensais da profundidade óptica de absorção (AAOD) em $637 \mathrm{~nm}$. Durante a estação chuvosa, o valor médio da AAOD foi de 0,004 \pm 0,006 para a EMBRAPA. Para Manacapuru, o valor médio foi cerca de quatro vezes maior, $0,017 \pm 0,010$. O maior valor para a componente de absorção em Manacapuru está relacionado às emissões de black carbon da cidade de Manaus, ou seja, é possível identificar uma influência da pluma de poluição de Manaus neste sítio. Já na estação seca, o valor médio foi de 0,010 $\pm 0,009$ para a EMBRAPA e de 0,029 \pm 0,012 em Manacapuru, valores maiores do que os obtidos na estação chuvosa. Isto se deve ao transporte regional das partículas de black carbon emitidas por queimadas que afeta os dois sítios. Todavia, no caso de Manacapuru, a absorção está associada sobretudo à pluma de poluição de Manaus e a outras emissões locais, tais como as emissões oriundas das olarias localizadas na região. 
Figura 31 - Dependência espectral do albedo de espalhamento simples (SSA) na estação chuvosa e na estação seca nos anos de 2014 e 2015.
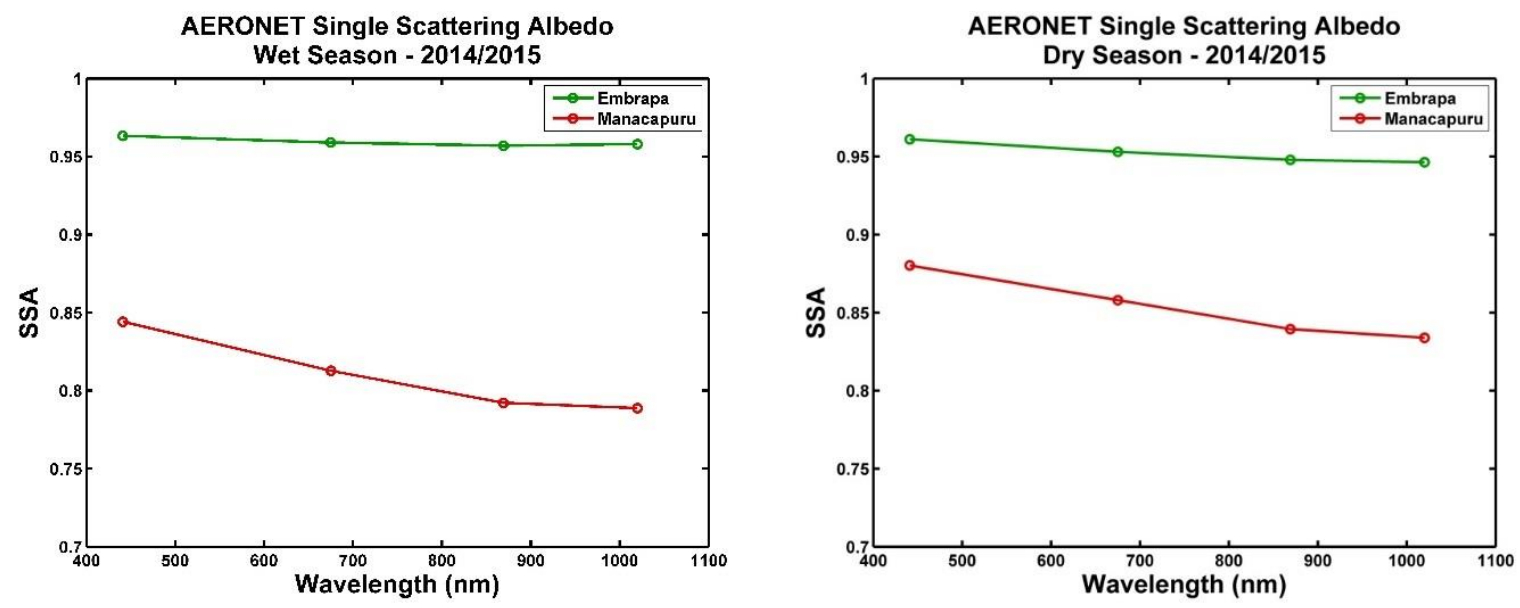

Figura 32 - Médias mensais da profundidade óptica de absorção (AAOD) em 637 nm medida na EMBRAPA, vento acima da pluma de Manaus, e em Manacapuru, vento abaixo da pluma, nos anos de 2014 e 2015.

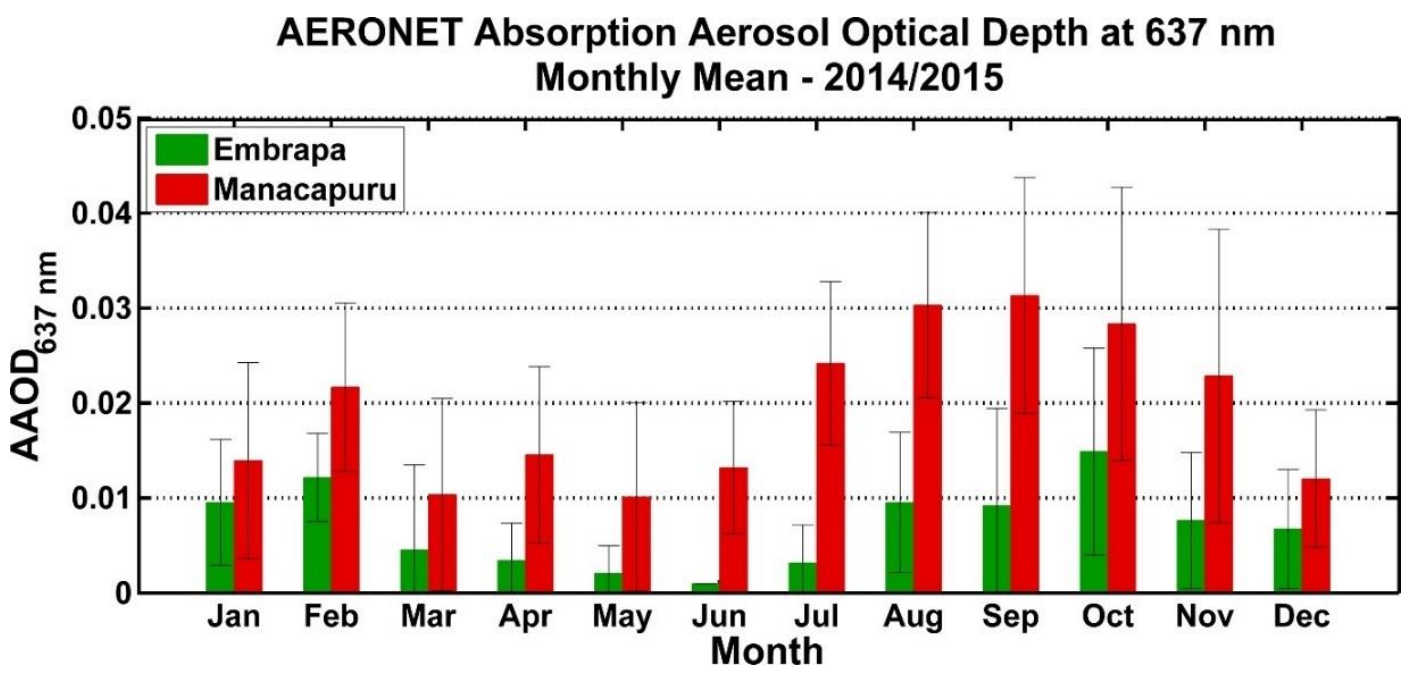

Uma outra forma de quantificar o impacto da pluma de poluição urbana proveniente de Manaus é a partir da forçante radiativa do aerossol. A Figura 33 mostra os valores médios da forçante radiativa direta no topo da atmosfera derivada pela rede AERONET, tanto na estação seca quanto na estação chuvosa, nos anos de 2014 e 2015. Também neste caso, só foram utilizadas medidas para ângulo zenital solar entre $50^{\circ}$ e $65^{\circ}$. Os valores médios obtidos na estação chuvosa foram de $-8,3 \pm 3,4 \mathrm{~W} / \mathrm{m}^{2}$ na EMBRAPA e de $-3,9 \pm 6,4 \mathrm{~W} / \mathrm{m}^{2}$ em Manacapuru. Os valores mais positivos em Manacapuru estão relacionados ao black carbon presente na pluma urbana, que é um aerossol altamente absorvedor. Na estação seca, os valores médios foram de $-23,9 \pm 11,9 \mathrm{~W} / \mathrm{m}^{2}$ na EMBRAPA e de $-18,4 \pm 14,3 \mathrm{~W} / \mathrm{m}^{2}$ em Manacapuru, valores mais negativos do que aqueles encontrados na estação chuvosa. Como já foi dito anteriormen- 
te, o efeito maior de resfriamento na estação seca em relação à estação chuvosa está relacionado à presença de $\mathrm{OC}$, que é o componente majoritário do aerossol carbonáceo emitido na queima de biomassa e é altamente espalhador.

Figura 33 - Média da forçante radiativa no topo da atmosfera na estação chuvosa e na estação seca, para a EMBRAPA e para Manacapuru, nos anos de 2014 e 2015.

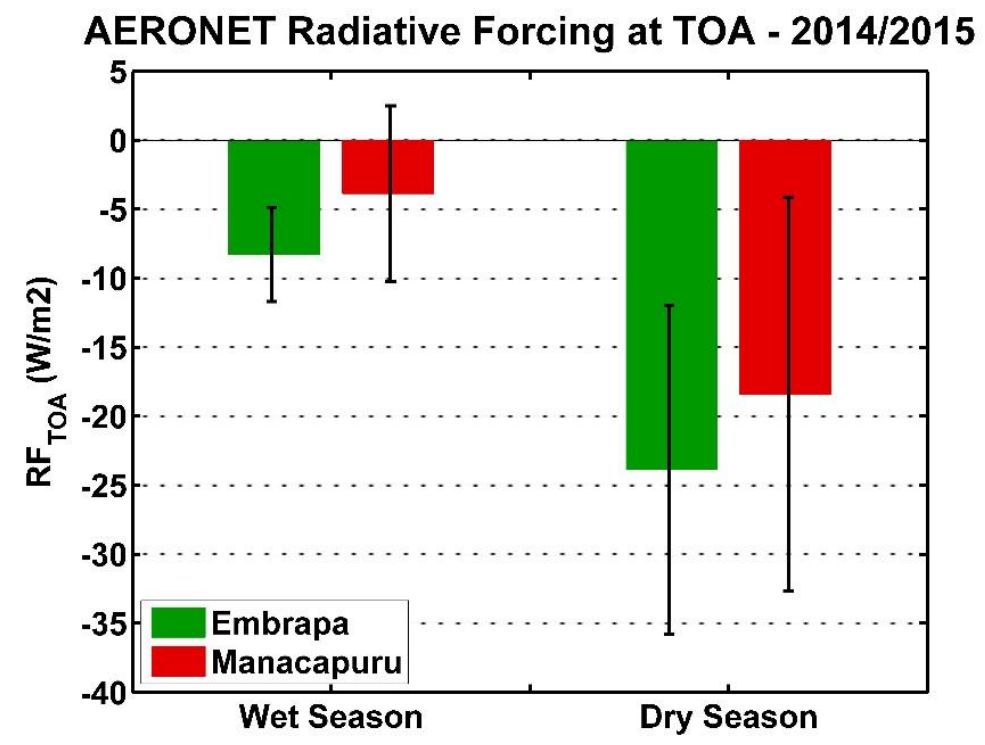

5.2.2 Análise do albedo de espalhamento simples obtido a partir de medidas in situ

Ainda com o intuito de melhorar a compreensão acerca da influência da pluma urbana de Manaus sobre as propriedades ópticas do aerossol, o albedo de espalhamento simples obtido a partir de medidas in situ de absorção e espalhamento foi analisado. Além disto, buscouse analisar um período maior de tempo, o que é essencial para o entendimento da variabilidade das propriedades de aerossol. Foram utilizadas as medidas in situ realizadas no ATTO (T0a), vento acima da pluma urbana de Manaus, e as medidas realizadas em Manacapuru (T3), vento abaixo da pluma.

As medidas de absorção foram realizadas pelo MAAP no ATTO (T0a), devido à disponibilidade de dados durante um período maior de tempo, e pelo Aetalômetro modelo AE31 em Manacapuru (T3). Como os dois instrumentos apresentam princípios diferentes para a medida da atenuação, fez-se necessário verificar a concordância entre os valores medidos por cada um deles, como podemos ver na Figura 34. Comparação semelhante já havia sido feita por HOLANDA (2015) para medidas realizadas na ZF2 (T0t), o que mostra que esta concor- 
dância não está associada ao local, e sim ao princípio de medição de cada instrumento e às correções feitas nas medidas (Figura 35).

Figura 34 - Comparação entre os coeficientes de absorção medidos pelo MAAP e pelo Aetalômetro modelo AE30 no ATTO para o corte de tamanho $\mathrm{PM}_{10}$.

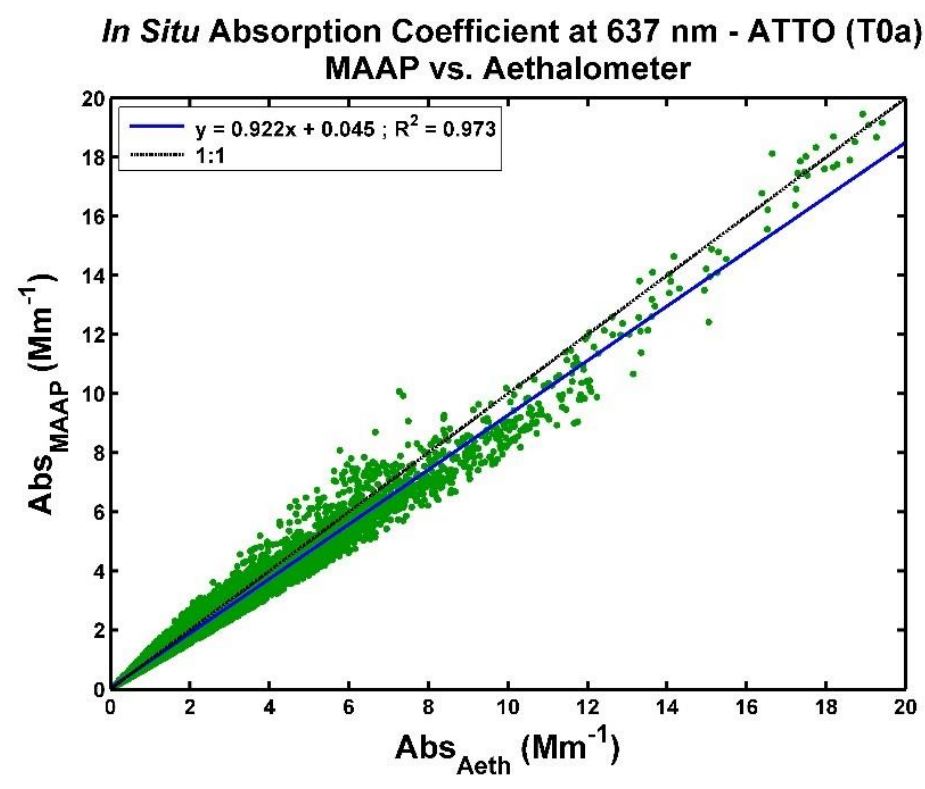

Figura 35 - Comparação entre os coeficientes de absorção medidos pelo Aetalômetro modelo AE33 e pelo MAAP no sítio experimental da ZF2 para os cortes de tamanho $\mathrm{PM}_{10}$ e $\mathrm{PM}_{2.5}$ feita por HOLANDA (2015).
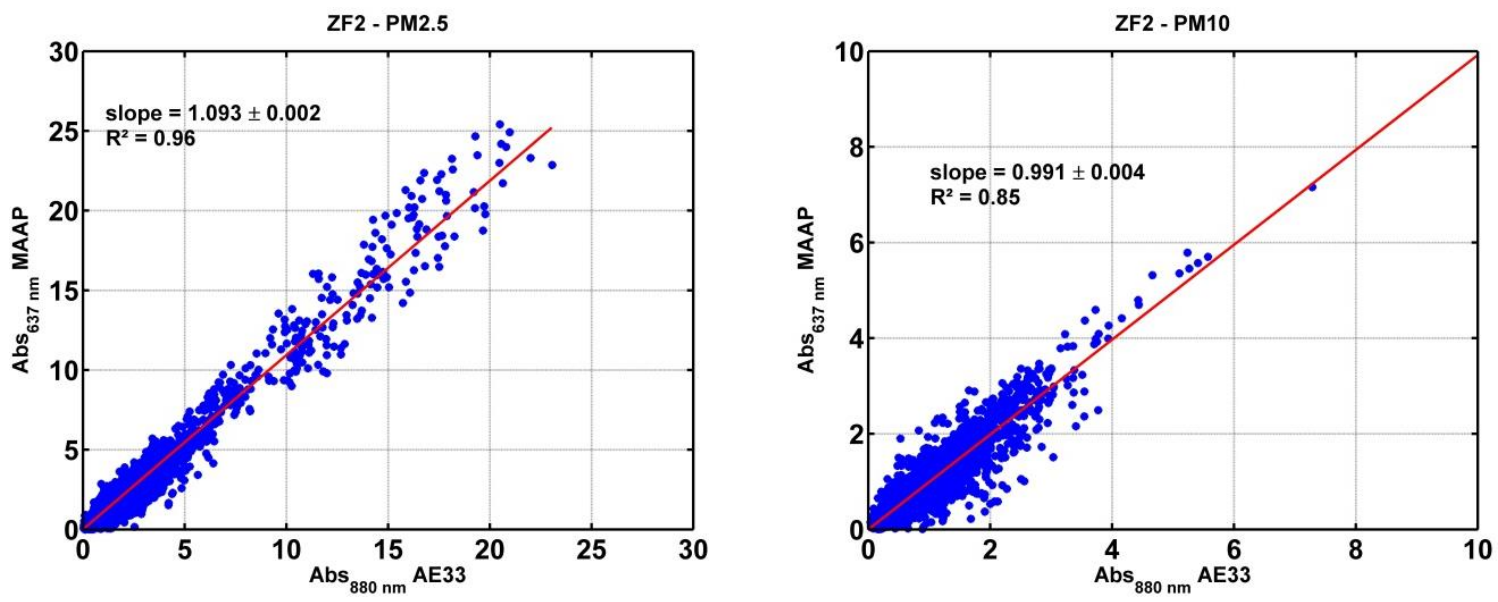

Por não haver uma uniformidade nos cortes de tamanho medidos durante todo o período de tempo no ATTO, no presente trabalho analisou-se somente a estação seca (agosto a novembro). Nesta estação, os coeficientes para os cortes de tamanho $\mathrm{PM}_{10}$ e $\mathrm{PM}_{2.5}$ apresentam alta correlação uma vez que a absorção se deve principalmente às partículas pertencentes à moda fina (HOLANDA, 2015; RIZZO et al., 2013). 
A Figura 36 mostra o histograma normalizado dos valores de albedo de espalhamento simples em 637 medido in situ no T0a e no T3 na estação seca em todos os anos de análise. No T0a, o valor médio medido foi de $0,86 \pm 0,04$. No T3, o valor médio do SSA foi de $0,85 \pm$ 0,06. Os valores dos dois sítios de medidas são indistinguíveis dentro das incertezas estatísticas. Sendo assim, não foi possível identificar influência da pluma urbana de Manaus vento abaixo da cidade a partir das medidas de SSA in situ. O sinal da pluma regional de queimadas, que afeta ambos os sítios experimentais, é muito mais forte do que a influência da pluma de Manaus para as medidas in situ durante a estação seca. E como colocado por CIRINO (2015), as causas adjacentes são complexas, principalmente devido à sensibilidade do SSA às variações na composição química das partículas e à dependência espectral estreita com os comprimentos de onda das medidas de absorção e espalhamento.

Figura 36 - Histograma normalizado dos valores de albedo de espalhamento simples (SSA) em 637 nm medidos in situ no ATTO (T0a) e em Manacapuru (T3) durante a estação seca em todos os anos de análise.

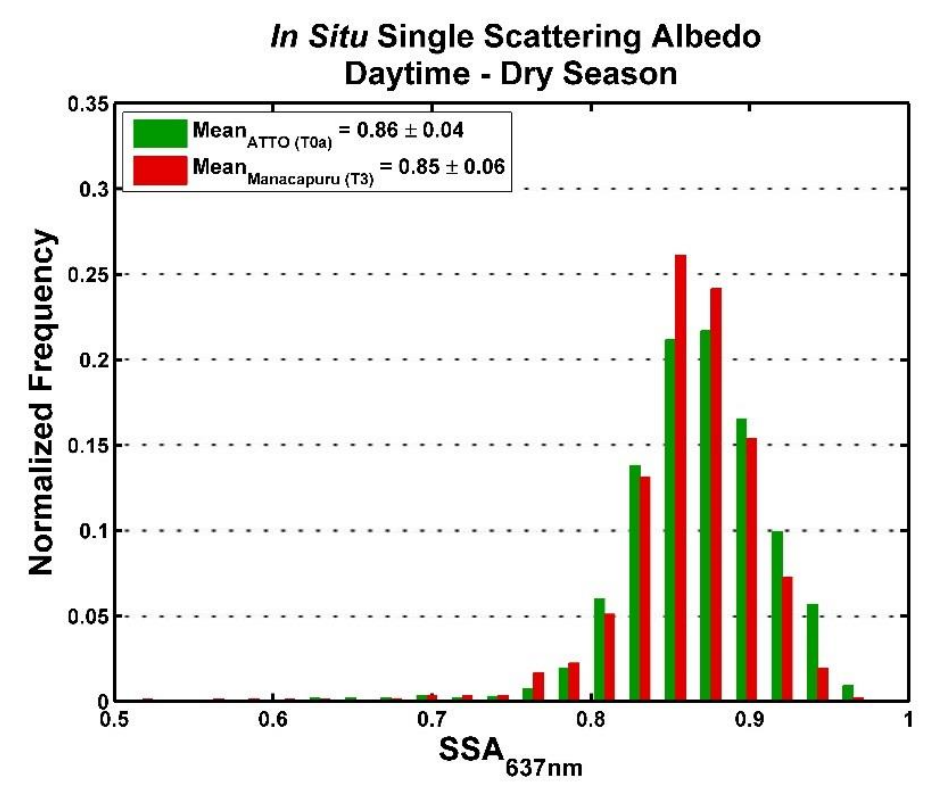

A fim de verificar se as medidas in situ do albedo de espalhamento simples são representativas das medidas integradas na coluna atmosférica, foi feita uma comparação entre as medidas in situ e as medidas obtidas a partir da rede AERONET. A Figura 37 mostra a série temporal para o SSA em $637 \mathrm{~nm}$ obtido a partir da rede AERONET e a partir de medidas in situ, entre os anos de 2012 e 2015, vento acima de Manaus. É importante ressaltar que a comparação foi feita entre as medidas in situ realizadas no ATTO (T0a) e as medidas realizadas pela rede AERONET no sítio da EMBRAPA. Tais sítios distam de aproximadamente $140 \mathrm{~km}$ e são representativos de uma região pouco impactada por emissões antrópicas. Foram consi- 
deradas apenas as medidas realizadas entre 10 e 22 horas no padrão UTC considerando que a rede AERONET só realiza medições no período do dia. Ainda que o pequeno número de medidas obtidas a partir da rede AERONET dificulte a visualização de um padrão sazonal, o que pode ser explicado por uma maior cobertura de nuvens na região, é possível comparar os valores médios do SSA na estação seca com uma estatística razoável. Assim sendo, o valor médio do SSA obtido a partir da rede AERONET foi de 0,95 $\pm 0,04$. O valor obtido a partir das medidas in situ foi de $0,87 \pm 0,04$. Esta diferença no SSA é significativa e está possivelmente relacionada ao limite inferior de 0,4 adotado pela AERONET para a obtenção dos valores da AOD e posterior cálculo do SSA. Como nas medidas in situ todos os valores de SSA, inclusive para baixos valores de AOD, são considerados, os valores de absorção do aerossol biogênico, que é intrinsicamente mais absorvedor que o aerossol de queimadas, também é levado em conta, o que resulta em um menor valor de SSA.

Figura 37 - Série temporal para o albedo de espalhamento simples (SSA) em $637 \mathrm{~nm}$ obtido a partir da rede AERONET (acima) e a partir de medidas in situ (abaixo) entre os anos de 2012 e 2015 vento acima de Manaus.
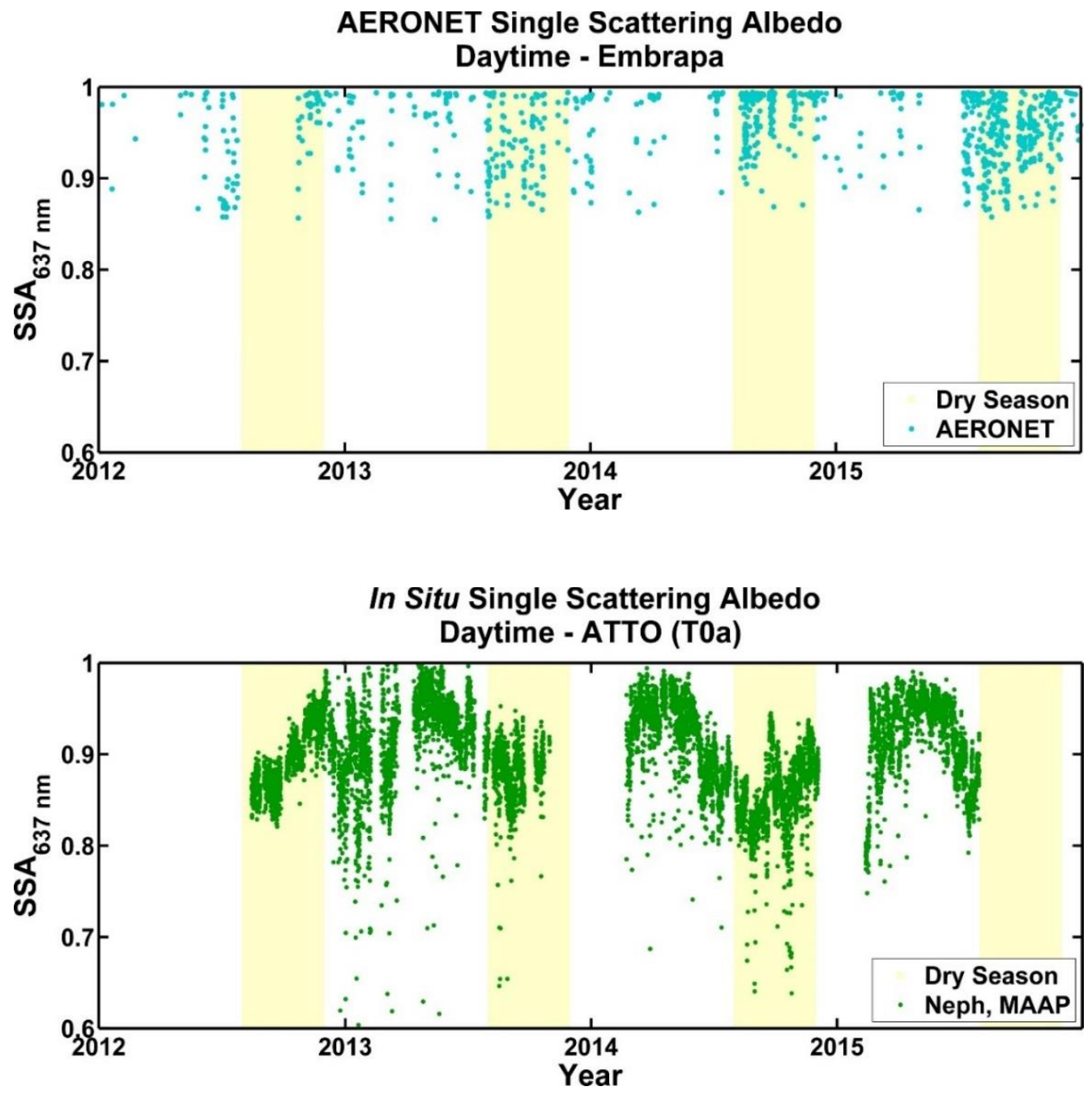
A Figura 38 mostra a série temporal para o SSA em $637 \mathrm{~nm}$ obtido a partir da rede AERONET e a partir de medidas in situ entre os anos de 2014 e 2015 vento abaixo de Manaus. Novamente, só foram consideradas apenas as medidas realizadas entre 10 e 22 horas no padrão UTC. Também neste sítio, o pequeno número de medidas obtidas a partir da rede AERONET dificulta a visualização de um padrão sazonal. Na estação seca, o valor médio do SSA obtido a partir da rede AERONET foi de 0,85 $\pm 0,07$ e o valor obtido a partir de medidas in situ foi de 0,87 $\pm 0,06$. Neste caso, é possível observar uma concordância entre o SSA medido in situ e o SSA integrado na coluna atmosférica. Nas medidas vento abaixo de Manaus, o impacto do aerossol biogênico é menor devido à absorção da pluma da cidade, com altos valores de BC, o que fez com que os valores de SSA estivessem de acordo. Um aumento de 25\% é previsto em condições de umidade relativa ambiente (RIZZO et al., 2013), já que as medidas in situ são tomadas em condições seca e a AERONET em condições ambientes.

Figura 38 - Série temporal para o albedo de espalhamento simples (SSA) em $637 \mathrm{~nm}$ obtido a partir da rede AERONET (acima) e a partir de medidas in situ (abaixo) entre os anos de 2014 e 2015 vento abaixo de Manaus.
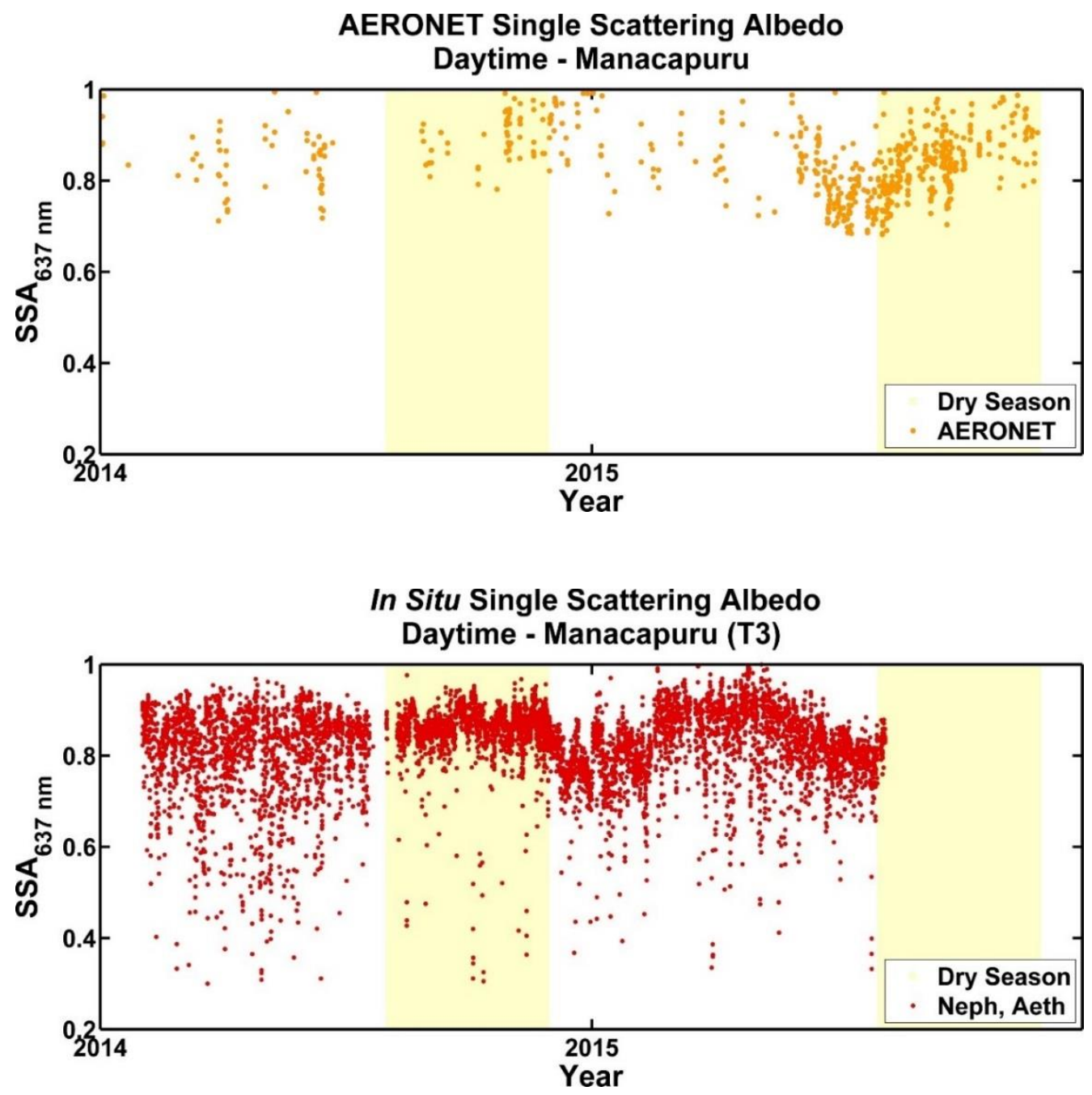


\subsection{INFLUÊNCIA DA PLUMA URBANA DE MANAUS SOBRE PROPRIEDADES DE} AEROSSOL E DE NUVENS MEDIDAS POR SENSORIAMENTO REMOTO A PARTIR DE SATÉLITES

Medidas por sensoriamento remoto a partir de satélites também foram analisadas buscando compreender os efeitos da pluma urbana de Manaus nas propriedades de aerossol e de nuvens. As médias mensais da profundidade óptica do aerossol, da temperatura e pressão do topo da nuvem e do raio efetivo de gotículas de nuvens foram obtidas com o auxílio do sistema de dados online NASA-Giovanni, como já mencionado na Seção 4.1.4. Todos os valores analisados correspondem a valores médios nas áreas selecionadas vento acima e vento abaixo de Manaus.

A Figura 39 mostra as médias anuais da profundidade óptica do aerossol em $550 \mathrm{~nm}$ derivada pelo sensor MODIS a bordo do satélite Terra na estação chuvosa e na estação seca. Na estação chuvosa, não foi possível observar qualquer diferença estatisticamente relevante entre as medidas de AOD nas duas áreas. Entretanto, era esperado que as maiores diferenças fossem observadas neste período, uma vez que o sinal das queimadas é menor e, por isso, o impacto da pluma urbana deveria ser mais evidente. Uma possível explicação seria a grande cobertura de nuvens na região, que impede a visualização da superfície terrestre. Na estação seca, as diferenças ficam um pouco mais claras, sobretudo entre anos de 2004 e 2010. A área vento abaixo de Manaus apresenta maior valor na AOD, o que indica maior carga de aerossol. 
Figura 39 - Médias anuais da profundidade óptica do aerossol em $550 \mathrm{~nm}$ medida pelo MODIS-Terra na estação chuvosa (acima) e na estação seca (abaixo) entre os anos de 2003 e 2015.
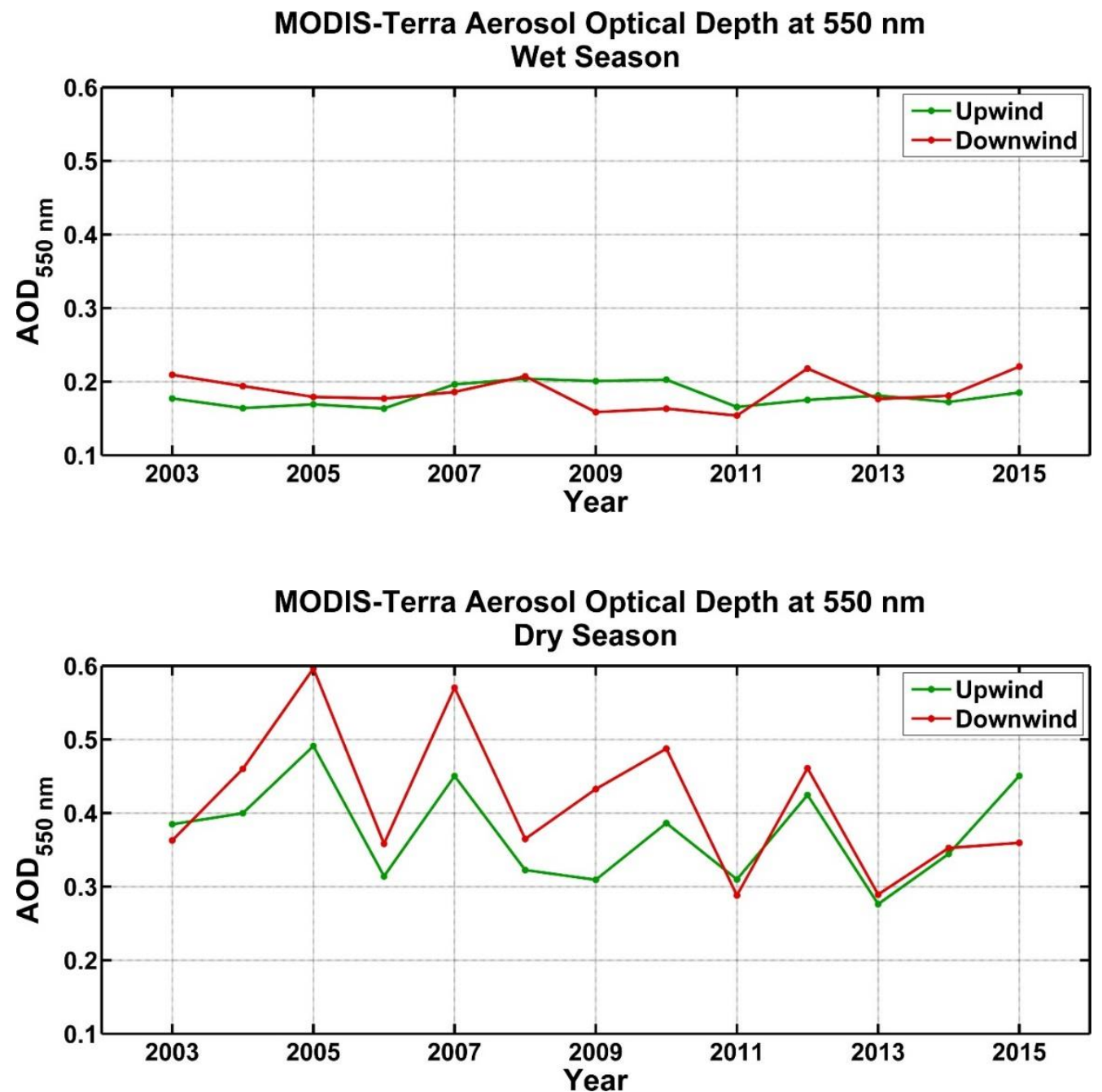

A Figura 40 mostra as médias anuais da profundidade óptica do aerossol em $550 \mathrm{~nm}$ derivada pelo sensor MODIS a bordo do satélite Aqua. Assim como para o satélite Terra, na estação chuvosa, não se observou qualquer diferença estatisticamente relevante entre as medidas de AOD nas duas áreas. Também na estação seca observou-se um comportamento semelhante, com valores de AOD maiores na área vento abaixo de Manaus. As diferenças foram mais evidentes entre os dois sítios de 2003 a 2009. 
Figura 40 - Médias anuais da profundidade óptica do aerossol (AOD) em $550 \mathrm{~nm}$ medida pelo MODIS-Aqua na estação chuvosa (acima) e na estação seca (abaixo) entre os anos de 2003 e 2015.

MODIS-Aqua Aerosol Optical Depth at $550 \mathrm{~nm}$

Wet Season

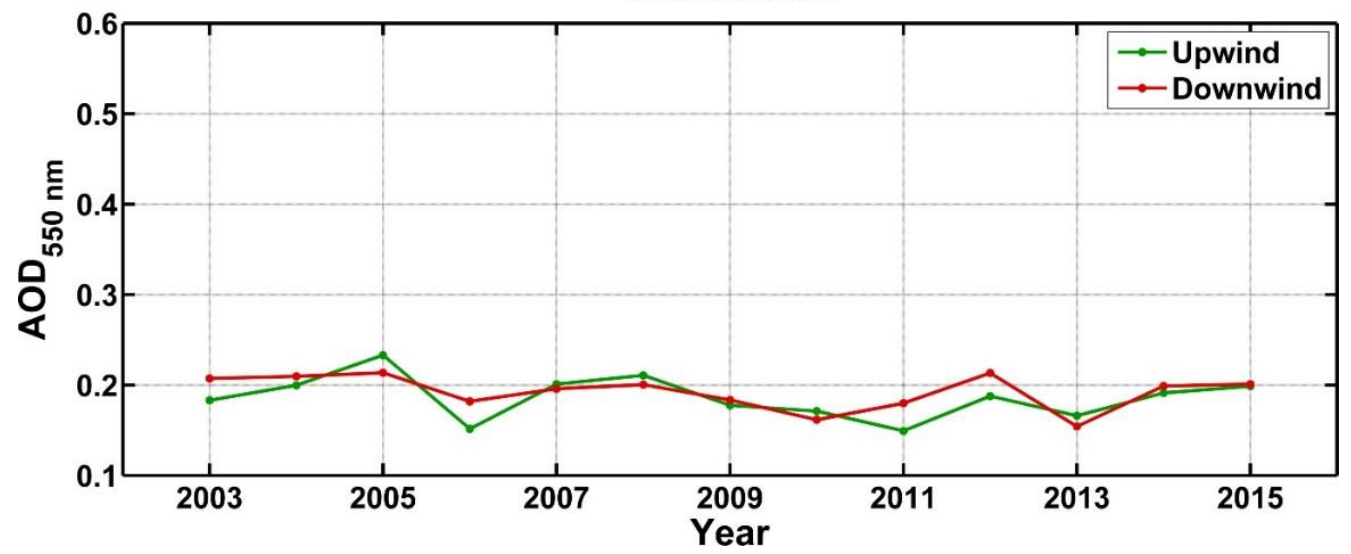

MODIS-Aqua Aerosol Optical Depth at 550 nm

Dry Season

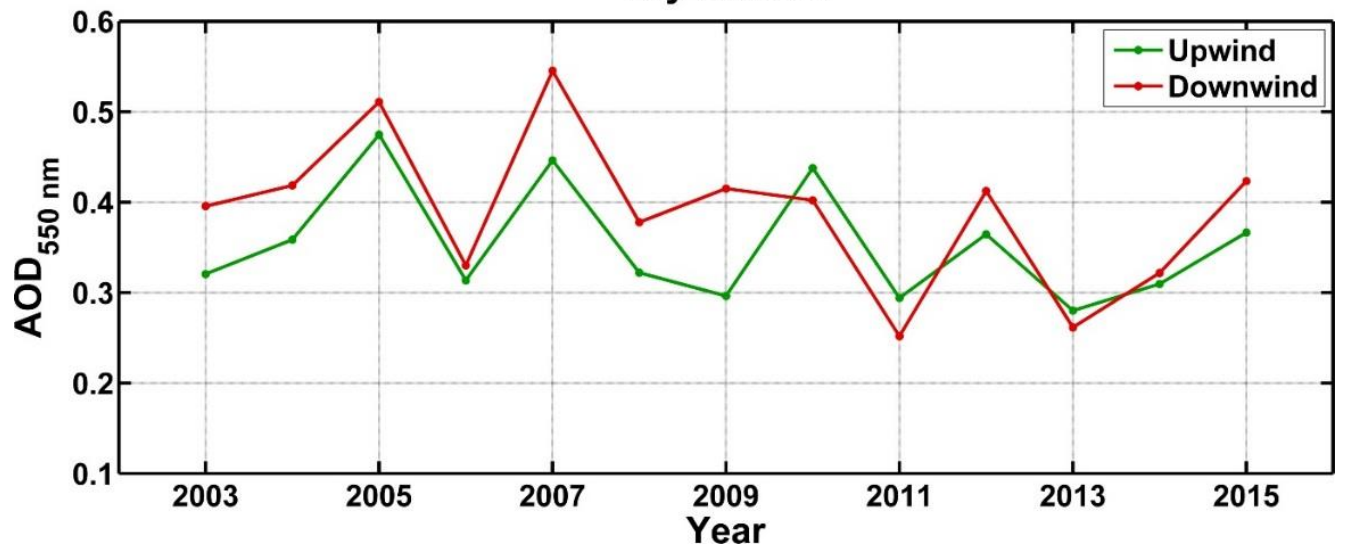

A profundidade óptica do aerossol em $555 \mathrm{~nm}$ derivada a partir do sensor MISR também foi analisada, contudo, não se observou diferença estatisticamente significativa entre as duas áreas em nenhuma das estações.

Outro produto derivado a partir do sensor MODIS é a temperatura do topo da nuvem (CTT, do inglês, Cloud Top Temperature). As médias anuais da CTT medidas pelos MODIS a bordo do satélite Terra podem ser vistas na Figura 41. Novamente, não foi possível observar diferenças entre os valores nas duas áreas durante a estação chuvosa. Na estação seca, as diferenças são mais perceptíveis e os menores valores de temperatura são observados na área vento abaixo de Manaus. Temperatura menor indica maior altura do topo da nuvem de conteúdo líquido, resultando em maior desenvolvimento vertical (DA ROCHA, 2011). Na área vento abaixo da cidade, devido a uma maior carga de aerossol, o número de NCN é maior, a disputa pelo vapor d'água disponível aumenta, as gotas crescem pouco e devagar enquanto a nuvem 
vai se desenvolvendo. Por outro lado, na área vento acima, ambiente com baixas concentrações de aerossol, há poucos NCN. Na disputa pelo vapor de água existente, se houver alguns NCN relativamente grandes ou solúveis em água, eles vão crescer rapidamente, colidir com os menores e cair como chuva. A nuvem não tem muito tempo para se desenvolver, chegando no máximo a alturas de 4 ou $5 \mathrm{~km}$ (ARTAXO et al., 2005). Na situação vento abaixo ocorre um aumento do tempo de vida médio das nuvens, com mais tempo para o desenvolvimento convectivo, resultando em nuvens mais altas.

Figura 41 - Médias anuais da temperatura do topo da nuvem medida pelo MODIS-Terra na estação chuvosa (acima) e na estação seca (abaixo).
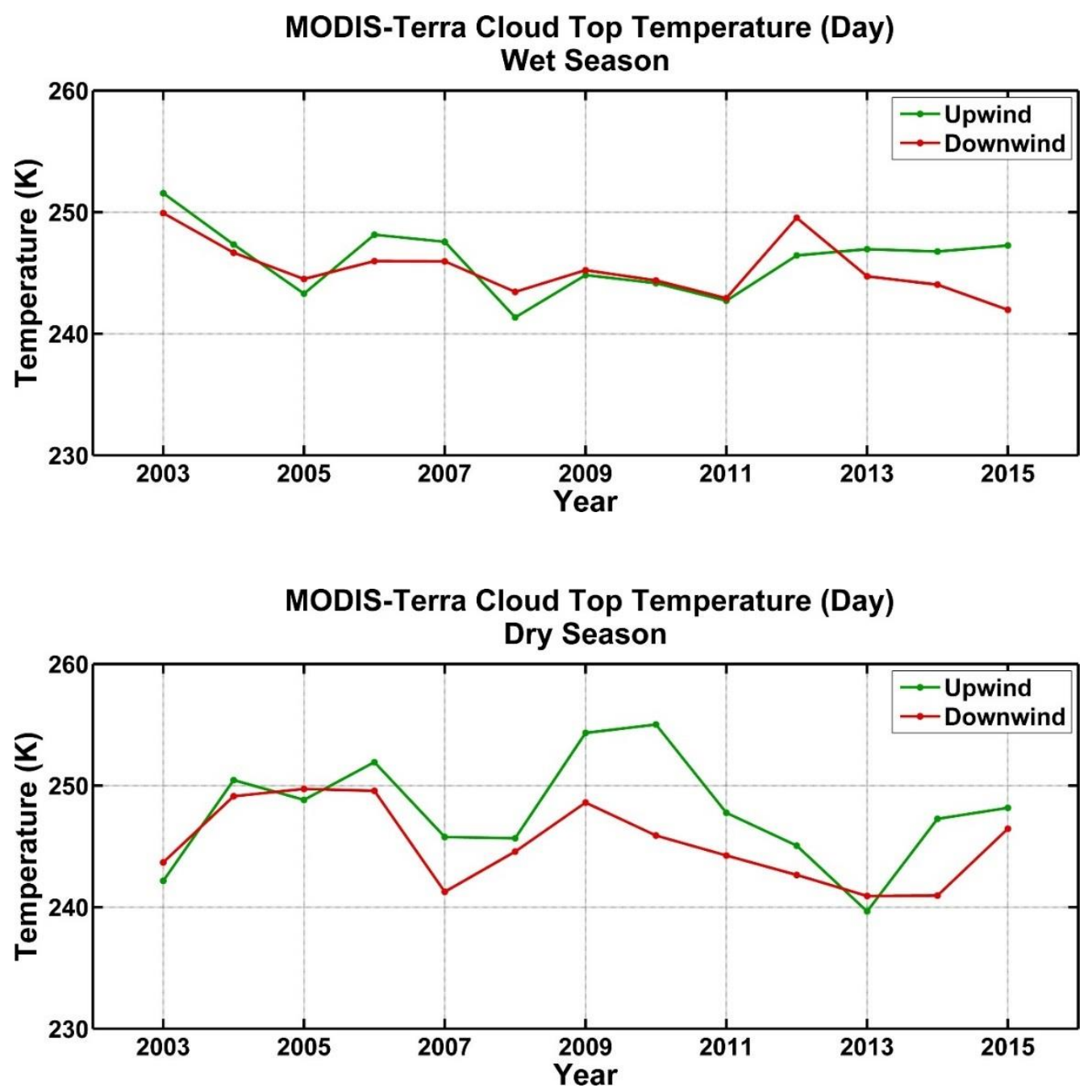

Análises semelhantes foram feitas para a temperatura do topo da nuvem derivada pelo sensor MODIS a bordo do satélite Aqua. A pressão do topo da nuvem também foi analisada. Para estas propriedades não foi possível observar nenhuma diferença dentro do desvio padrão nem na estação chuvosa nem na estação seca. 
$\mathrm{O}$ raio efetivo de gotículas de nuvem também foi analisado. A Figura 42 mostra as médias anuais do raio efetivo das gotículas de nuvem medido pelo sensor MODIS a bordo do satélite Aqua. Tanto na estação chuvosa quanto na estação seca foi possível observar diferenças estatisticamente relevantes entre as duas áreas, com maiores valores para a área vento acima da pluma, o que é consistente com o que foi dito anteriormente. Em ambientes com baixas concentrações de aerossol, as gotas crescem rapidamente, o raio efetivo é maior. Já em ambientes com uma carga maior de aerossol, as gotas crescem pouco, o raio efetivo é menor.

Figura 42 - Médias anuais do raio efetivo de gotículas de nuvem medido pelo MODIS-Aqua na estação chuvosa (acima) e na estação seca (abaixo).

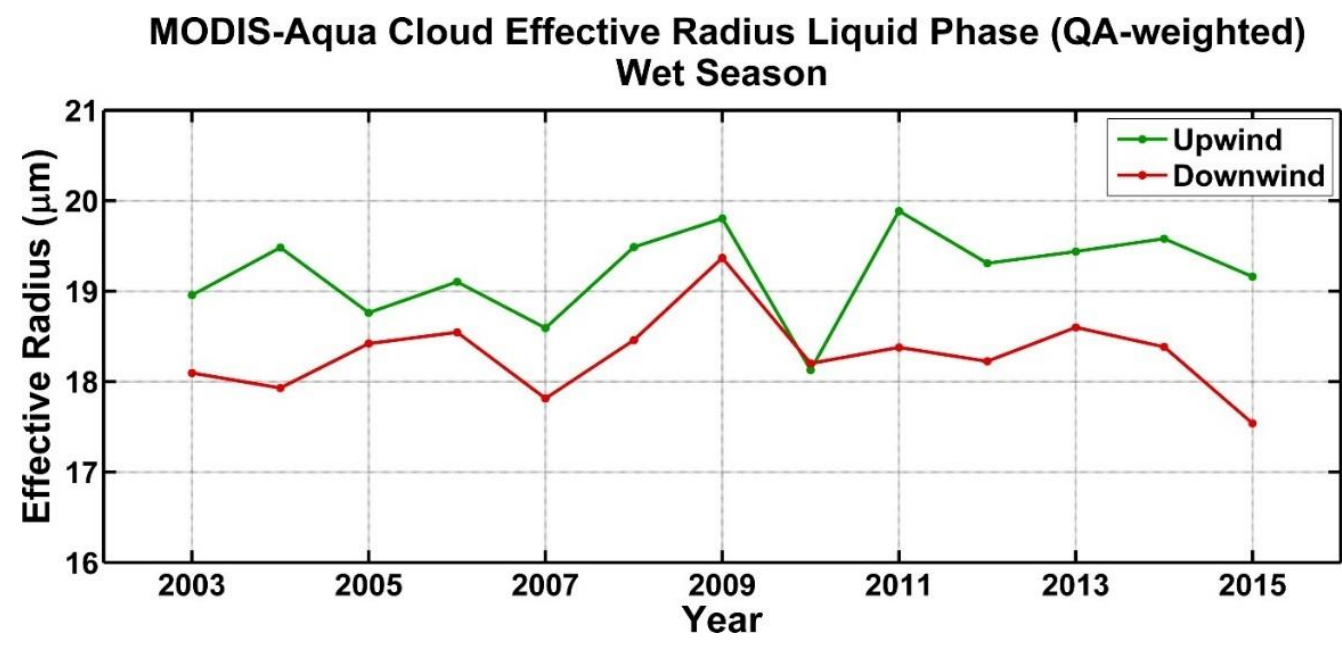

MODIS-Aqua Cloud Effective Radius Liquid Phase (QA-weighted) Dry Season

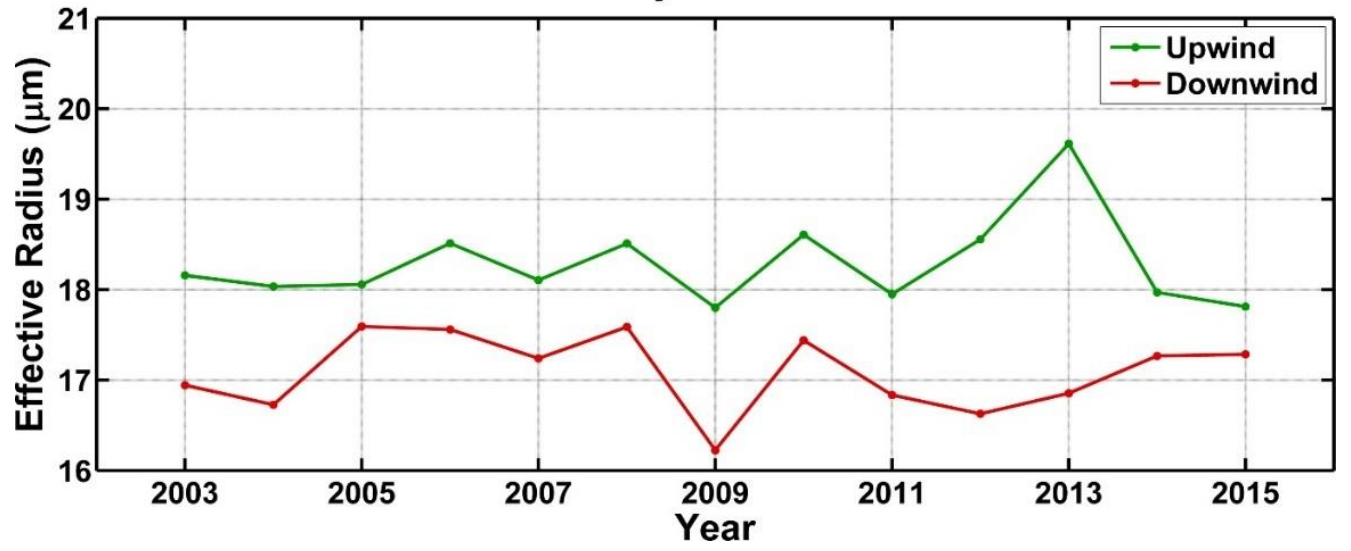

Uma forma de validar as medidas obtidas a partir do sensor MODIS é a comparação com medidas equivalentes obtidas a partir da rede AERONET. Para tal, foram utilizados os dados de nível 1.5 da AERONET medidos na EMBRAPA, localizada vento acima da pluma de Manaus, e Manacapuru, localizada vento abaixo da pluma. A Equação (20) foi utilizada para derivar a AOD em $550 \mathrm{~nm}$ a partir da rede AERONET e, posteriormente, médias men- 
sais foram calculadas incluindo somente valores para ângulo zenital solar entre 10 e $55^{\circ}$ (CIRINO et al., 2014). Além disso, foram combinadas as médias mensais obtidas a partir do sensor MODIS a bordo do satélite Aqua e do satélite Terra. A Figura 43 mostra a comparação entre as médias mensais da profundidade óptica do aerossol obtida a partir do sensor MODIS e a partir da rede AERONET. Observa-se uma boa concordância entre os valores. Entretanto, nesta análise, as medidas do MODIS são superestimadas em relação à AERONET. É importante ressaltar que as medidas da AERONET foram feitas em 2014 e 2015, enquanto que as medidas utilizando o MODIS foram feitas ao longo de vários anos, de 2003 a 2015. Mudanças na estrutura de fontes de Manaus ocorreram ao longo destes 12 anos.

Figura 43 - Comparação entre as medidas da profundidade óptica do aerossol (AOD) em 550 nm obtidas a partir do sensor MODIS e a partir de interpolação dos valores obtidos pela rede AERONET vento acima (esquerda) e vento abaixo (direita) de Manaus.
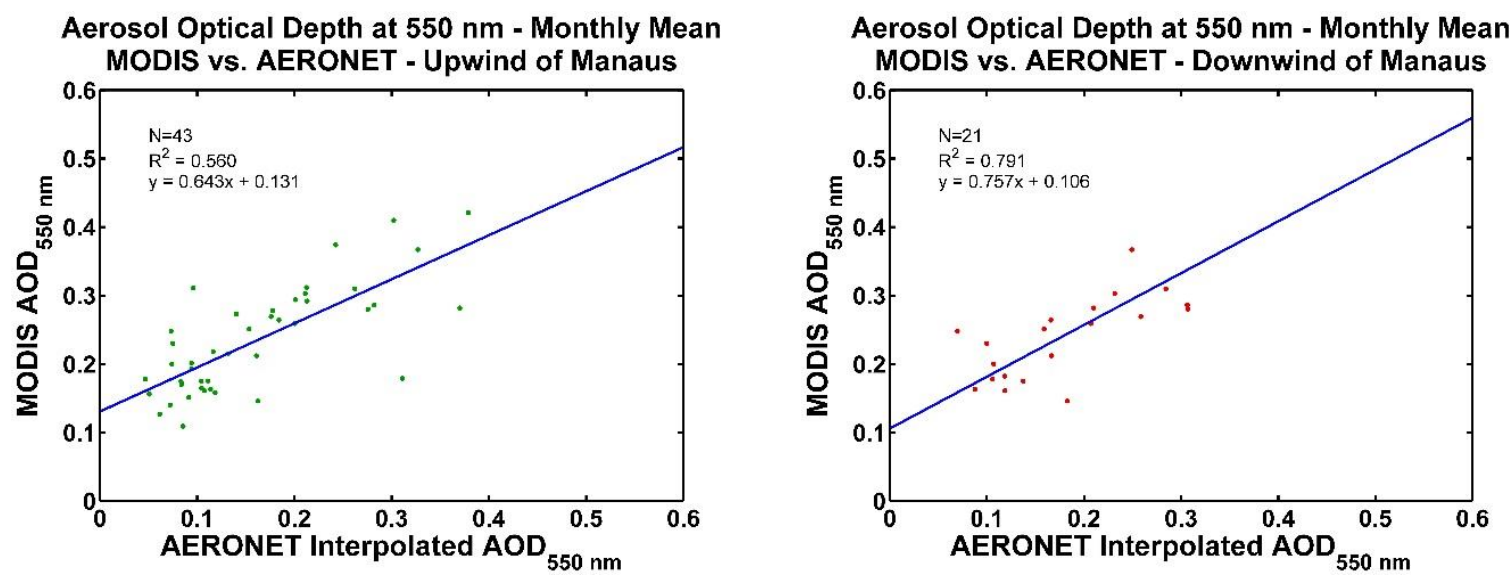


\section{CONCLUSÕES}

O presente trabalho procurou entender a influência de atividades antrópicas, tais como queimadas e emissões urbanas, nas propriedades de aerossol em diferentes regiões da Amazônia. Para tal, medidas contínuas realizadas pela rede AERONET ao longo de mais de 15 anos foram analisadas. Todos os sítios estudados apresentaram forte sazonalidade nas medidas da profundidade óptica do aerossol, com baixas concentrações de partículas durante a estação chuvosa em todas as regiões. Nos sítios localizados no arco do desflorestamento, durante a estação seca, observou-se um aumento na concentração de partículas associado às emissões de queimadas na região. A região do Cerrado também apresentou grande carga de aerossol, sendo afetada tanto pela queima de savana regional quanto pelo aerossol "envelhecido" oriundo da queima de floresta. Nos sítios localizados no Norte da Amazônia, a presença de aerossol de queimadas se dá por transporte de modo que a região é menos impactada por emissões de queima de biomassa. Durante o período de queimadas, notou-se um aumento significativo no volume de partículas pertencentes à moda fina principalmente nos sítios localizados no arco do desflorestamento. É importante considerar que o volume de partículas na moda fina também pode ser atribuído ao aerossol orgânico secundário formado a partir da oxidação dos COVs emitidos pela vegetação, e não somente pelas emissões de queimadas. O volume de partículas da moda grossa não sofreu grandes alterações da estação chuvosa para a estação seca, indicando que as condições meteorológicas não afetam muito a componente do aerossol biogênico primário.

O método descrito por CAZORLA (2013) envolvendo a dependência espectral da absorção e espalhamento permitiu separar os diferentes tipos de aerossol absorvedor de forma relativamente clara. Além disso, a partir desta análise foi possível avaliar o impacto de cada tipo de aerossol na forçante radiativa. As medidas classificadas como OC apresentaram forçantes mais negativas, indicando que o OC é um componente altamente espalhador e provoca um efeito de resfriamento. Foi observado também que o OC é a fração dominante da estação seca apesar do aumento da concentração de partículas absorvedoras provenientes da emissão de queimadas. Os valores mais positivos da forçante foram associados ao EC e às partículas biogênicas, que são também partículas absorvedoras.

No âmbito do experimento GoAmazon2014/5, foram analisadas propriedades de absorção e espalhamento medidas por sensoriamento remoto e in situ buscando entender como as propriedades de aerossol são influenciadas pelas emissões urbanas de Manaus. A partir das 
medidas derivadas pela rede AERONET foi possível observar uma diferença na absorção vento acima e vento abaixo de Manaus, diferença esta que pode ser atribuída sobretudo à pluma de poluição da cidade e a outras emissões locais, tais como as emissões oriundas das olarias localizadas da região. Foi possível também quantificar o impacto da pluma urbana proveniente de Manaus a partir da forçante radiativa direta do aerossol. Na estação chuvosa, os valores mais positivos foram observados vento acima de Manaus, indicando a presença de black carbon, que é um aerossol altamente absorvedor, oriundo da pluma urbana. Na estação seca, os valores foram mais negativos do que aqueles encontrados na estação chuvosa, ou seja, observou-se um efeito maior de resfriamento, que está associado à forte influência do OC.

Com base nas medidas in situ, não foi possível observar uma diferença estatisticamente relevante no albedo de espalhamento simples vento acima e vento abaixo de Manaus. Isto se deve à sensibilidade do SSA às variações na composição química das partículas e à dependência espectral estreita com os comprimentos de onda das medidas de absorção e espalhamento. Buscando verificar se as medidas in situ do SSA são representativas das medidas integradas da coluna atmosférica, foi feita uma comparação entre as medidas in situ e as medidas obtidas a partir da rede AERONET. Apenas para o sítio vento abaixo, Manacapuru, foi possível observar uma concordância entre os valores.

Ainda com o objetivo de entender como as propriedades de aerossol e de nuvens são influenciadas pelas emissões urbanas de Manaus, medidas por sensoriamento remoto a partir de satélites foram analisadas. A partir da análise da profundidade óptica do aerossol obtida a partir do sensor MODIS a bordo dos satélites Aqua e Terra, foi possível observar uma maior carga de aerossol vento abaixo de Manaus durante a estação seca. A análise da temperatura do topo da nuvem e do raio efetivo de gotículas de nuvem mostrou que, na área vento abaixo da cidade, devido a uma maior carga de aerossol, o maior número de NCN contribui para um raio efetivo menor das gotas e em nuvens mais desenvolvidas verticalmente. O contrário acontece em regiões com concentrações relativamente baixas de partículas, como a área vento acima. Uma validação das medidas de AOD obtidas pelo MODIS tendo como referência as medidas da AERONET foi realizada e foi possível observar correlação entre os valores, embora os valores das médias mensais da AOD do MODIS sejam, neste trabalho, superestimados em relação aos da AERONET. A alta taxa de cobertura afeta sobremaneira a estatística de medidas na Amazônia. O baixo valor de AOD e a baixa carga de partículas também trazem dificuldades significativas para aplicação destas técnicas na região da Amazônia. Apesar das limitações na resolução temporal e espacial no sistema NASA-Giovanni, as análises foram 
bastante satisfatórias e apresentaram resultados coerentes. Entretanto, uma análise a partir de medidas individuais do MODIS se faz necessária, sobretudo na estação chuvosa, quando a cobertura de nuvens na região é maior.

A análise de medidas in situ em paralelo com medidas de sensoriamento remoto em solo e por satélites realizada neste trabalho mostrou correlação independente da técnica utilizada, o que é importante para a validação das medidas e mostra a robustez das diferentes técnicas. 



\section{REFERÊNCIAS BIBLIOGRÁFICAS}

ACKER, J. et al. Use of the NASA Giovanni Data System for Geospatial Public Health Research: Example of Weather-Influenza Connection. ISPRS International Journal of GeoInformation, v. 3, n. 4, p. 1372-1386, 2014.

ANDREAE, M. O. et al. Smoking rain clouds over the Amazon. Science, v. 303, n. 5662, p. 1337-1342, 2004.

ANDREAE, M. O. et al. The Amazon Tall Tower Observatory (ATTO): overview of pilot measurements on ecosystem ecology, meteorology, trace gases, and aerosols. Atmospheric Chemistry and Physics, v. 15, n. 18, p. 10723-10776, 2015.

ANDREAE, M. O.; JONES, C. D.; COX, P. M. Strong present-day aerosol cooling implies a hot future. Nature, v. 435, n. 7046, p. 1187-1190, 2005.

ANDREWS, D. G. An Introduction to Atmospheric Physics. 2nd ed. Cambridge University Press, 2010.

ARANA, A. A. Aerossóis atmosféricos na Amazônia: composição orgânica e inorgânica em regiões com diferentes usos do solo. Universidade do Estado do Amazonas, 2014.

ARTAXO, P. et al. Large-scale aerosol source apportionment in Amazonia. Journal of Geophysical Research, v. 103, n. D24, p. 31837, 1998.

ARTAXO, P. Physical and chemical properties of aerosols in the wet and dry seasons in Rondônia, Amazonia. Journal of Geophysical Research, v. 107, n. D20, p. 8081, 2002.

ARTAXO, P. et al. Química atmosférica na Amazônia: a floresta e as emissões de queimadas controlando a composição da atmosfera amazônica. Acta Amazonica, v. 35, n. 2, p. 185-196, 2005.

ARTAXO, P. et al. Efeitos Climáticos De Partículas De Aerossóis Biogênicos E Emitidos Em Queimadas Na Amazônia. Revista Brasileira de Meteorologia, p. 168-189, 2006.

ARTAXO, P. et al. Partículas de Aerossóis na Amazônia: Composição, Papel no Balanço de Radiação, Formação de Nuvem e Ciclos de Nutrientes, 2009.

ARTAXO, P. et al. Atmospheric aerosols in Amazonia and land use change: from natural biogenic to biomass burning conditions. Faraday Discussions, v. 165, p. 203, 2013.

ARTAXO, P. et al. Interactions between urban and forest emissions in Manaus, Amazonia: The Brazilian component of GoAmazon. 2014.

ARTAXO, P.; SILVA DIAS, M. A. F.; ANDREAE, M. O. O mecanismo da floresta para fazer chover. Scientific American Brasil, p. 38-45, 2003. 
BAARS, H. et al. Further evidence for significant smoke transport from Africa to Amazonia. Geophysical Research Letters, v. 38, n. 20, 2011.

BARBOSA, H. M. J. et al. A permanent Raman lidar station in the Amazon: description, characterization, and first results. Atmospheric Measurement Techniques, v. 7, n. 6, p. 1745-1762, 2014.

BIBI, H. et al. Intercomparison of MODIS, MISR, OMI, and CALIPSO aerosol optical depth retrievals for four locations on the Indo-Gangetic plains and validation against AERONET data. Atmospheric Environment, v. 111, p. 113-126, 2015.

BOND, T. C. et al. Bounding the role of black carbon in the climate system: A scientific assessment. Journal of Geophysical Research: Atmospheres, v. 118, n. 11, p. 5380-5552, 2013.

BOUCHER, O. et al. Clouds and Aerosols. In: INTERGOVERNMENTAL PANEL ON CLIMATE CHANGE. . Climate Change 2013 - The Physical Science Basis. Cambridge University Press, 2013. p. 571-658, 2013.

BRITO, J. et al. Ground-based aerosol characterization during the South American Biomass Burning Analysis (SAMBBA) field experiment. Atmospheric Chemistry and Physics, v. 14, n. 22, p. 12069-12083, 2014.

CALVELLO, M. et al. Physical and optical properties of atmospheric aerosols by in-situ and radiometric measurements. Atmospheric Chemistry and Physics, v. 10, n. 5, p. 2195-2208, 2010.

CARVALHO, D. L. R.; SOARES, C. B. S. DA S.; DA SILVA, M. M. Identificação de Ilhas de Calor Urbana na Cidade de Manaus-AM. XVI Simposio Brasileiro de Sensoriamento Remoto, 2013

CASTANHO, A. D. DE A. Propriedades ópticas das partículas de aerossol e uma nova metodologia para a obtenção de espessura óptica via satélite sobre São Paulo.

Universidade de São Paulo, 2005.

CAZORLA, A. et al. Relating aerosol absorption due to soot, organic carbon, and dust to emission sources determined from in-situ chemical measurements. Atmospheric Chemistry and Physics, v. 13, n. 18, p. 9337-9350, 2013.

CIRINO, G. G. et al. The effect of atmospheric aerosol particles and clouds on net ecosystem exchange in the Amazon. Atmospheric Chemistry and Physics, v. 14, n. 13, p. 6523-6543, 2014.

CIRINO, G. G. Caracterização físico-química de aerossóis no experimento GOAMAZON2014/15: A interação entre emissões urbanas de Manaus com emissões naturais da floresta. Universidade do Estado do Amazonas, 2015.

CORREIA, A. et al. Forçante radiativa natural e antrópica. Primeiro Relatório De Avaliação Nacional Volume 1 - Bases Científicas Das Mudanças Climáticas, p. 139-160, 2012. 
DA ROCHA, V. R. Análise de propriedades de nuvens em função da profundidade óptica do aerossol a partir de produtos derivados pelo MODIS na região Amazônica durante a estação seca. Universidade de São Paulo, 2011.

DAVIDSON, E. A. et al. The Amazon basin in transition. Nature, v. 481, n. 7381, p. 321$328,2012$.

DE LUCCA, S. Sensoriamento remoto de aerossóis em alta resolução espacial na região amazônica. Universidade de São Paulo, 2009.

DE SOUZA, D. O.; DOS SANTOS ALVALÁ, R. C. Observational evidence of the urban heat island of Manaus City, Brazil. Meteorological Applications, v. 21, n. 2, p. 186-193, 2014.

DENATRAN. Frota de veículos. Disponível em:

<http://www.denatran.gov.br/frota2016.htm>. Acesso em: 17 maio. 2016.

DINER, D. J. et al. Multi-angle Imaging SpectroRadiometer (MISR) instrument description and experiment overview. IEEE Transactions on Geoscience and Remote Sensing, v. 36, n. 4, p. 1072-1087, 1998.

DRINOVEC, L. et al. The "dual-spot" Aethalometer: an improved measurement of aerosol black carbon with real-time loading compensation. Atmospheric Measurement Techniques, v. 8, n. 5, p. 1965-1979, 2015.

DUBOVIK, O. et al. Accuracy assessments of aerosol optical properties retrieved from Aerosol Robotic Network (AERONET) Sun and sky radiance measurements. Journal of Geophysical Research: Atmospheres, v. 105, n. D8, p. 9791-9806, 2000.

DUBOVIK, O. et al. Variability of Absorption and Optical Properties of Key Aerosol Types Observed in Worldwide Locations. Journal of the Atmospheric Sciences, v. 59, n. 3, p. 590-608, 2002a.

DUBOVIK, O. et al. Non-spherical aerosol retrieval method employing light scattering by spheroids. Geophysical Research Letters, v. 29, n. 10, 2002 b.

DUBOVIK, O. et al. Application of spheroid models to account for aerosol particle nonsphericity in remote sensing of desert dust. Journal of Geophysical Research, v. 111, n. D11, 2006.

DUBOVIK, O.; KING, M. D. A flexible inversion algorithm for retrieval of aerosol optical properties from Sun and sky radiance measurements. Journal of Geophysical Research: Atmospheres, v. 105, n. D16, p. 20673-20696, 2000.

\section{EARTH SYSTEM RESEARCH LABORATORY. Three Wavelength Integrating}

Nephelometer. Disponível em:

<http://www.esrl.noaa.gov/gmd/aero/instrumentation/neph_desc.html>. Acesso em: 26 abr. 2016. 
ECK, T. F. et al. Wavelength dependence of the optical depth of biomass burning, urban, and desert dust aerosols. Journal of Geophysical Research: Atmospheres, v. 104, n. D24, p. 31333-31349, 1999.

FEARNSIDE, P. M. Desmatamento na Amazônia brasileira: história, índices e consequiências. Megadiversidade, v. 1, n. 1, p. 113 - 123, 2005.

FORSTER, P. et al. Changes in Atmospheric Constituents and in Radiative Forcing. Climate Change 2007. The Physical Science Basis, p. 129-234, 2007.

GARCÍA, O. E. et al. Shortwave radiative forcing and efficiency of key aerosol types using AERONET data. Atmospheric Chemistry and Physics, v. 12, n. 11, p. 5129-5145, 2012.

GODDARD SPACE FLIGHT CENTER. AERONET Site Information. Disponível em: <http://aeronet.gsfc.nasa.gov/cgi-bin/site_info>. Acesso em: 18 maio. 2016.

HOLANDA, B. A. Absorção da Radiação por Aerossóis na Amazônia. Universidade de São Paulo, 2015.

HOLBEN, B. N. et al. An emerging ground-based aerosol climatology: Aerosol optical depth from AERONET. Journal of Geophysical Research: Atmospheres, v. 106, n. D11, p. 12067-12097, 2001.

HOLBEN, B. N. et al. AERONET's Version 2.0 quality assurance criteria. Remote Sensing of Atmosphere and Clouds, 2006.

HYVÄRINEN, A.-P. et al. Correction for a measurement artifact of the Multi-Angle Absorption Photometer (MAAP) at high black carbon mass concentration levels.

Atmospheric Measurement Techniques, v. 6, n. 1, p. 81-90, 2013.

IBGE. Cidades. Disponível em:

$<$ http://www.cidades.ibge.gov.br/xtras/perfil.php?lang=\&codmun=130260\&search=amazonas |manaus>. Acesso em: 17 maio. 2016.

IMAZON. Mapas da Amazônia Legal. Disponível em: < http://imazon.org.br/categoriasmapas/amazonia-legal/>. Acesso em: 10 maio. 2016.

INPE. Projeto PRODES. Disponível em: <http://www.obt.inpe.br/prodes/index.php>. Acesso em: 15 maio. 2016a.

INPE. Monitoramento de Queimadas e Incêndios. Disponível em: <http://www.inpe.br/queimadas/>. Acesso em: 16 maio. $2016 \mathrm{~b}$.

IPCC. Climate CHANGE 2013: The Physical Science Basis. 2013.

JUSTICE, C. O. et al. An overview of MODIS Land data processing and product status.

Remote Sensing of Environment, v. 83, n. 1-2, p. 3-15, 2002. 
KAUFMAN, Y. J. et al. Operational remote sensing of tropospheric aerosol over land from EOS moderate resolution imaging spectroradiometer. Journal of Geophysical Research: Atmospheres, v. 102, n. D14, p. 17051-17067, 1997.

KING, M. D. et al. Remote sensing of cloud, aerosol, and water vapor properties from the moderate resolution imaging spectrometer (MODIS). IEEE Transactions on Geoscience and Remote Sensing, v. 30, n. 1, p. 2-27, 1992.

KING, M. D. et al. Remote Sensing of Tropospheric Aerosols from Space: Past, Present, and Future. Bulletin of the American Meteorological Society, v. 80, n. 11, p. 2229-2259, 1999.

KING, M. D. et al. Cloud and aerosol properties, precipitable water, and profiles of temperature and water vapor from MODIS. IEEE Transactions on Geoscience and Remote Sensing, v. 41, n. 2, p. 442-458, 2003.

KOGAN, F.; POWELL, A.; FEDOROV, O. Use of Satellite and In-Situ Data to Improve Sustainability. 1st ed. Dordrecht: Springer Netherlands, 2011.

LIOU, K. N. An Introduction to Atmospheric Radiation. 2nd ed. Academic Press, 2002.

MARTIN, S. T. et al. Sources and properties of Amazonian aerosol particles. Reviews of Geophysics, v. 48, n. 2, 2010.

MARTIN, S. T. et al. Introduction: Observations and Modeling of the Green Ocean Amazon (GoAmazon2014/5). Atmospheric Chemistry and Physics Discussions, v. 15, n. 21, p. 30175-30210, 2015.

MARTINSSON, J. Using the Aethalometer for Source Apportionment of Carbonaceous Aerosols. v. 6, p. 1-10, 2013.

MAYOL-BRACERO, O. L. Water-soluble organic compounds in biomass burning aerosols over Amazonia 2. Apportionment of the chemical composition and importance of the polyacidic fraction. Journal of Geophysical Research, v. 107, n. D20, p. 8091, 2002.

MINISTÉRIO DO MEIO AMBIENTE. Inpe Monitora Amazônia. Disponível em: <http://www.mma.gov.br/florestas/controle-e-prevenção-do-desmatamento/inpe-monitoraamazônia>. Acesso em: 5 maio. 2016.

MOREIRA, M. A. Fundamentos do Sensoriamento Remoto e Metodologias de Aplicação. $3^{\mathrm{a}}$ ed. 2007.

MÜLLER, T. et al. Characterization and intercomparison of aerosol absorption photometers: result of two intercomparison workshops. Atmospheric Measurement Techniques, v. 4, n. 2, p. 245-268, 2011.

MYHRE, G. et al. Anthropogenic and Natural Radiative Forcing. In: INTERGOVERNMENTAL PANEL ON CLIMATE CHANGE. . Climate Change 2013 The Physical Science Basis. Cambridge University Press, 2013. p. 659-740. 
NASA SPACE PLACE. The many-eyed Earth watcher. Disponível em:

$<$ http://spaceplace.nasa.gov/misr-xword/en/>. Acesso em: 1 maio. 2016.

NEPSTAD, D. et al. Slowing Amazon deforestation through public policy and interventions in beef and soy supply chains. Science, v. 344, n. 6188, p. 1118-1123, 2014.

NÖLSCHER, A. C. et al. Unexpected seasonality in quantity and composition of Amazon rainforest air reactivity. Nature Communications, v. 7, p. 10383, 2016.

PAIXÃO, M. A. Propriedades ópticas de aerossóis naturais e de queimadas da Amazônia. Universidade de São Paulo, 2011.

PAULIQUEVIS, T. et al. O Papel Das Partículas De Aerossol No Funcionamento Do Ecossistema Amazônico. Cienc. Cult., v. 59, n. 3, p. 48-50, 2007.

PETZOLD, A. et al. Evaluation of Multiangle Absorption Photometry for Measuring Aerosol Light Absorption. Aerosol Science and Technology, v. 39, n. 1, p. 40-51, 2005.

PETZOLD, A. et al. Recommendations for reporting "black carbon" measurements. Atmospheric Chemistry and Physics, v. 13, n. 16, p. 8365-8379, 2013.

PETZOLD, A.; SCHÖNLINNER, M. Multi-angle absorption photometry-a new method for the measurement of aerosol light absorption and atmospheric black carbon. Journal of Aerosol Science, v. 35, n. 4, p. 421-441, 2004.

PROCÓPIO, A. S. Forçante radiativa direta dos aerossóis na Região Amazônica devido à queima de biomassa. Universidade de São Paulo, 2005.

RAES, F. et al. Formation and cycling of aerosols in the global troposphere. Atmospheric Environment, v. 34, n. 25, p. 4215-4240, 2000.

RAMANATHAN, V. Aerosols, Climate, and the Hydrological Cycle. Science, v. 294, n. 5549, p. 2119-2124, 2001.

REDDINGTON, C. L. et al. Air quality and human health improvements from reductions in deforestation-related fire in Brazil. v. 8, 2015.

REMER, L. A. et al. The MODIS Aerosol Algorithm, Products, and Validation. Journal Of The Atmospheric Sciences, v. 62, p. 947-973, 2005.

RIZZO, L. V. Os fluxos turbulentos de partículas e de compostos orgânicos voláteis, e a distribuição vertical de aerossóis na baixa troposfera da Amazônia. Universidade de São Paulo, 2006.

RIZZO, L. V. et al. Spectral dependence of aerosol light absorption over the Amazon Basin. Atmospheric Chemistry and Physics, v. 11, n. 17, p. 8899-8912, 2011. 
RIZZO, L. V. et al. Long term measurements of aerosol optical properties at a pristine forest site in Amazonia. Atmospheric Chemistry and Physics Discussions, v. 12, n. 9, p. 2333323401, 2013.

RUSSELL, P. B. et al. Absorption Angstrom Exponent in AERONET and related data as an indicator of aerosol composition. Atmospheric Chemistry and Physics Discussions, v. 9, n. 5, p. 21785-21817, 2010.

SCHAAP, M. et al. Exploring the relation between aerosol optical depth and PM2.5 at Cabauw, the Netherlands. Atmospheric Chemistry and Physics Discussions, v. 8, n. 5, p. 17939-17986, 2009.

SCHAFER, J. S. Atmospheric effects on insolation in the Brazilian Amazon: Observed modification of solar radiation by clouds and smoke and derived single scattering albedo of fire aerosols. Journal of Geophysical Research, v. 107, n. D20, p. 8074, 2002.

SCHAFER, J. S. et al. Characterization of the optical properties of atmospheric aerosols in Amazônia from long-term AERONET monitoring (1993-1995 and 1999-2006). Journal of Geophysical Research, v. 113, n. D4, p. 1-16, 2008.

SCHMID, O. et al. Spectral light absorption by ambient aerosols influenced by biomass burning in the Amazon Basin - I. Comparison and field calibration of absorption measurement techniques. Atmospheric Chemistry and Physics Discussions, v. 5, n. 5, p. 9355-9404, 2006.

SEINFELD, J. H.; PANDIS, S. N. Atmospheric Chemistry and Physics: From Air Pollution to Climate Change. 2nd ed. John Wiley \& Sons, Inc., 2006.

SEINFELD, J. H.; PANDIS, S. N. Atmospheric Chemistry and Physics: From Air Pollution to Climate Change. 3rd ed. John Wiley \& Sons, Inc., 2016.

TANRÉ, D. et al. Remote sensing of aerosol properties over oceans using the MODIS/EOS spectral radiances. Journal of Geophysical Research: Atmospheres, v. 102, n. D14, p. 16971-16988, 1997.

TEN HOEVE, J. E. et al. Recent shift from forest to savanna burning in the Amazon Basin observed by satellite. Environmental Research Letters, v. 7, n. 2, p. 024020, 2012.

TRENBERTH, K. E.; FASULLO, J. T.; KIEHL, J. Earth's Global Energy Budget. Bulletin of the American Meteorological Society, v. 90, n. 3, p. 311-323, 2009.

TWOMEY, S. The Influence of Pollution on the Shortwave Albedo of CloudsJournal of the Atmospheric Sciences, 1977.

WALLACE, J. M.; HOBBS, P. V. Atmospheric Science: An Introductory Survey. 2nd ed., 2006. 
WANG, X. et al. Deriving Brown Carbon from Multi-Wavelength Absorption Measurements: Method and Application to AERONET and Surface Observations. Atmospheric Chemistry and Physics Discussions, p. 1-33, 2016.

WILD, M. et al. The global energy balance from a surface perspective. Climate Dynamics, v. 40, n. 11-12, p. 3107-3134, 2013.

YAMASOE, M. A.; CORRÊA, M. DE P. Processos radiativos na atmosfera Fundamentos. $1^{\text {a }}$ ed. Oficina de Textos, 2016. 
